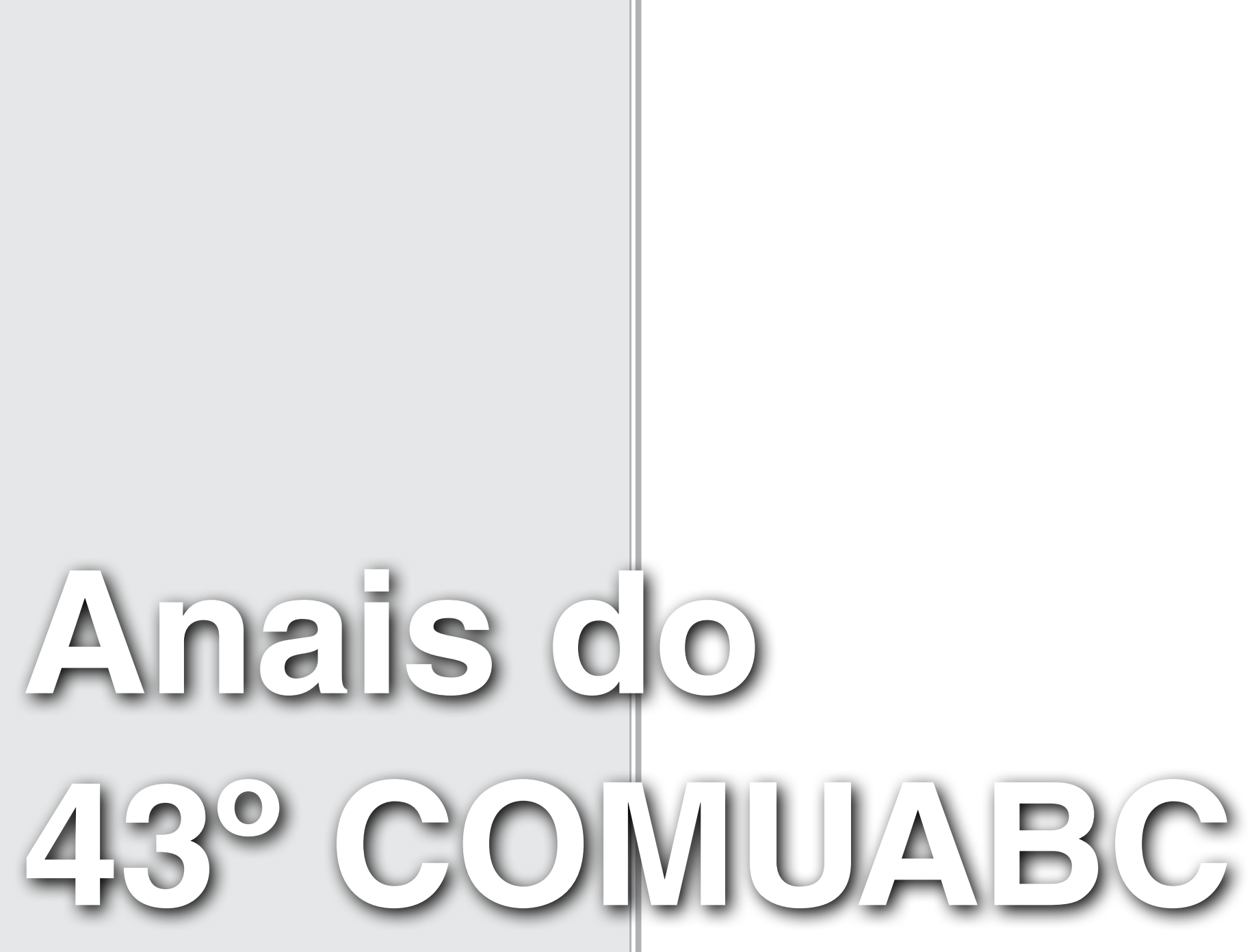

Congresso Médico Universitário do ABC Santo André - 6 a 11 de agosto de 2018 DOI: https://doi.org/10.7322/abcshs.v43i0.1185

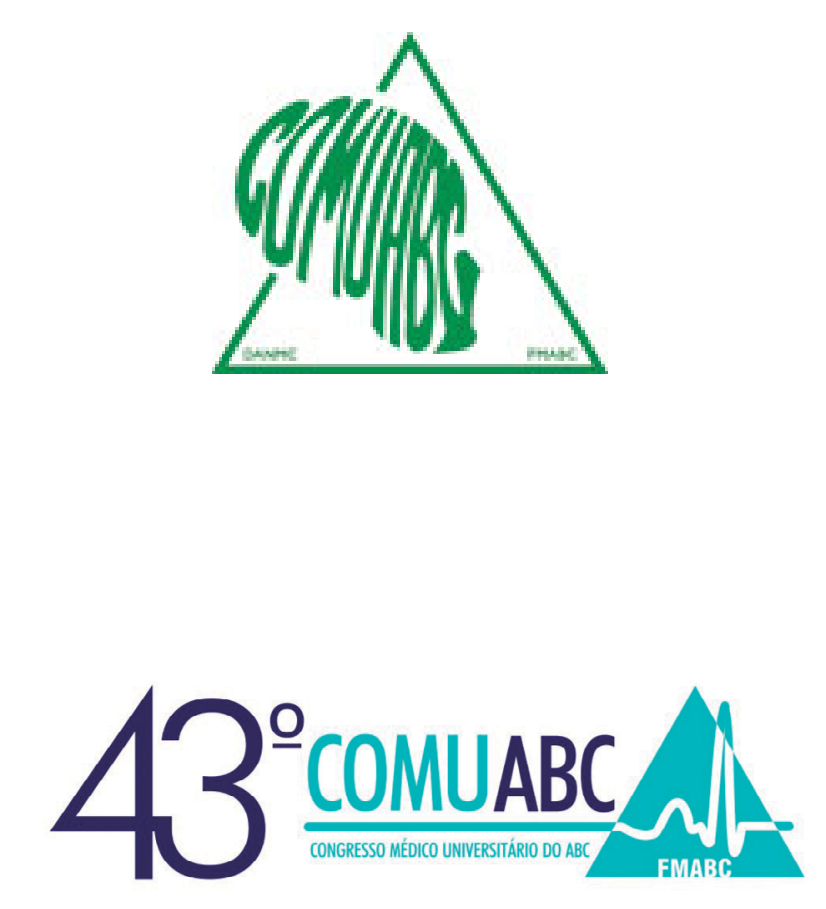




\section{COMISSÃO TÉCNICA}

DIRETORIA GERAL

Presidente:

Marina Alves Pinto

Vice-Presidente:

Isabela Corralo Ramos

Tesoureira:

Vanessa Lopes Mathia

DEPARTAMENTO DE DIVULGAÇÃO (DD)

Coordenação:

Isabel Pereira Suplicy

Safire de Lima Zambianco

Membros:

Ana Paula Possar do Carmo

Beatriz Conti Naves

Carolina Villalba Moya Rodrigues

Fábio Brandão Yoshimura

Laura Romanholi de Oliveira Pereira

Luiza Fernandes Giro

Marcella Canato Tolo

Matheus Prado Nascimento

Milena Amicci Kiqumotom

Natália D'Amore Marciano

Thaís Salomão Marques Torrado

Thais Stahl de Novais

DEPARTAMENTO CIENTÍFICO CULTURAL (DCC)

Coordenação:

Philip Hoover

Roberta Ferraz Salles Kesselring

Membros:

Amyr Braverman

Anna Beatriz Vieira de Lima Veloso

Beatriz Galves Magnoni

Beatriz Villas-Boas Weffort

Bruno Pasquini Ferraz

Daniel Henrique Madureira de Assis

Isabela Alves Goldberg

João Vitor Maroneze Porfirio

Julia Araújo Vigiato

Luiza Franco de Moraes Jorge Racy

Marina Quaglio Oinegue Fulfaro

Pedro Borghesi Poltronieri

Rachel Fior Franchini

Tamy Drummond Zlochevsky

Thiago Artioli

DEPARTAMENTO DE TRABALHOS CIENTÍFICOS (DTC)

\section{Coordenação:}

Júlia Aith Balthaza

Luiza Gama Ancona de Faria

Membros:

Giulia Cerchiari Silva

Isabella Cristina Prates Couto

Leonardo Pedro Kenzo Olivi Tanaka

Mariana Mika Hanita

Milena Lucindo Lima

Natália Raissa de Camargo e Silva

Rafael Lopes de Oliveira

Sofia Fernandes Maestre

Thais Henriques Abud

\section{DEPARTAMENTO DE MÍDIA}

Coordenação:

Carolina Guimarães

Gabriella Clementino da Silva
Membros:

Leonardo Alfano de Lima

Maria Carolina Martins Smanio

Maria Laura dos Reis Leitão

Natalia Marques dos Santos

Pedro Mastrocinque Pereira Ferreira

Rachel Hordonho Guidolim

Rafaela Oliveira de Sousa

DEPARTAMENTO DE RELAÇÕES EXTERNAS (RE)

Coordenação:

Juliana Lie Taya

Victor Mendes Ribeiro

Membros:

Ana Carolina Bertelli Maschietto

Beatriz Yukari Yokoyama

Flávia Altheman Loureiro

Henrique de Moraes Berna

João Victor Ji Young Suh

Julio Santos Teixeira

Mônica Yhasmin Redondo

Thomas Israel Dornelas

\section{DEPARTAMENTO DE SECRETARIA}

Coordenação:

Maria Isabel Sacchi Mendonça

Yasmin Cristina Cesquim

Membros:

Amanda Ribeiro Batlle

Ana Carolina Pereira Cardoso

Anna Carolina Miscolty e Silva

Bruna Bortolini Santana

Carolina Fargione Dantas de Assis

Caroline Hamati Rosa Batista

Gabriela Veronese dos Santos

Gabrielle de Almeida Fernandes

Isabela Mazzeo Turcatto

Isabella Alves Furlan

Isabella Rodrigues Pace de Oliveira

Jacqueline Molina Bassi

Jessica Miwa Takasu

Laura Ramos de Almeida

Maria Eugenia Mendes de Almeida Mourad

Maria Laura Kachan Bordignon

Marina Longo Machado de Almeida

Pyetra Mariê Kamitani de Oliveira

Thais Catalano Giunco

Thais Vidal Salles

Yasmin Vianna Sym

\section{DEPARTAMENTO SOCIAL}

\section{Coordenação:}

Fernanda Ferreira Banhos

Paola Augusto Gomes

Membros:

Ana Beatriz Alvarenga Cansancao

Fabiana Reis Decicino Campos

Felipe Marsiglia Faustino Saporito

Gustavo Luis Ramos Moralejo

Julia Barbizan Previd

Julia Hoici Brunin

Juliana Teixeira Gomes

Luísa Félix Sanchez

Luiz Gustavo Martins Buranello

Murilo Rocha Laragnoit De Martino

Paola Mortean dos Santos

Rafael Giannella Kusabara
Adriano Meneghini

Alessandra Migotto Zoppi Cunha

Andrea Paula Kafejian

Anete Grumach

Bianca Bianco

Cesar Fernandes

Cristina Laczynski

David Feder

Débora Krutman Zveibil

Fabíola Suano

Francisco Paschoal

Gilberto D'Elia

Jairo Cartum

\section{COMISSÃO CIENTÍFICA}

João Maurício Castaldelli Maia José Antonio Bento

Jossi Kanda

Juvêncio Furtado

Katya Cristina Rocha da Silva

Leonardo Seligra Lopes

Lígia Reato

Márcia Tamosauskas

Mario Faro

Nicolás Douglas

Odete Miranda

Onesimo Duarte Ribeiro

Orsine Valente
Oswaldo Roberto

Priscila Bogar

Ricardo Souto

Roberto Lopes Almeida

Rogerio Palma

Sergio Baldassin

Silmara Conchão

Sonia Hix

Vagner Loduca

Vânia Barbosa do Nascimento

Vitor Augusto Mauad

Wladmir Faustino Saporito 


\section{Palavra da Presidente}

O Congresso Médico Universitário do ABC - COMUABC é o congresso realizado pelos alunos da Faculdade de Medicina do $\mathrm{ABC}$, e que atualmente encontra-se em sua $43^{\mathrm{a}}$ edição! O COMUABC é considerado um dos maiores congressos de sua categoria e vem crescendo cada vez mais graças a todo esforço e empenho dos alunos, que organizam e estruturam todo o evento. O congresso tem como objetivo principal proporcionar uma semana de atividades capazes de promover reflexões que ultrapassem o conteúdo administrado em sala de aula, explorando assuntos e temas que contribuam para a formação acadêmica e pessoal de alunos de medicina. Para isso, contamos com palestras e workshops práticos. Também ocorre apresentação de trabalhos científicos, que são avaliados e selecionados pela banca interna da FMABC previamente e são julgados por uma banca convidada na semana do Congresso. Os melhores são premiados na festa de encerramento!

É uma honra dar continuidade e fazer parte de mais um ano do maior e mais antigo congresso médico universitário do país!

Marina Alves Pinto

Presidente do $43^{\circ}$ COMUABC 


\section{CATEGORIA - BÁSICO EXPERIMENTAL}

\section{BAS - 01 AÇÃO DA ANGIOTENSINA 1-7 PERIFÉRICA E CENTRAL NA REGULAÇÃO DA BEXIGA URINÁRIA DE RATAS WISTAR}

Gustavo Bertollini Lamy, Monica Akemi Sato

\section{E-mail: aeig92@ hotmail.com}

INTRODUÇÃO: Marcações por imunohistoquímica evidenciaram a presença de receptores Mas para angiotensina 1-7 (ang 1-7) na área pré óptica lateral (APL). Não é sabido se os receptores Mas presentes na APL interferem na regulação da bexiga urinária (BU). OBJETIVO: Investigar os efeitos da ang 1-7 na APL e na BU sobre a pressão intravesical (PI) e parâmetros cardiovasculares de ratas Wistar MÉTODO: Dezoito ratas ( $240 \mathrm{~g}$, protocolo CEUA\#07/2015) foram submetidas à estereotaxia para implante de cânulas-guia na APL sob anestesia com cetamina e xilazina. Sete dias depois, as ratas foram anestesiadas com isoflurano $2 \%$ em O2 $100 \%$ e submetidas à canulação da artéria femoral, colocação de sonda miniaturizada de fluxometria Doppler ao redor da artéria renal esquerda para medida da condutância renal (CR) e canulaç̃̃o da BU para medida da PI. Após a medida basal da PI, pressão arterial (PA) frequência cardíaca (FC) e CR por 15 min, foi realizada a injeção de ang 1-7, A779 (antagonista de receptores Mas) ou salina na APL ou a administração in situ na BU de ang 1-7 ou salina e as variáveis foram mensuradas por $60 \mathrm{~min}$. Outras 8 ratas foram anestesiados com isoflurano $2 \%$ em O2 100\% e realizada a retirada do encéfalo e BU para posterior realização de $\mathrm{qPCR}$ para determinar a expressão gênica do receptor MAS e da ciclofilina (housekeeping gene).Os dados estão expressos como média $\pm E P$ (teste $t-S t u d e n t, ~ p<0,05$ ). RESULTADO: A injeção de ang 1-7 na APL promoveu aumento da PI $(187,5 \pm 37,2 \%)$ das ratas $(\mathrm{N}=6)$ comparado à injeção de salina (veículo, $-2,1 \pm 1,9 \%)$. A injeção unilateral de $\mathrm{A}-779(\mathrm{~N}=6)$ na APL promoveu redução da PI $(-15,9 \pm 2,8 \%)$ comparado à salina $(-2,0 \pm 1,1 \%)$. A injeção de A-779 bilateralmente na APL ( $\mathrm{N}=6)$ promoveu diminuição significante e mais acentuada da PI $(-27,3 \pm 3,4 \%)$ comparado à salina $(-2,9 \pm 1,6 \%)$. A administração in situ de ang1-7 promoveu aumento da PI $(147,4 \pm 18,9 \%)$ das ratas $(\mathrm{N}=6)$ comparado à salina $(3,2 \pm 2,8 \%)$. Não foram observadas alterações significativas da PA, FC e CR. Observou-se também a expressão gênica de receptores MAS na APL $(\mathrm{CT}=27,62 \pm 0,03, \mathrm{~N}=6)$ e na $\mathrm{BU}(\mathrm{CT}=28,56 \pm 0,12, \mathrm{~N}=6)$, bem como da ciclofilina na $\operatorname{APL}(16,39 \pm 0,50)$ e na BU $(18,89 \pm 0,8)$. DISCUSSÃO/CONCLUSÃO: A ang1-7 promove aumento da PI ao se ligar a receptores Mas na APL e BU e os resultados sugerem que a APL é uma parte importante do circuito que regula a atividade da BU mediada pela ang1-7.

Palavras-chave: Angiotensina 1-7; área pré óptica lateral; bexiga urinária; receptor Mas.

\section{BAS - 02 ANÁLISE DA CONSTITUIÇÃO DE COLÁGENOS NA DOENÇA DE PEYRONIE}

Autores: Giovanna Milani, Gabriela Fernandes Conrado, Maria Aparecida da Silva Pinhal, Thérèse Rachel Theodoro

\section{E-mail: giovanna23milani@gmail.com}

INTRODUÇÃO: Na Doença de Peyronie (DP) há aparecimento de placas de fibrose na túnica albugínea (TA) do pênis que afetam a elasticidade do tecido durante a erecão e produzem curvatura peniana. Ocorre um processo de cicatrização anormal, que ocorre no tecido conjuntivo peniano na DP, acarretando alterações histológicas que envolvem o aparecimento de processos inflamatórios e depósito de fibrina e colágeno. OBJETIVO: O objetivo principal do presente estudo foi avaliar as alterações anátomo patológicas TA de portadores de DP, comparativamente com tecidos obtidos de cadáveres não acometidos pela DP. MÉTODO: As amostras foram divididas em dois grupos: TA de pacientes com a DP e a TA de amostras controle, obtidas de cadáveres não acometidos pela doença. A análise foi feita com: 1. H/E para identificação de núcleo, citoplasma e outros componentes teciduais; 2. Picrosírius para identificação de fibras de colágeno tipo I e tipo III, com luz polarizada. 3. Reticulina: para identificação de fibras colágenas tipo I e tipo III; 4. Tricômio de Masson: identificação de quantidade total de fibras colágenas. Análise estatística foi realizada com o Programa GraphPad Prism ${ }^{\oplus}$. RESULTADO: análise H/E: alterações histológicas, tais como diminuição da celularidade, de vasos e de apoptose nos pacientes com DP. Coloração de Picrosirius: diminuição de colágeno III em relação ao colágeno I nos pacientes com DP, quando comparados ao grupo controle. Reticulina: aumento de colágeno I em relação ao colágeno III nos pacientes com DP. Tricômio de Masson: a quantidade total de fibras colágenas entre o grupo controle e o grupo de DP possuía uma média semelhante, mas os pacientes com DP apresentavam maior homogeneidade. DISCUSSÃO: o tecido conjuntivo denso não modelado, durante a cicatrização, apresenta número menor de células e maior concentração de fibras colágenas entrecruzadas; diminuição da apoptose devido às alterações fisiopatológicas na TA; redução no número de vasos porque na DP ocorre venoclusão; placa fibrótica inibe colagenases e estimula a deposição de colágenos. CONCLUSÃO: Colágeno I substitui colágeno III durante o remodelamento tecidual da túnica albugínea independentemente da fase da DP (aguda ou crônica) e a dosagem colágeno I em relação ao colágeno III pode ser um bom marcador histopatológico no diagnóstico e evolução da doença de Peyronie.

Palavras-chave: Doença de Peyronie; túnica albugínea; colágeno I; colágeno III.

\section{BAS - 03 BIOMONITORAMENTO COM ÁRVORES E POSSÍVEIS EFEITOS DE METAIS TÓXICOS AMBIENTAIS SOBRE A GLÂNDULA TIREÓIDE EM ÁREAS INDUSTRIAIS NO ESTADO DE SÃO PAULO, BRASIL}

Marcel Gutierrez, Natália Corrêa Gabriel, Paulo Afonso Ribeiro, Luiza Fernandes Giro, Thais Stahl de Novais, Rafaella Elias Bosco, Karola Beserra de Araújo, Victoria Cassioti Teodoro, Thalles Zaccarelli Balderi, Maria Angela Zaccarelli Marino

\section{E-mail: marcelgutierrez07@gmail.com}

INTRODUÇÃO: A poluição ambiental por metais tóxicos é uma ameaça para o ser humano apresentando efeitos nocivos na saúde acometendo, por exemplo, a glândula tireóide e olhos. OBJETIVO: Correlacionar a poluição ambiental e o aumento da incidência de hipotireoidismo primário (HP) nas proximidades de indústrias produtoras de derivados de petróleo em Santo André, São Paulo, Brasil. MÉTODO: Entre abril e maio de 2009, coletou-se amostras de cascas de árvores $(\mathrm{n}=37)$ de duas espécies, na região próxima a um Polo Petroquímico, em Santo André e Mauá. Para controle da poluição, foram coletadas amostras da área rural (em Embu-Guaçu), fora da área de poluição. O produto da coleta foi passado em preparo laboratorial: limpeza com escova de nylon, camada externa processada, ralada e peneirada. As amostras foram comprimidas sob pressão e 5 ton min-1 e analisadas para descrever as concentrações de Chumbo $(\mathrm{Pb})$, Bário $(\mathrm{Ba})$, Enxofre $(\mathrm{S})$, Zinco $(\mathrm{Zn})$, Cobre $(\mathrm{Cu})$, Manganês $(\mathrm{Mn})$, Ferro $(\mathrm{Fe})$ pela espectrometria de fluorescência de raios $\mathrm{X}$ por dispersão de energia. O hipotireoidismo primário (HP) foi determinado pelos dados obtidos de um estudo epidemiológico realizado entre 2003 e 2005. RESULTADO: Após preparo do material, obteve-se a concentração $(\mathrm{mg} / \mathrm{Kg})$ dos elementos das amostras: $\mathrm{Pb}$ : Mínimo=1,0; Máximo=15,6; Média=4,0; Média-Controle $=2,0 . \quad$ Ba: $\quad$ Mínimo $=92,4 ; \quad$ Máximo $=5915,4 ; \quad$ Média $=578,2$; Média-Controle $=225,1$. S: $\quad$ Mínimo $=2570,0 ; \quad$ Máximo $=8790.0 ; \quad$ Média $=4961,6$; Média-Controle $=2960,0 . \quad Z n: \quad$ Mínimo $=43,7 ; \quad$ Máxima $=1440,0 ; \quad$ Média $=322,7$ Média-Controle $=21,83$. Cu: Mínimo=5,5; Máximo=38,2; Média=11,6; MédiaControle $=21,75$. Mn: Mínimo=23,4; Máximo $=671,1 ; \quad$ Média=124,6; MédiaControle=82,4. Fe: Mínimo=797.0; Máximo=5071,2; Média=2065,6; MédiaControle=1055,7. A média-controle refere-se às amostras de Embu-Guaçu. DISCUSSÃO: Metais tóxicos podem agir como disruptores endócrinos potenciais e são capazes de desencadear HP. Pb pode desencadear uma resposta inflamatória crônica reduzindo os níveis de T4 em indivíduos expostos. CONCLUSÃO Biomonitoramento com árvores pode ser usado para determinar como a poluição causa impacto direto na qualidade do ar e na natureza, que podem agir como disruptores endócrinos, desencadeando o HP.

Palavras-chave: biomonitoramento; árvores; metais tóxicos; Brasil.

\section{BAS - 04 EFEITO DA REPOSIÇÃO DE TESTOSTERONA ASSOCIADA OU NÃO AO ESTRADIOL SOBRE GORDURA INTRAMEDULAR, VISCERAL E INGUINAL DE RATAS OOFORECTOMIZADAS}

Anna Carolina Haddad Sayeg, Fernanda Esteves Simões Ramos, Lorena Doretto da Silva, Marcelo Luis Steiner

\section{E-mail: anna_sayeg@hotmail.com}

INTRODUCCÃO: Questões referentes à segurança e aos efeitos biológicos teciduais da reposição de testosterona permanecem controversos. OBJETIVOS: Avaliar os efeitos da utilização de testosterona nas doses de $5 \mu \mathrm{g} / \mathrm{dia}$ e $30 \mu \mathrm{g} / \mathrm{dia}$, associado ou não a reposição estrogênica, sobre a expansão dos tecidos adiposos viscerais, subcutâneo e intramedular e sobre a expressão do PPAR gama nos tecidos adiposos visceral e subcutâneo de ratas ooforectomizadas. MÉTODOS: 48 ratas Wistar foram castradas e distribuídas aleatoriamente em 6 grupos de tratamento: grupo $\mathrm{E} 2$ que recebeu $5 \mu \mathrm{g} / \mathrm{dia}$ de estradiol; grupo $\mathrm{T}$ tratado com $5 \mu \mathrm{g} / \mathrm{dia}$ de testosterona grupo $\mathrm{E} 2+\mathrm{T}$ tratado com $5 \mu \mathrm{g} / \mathrm{dia}$ de estradiol $+5 \mu \mathrm{g} / \mathrm{dia}$ de testosterona; grupo TT tratado com $30 \mu \mathrm{g} /$ dia de testosterona; grupo E2+TT tratado com $5 \mu \mathrm{g} / \mathrm{dia}$ de estradiol $+30 \mu \mathrm{g} / \mathrm{dia}$ de testosterona e grupo $\mathrm{P}$ que recebeu placebo para estradiol e testosterona. Após 5 semanas do início do tratamento, as ratas foram sacrificadas e tiveram ressecados o tecido adiposo inguinal, o visceral e os fêmures do lado direito. Os tecidos adiposos foram pesados e avaliados a expressão de PPAR gama por PCR em tempo real. Já os fêmures foram descalcificados para a confecção de lâminas histológicas, que foram coradas com HE para contagem do número de adipócitos intramedular. A comparação entre os grupos foi feita por ANOVA ou Kruskal Wallis. RESULTADOS: a média de peso dos tecidos adiposos viscerais foi muito maior no grupo TT em relação ao demais grupos tratados com hormônio $(p<0.05)$. Neste grupo também se observou maior número de adipócitos intramedular. A média de peso da gordura inguinal nos grupos $\mathrm{E} 2+\mathrm{T}$ e E2+TT foi significativamente menor que os grupos TT e P $(\mathrm{p}<0.05)$. Os grupos tratados com E2 apresentaram menor expressão de PPAR gama e o grupo T expressou significativamente maior do que o grupo E2 em ambos tecidos gordurosos. CONCLUSÃO: a utilização de testosterona em alta dose determina expansão importante do tecido adiposo visceral, inguinal e intramedular. A associação com estradiol tem efeito repressor nessa expansão. $\mathrm{O}$ uso de estradiol demonstra inibir a expressão de PPAR gama.

Palavras-chave: reposição hormonal; testosterona; tecido adiposo; PPAR gama. 
BAS - 05 ESTUDO DOS EFEITOS DE BUPROPIONA, TOPIRAMATO E NALTREXONA SOBRE O CRAVING POR AÇÚCAR, EM RATOS, NO MODELO DE CONDICIONAMENTO EM LABIRINTO EM CRUZ ELEVADO

Stephania Morreale, Paola Augusto Gomes, Juliana Jorge Romano, Giuliana Petri, Cristina de Zotti Nassis

\section{E-mail: stephania.morreale@yahoo.com.br}

INTRODUÇÃO: Craving é o termo utilizado para definir a fissura,que se caracteriza como o desejo intenso de se consumir uma substância como açúcar.O topiramato (aumenta a atividade do GABA), a bupropiona (antidepressivo IRND) e a naltrexona (diminui o prazer de comer) são drogas que estão sendo empregadas de forma empírica no tratamento da obesidade. O labirinto em cruz elevado (LCE) é modelo animal comportamental exploratório utilizado para o estudo da neurobiologia do estudo da adicção. OBJETIVO: Estudar os efeitos de topiramato, bupropiona e naltrexona na farmacoterapia do craving por açúcar, em ratos. MÉTODO: 35 ratos Wistar machos foram divididos em 7 grupos $(n=5)$. O grupo 0 foi mantido sem condicionamento, e recebeu solução salina VO. Os demais foram divididos em 6 grupos e tratados a partir do $21^{\circ}$ dia, pelas manhãs, VO. Grupo 1: solução salina por via oral (1ml/dia). Grupo 2: bupropiona $(5,0 \mathrm{mg} / \mathrm{kg})$. Grupo 3: naltrexona $(2,0 \mathrm{mg} / \mathrm{kg})$. Grupo 4: topiramato $(20,0 \mathrm{mg} / \mathrm{kg})$. Grupo 5 topiramato $(20,0 \mathrm{mg} / \mathrm{kg})$ e bupropiona $(5,0 \mathrm{mg} / \mathrm{kg})$. Grupo 6: topiramato $(20,0 \mathrm{mg} / \mathrm{kg})$, bupropiona $(5,0 \mathrm{mg} /$ $\mathrm{kg})$ e naltrexona $(2,0 \mathrm{mg} / \mathrm{kg})$. Todos os animais receberam, até o $40^{\mathrm{a}}$ dia, ração e Leite Condensado Moça ${ }^{\oplus}$. A seguir, receberam apenas a ração, ad libitum, durante 10 dias. Depois, os animais foram submetidos às sessões de condicionamento: uma sessão por rato no turno da manhã e mais uma no turno da tarde, durante 4 dias. Nas manhãs o Grupo 0 teve acesso à ração ad libitum e os demais grupos tiveram também acesso ao Moça ${ }^{\circledast}$. Após 30 minutos, cada rato foi colocado na porção proximal de um dos braços abertos do LCE, onde ficou confinado por 20 minutos. Nas tardes, todos os animais receberam salina VO e foram submetidos ao mesmo procedimento. No dia do teste os animais foram colocados individualmente no centro do LCE, com a cabeça direcionada para um dos braços fechados, e exploraram livremente todo o aparato durante 5 minutos. O Grupo 1 foi comparado aos outros grupos por ANOVA 2 vias + Fisher $(\mathrm{p}<5 \%)$. RESULTADOS: $\%$ de tempo nos braços abertos: Grupos:0: $36,9+/-9,4^{*} ; 1: 59,7+/-14,7 ; 2: 49,3+/-13,1 ; 3: 42,9+/-10,4$ $4: 45,9+/-13,2 ; 5:: 21,3+/-7,1^{\star} ; 6: 26,4+/-8,9^{*} ;{ }^{*}$ : diferenças significativas entre cada grupo e o grupo 1. DISCUSSÃO E CONCLUSÃO: As associações foram capazes de diminuir o craving, indicando que é necessário um sinergismo de diferentes mecanismos de ação para se obter o efeito estudado.

Palavras-chave: Açúcar; Craving; Ratos; Labirinto de Cruz Elevado.

\section{BAS - 06 INVESTIGAÇÃO DA AÇÃO SEROTONÉRGICA CENTRAL NA REGULAÇÃO DA BEXIGA URINÁRIA DE RATAS WISTAR}

Fabio lazzetti Lopes, Monica Akemi Sato

\section{E-mail: fabioizlopes@gmail.com}

INTRODUÇÃO: As disfunções do trato urinário inferior representam até $40 \%$ das consultas em ambulatórios de nefrologia e urologia. A manutenção da excreção urinária depende de mecanismos reflexos, porém, sofre modulação cortical, bem como de áreas pontinas e bulbares. Diferentes neurotransmissores/neuromoduladores estão presentes nas áreas bulbares, entre os quais o L-glutamato, acetilcolina, noradrenalina e serotonina. Até o momento, não foi descrito se a transmissão serotonérgica possui participação nas vias neurais responsáveis pela regulação da bexiga urinária. OBJETIVO: Investigar a influência da transmissão serotonérgica bulbar sobre a regulação da bexiga urinária e de parâmetros cardiovasculares de ratas Wistar. MÉTODO: Para este estudo foram utilizadas ratas Wistar ( 250 g, protocolo CEUA \#11/2017). Os animais foram submetidos à cirurgia para implante de uma cânula-guia no $4 \mathrm{o}$ ventrículo $(4 \mathrm{oV})$. Após uma semana, fez-se o registro das medidas de pressão intravesical (PI), pressão arterial média (PAM), frequência cardíaca (FC) e condutância renal antes e após a injeção de cloridrato de fenilbiguanida $(5 \mathrm{ng} / \mu \mathrm{L}$., agonista 5 -HT3) ou salina ( $1 \mu \mathrm{L}$, controle) no 4 o V. Os resultados estão expressos como média $\pm \mathrm{EP}$ e foram submetidos ao teste t-Student não-pareado ( $\mathrm{p}<0,05)$. RESULTADO: A injeção de fenilbiguanida promoveu aumento da PI $(57,6 \pm 43,2 \%)$ quando comparado ao grupo controle $(3,4 \pm 8,1 \%)(\mathrm{p}<0,05)$. A latência para o aparecimento de aumento da PI foi de 5 min e persistiu por $35 \mathrm{~min}$. Não foram observadas alterações significantes da PAM, FC e condutância renal após a injeção de fenilbiguanida em ambos os grupos. Discussão: Os dados obtidos sugerem que houve aumento significante da pressão intravesical após a injeção de fenilbiguanida no 4o V. Este aumento parece não ser dependente de alterações da taxa de filtração glomerular ou de demais alterações hemodinâmicas. A latência para o início do efeito de fenilbiguanida até o pico da resposta indica uma possível liberação hormonal e que este possa vir a atuar sobre a bexiga urinária levando ao aumento da pressão intravesical. CONCLUSÃO: A ativação de receptores 5HT-3 em áreas bulbares promove aumento da pressão intravesical e este mecanismo possivelmente está vinculado à ação hormonal secundária ainda desconhecida. Palavras-chave: Agonistas de Receptores de Serotonina; Quarto Ventrículo; Bulbo; Bexiga Urinária.
CATEGORIA - CIÊNCIAS SOCIAIS E HUMANAS

\section{CSH - 01 ANTICONCEPÇÃO NO PÓS-PARTO IMEDIATO EM PUÉRPERAS VULNERÁVEIS: UMA JANELA DE OPORTUNIDADES}

Nicolas Augusto Cabral Ribeiro, Livia Akemi Ramos Takahashi, André Akira Ramos Takahashi, Mariliza Henrique da Silva, Silvana A. Giovanelli

\section{E-mail: nicolas.cabral08@gmail.com}

INTRODUÇÃO: Sabe-se que as gestações indesejadas são mais frequentes em mulheres vulneráveis. Estas têm menor acesso a saúde reprodutiva, menor uso de contraceptivos (com produto final de $8 \mathrm{em} 10$ gestações não planejadas), maior complicação durante a gestação e parto, à maior incidência de prematuridade, baixo peso ao nascer, desmame precoce, maior número de crianças em abrigos e aumento de IST (infecção sexualmente transmissível). Portanto, reduzir o número de gravidezes não desejadas pode evitar $60 \%$ das mortes maternas e $57 \%$ das infantis. Os métodos contraceptivos são prescritos no ambulatório de puerpério, no entanto as vulneráveis apresentam altos índices de falta à consulta. Neste quadro, o pós-parto constitui uma janela de oportunidade para o aconselhamento e início da contracepção. OBJETIVO: Avaliar a aceitabilidade a uma estratégia multifacetada de prevenção da gravidez em mulheres vulneráveis no pós-parto imediato, baseada na utilização de métodos contraceptivos e fatores associados. MÉTODOS: Estudo descritivo que analisou 106 gestantes de alta vulnerabilidade, admitidas no HMU de SBC, no período de janeiro a março de 2018. A análise foi realizada pelo Software Stata 11.0. RESULTADOS: A média da idade da amostra é de 24 anos, variando de 14 a 43 anos. Foi observado que em $58 \%$ dos casos a atividade sexual iniciou-se antes dos 16 anos, sendo que $49 \%$ das gestantes eram solteiras, e destas $29,25 \%$ estavam fazendo uso de algum método contraceptivo quando engravidaram, e apenas uma paciente utilizava LARC (Long Acting Reversible Contraception). Em 38,68\% dos casos não houve anticoncepção no pós-parto imediato. Das que realizaram $50 \%$ escolheram o DIU de cobre, 6,6\% implante subdérmico e 4,72\% laqueadura. DISCUSSÃO: Para mulheres com acesso limitado à serviços de saúde, a possibilidade de anticoncepção no pós-parto imediato surge como uma oportunidade a prevenção da gravidez não desejada. CONCLUSÃO: O pós-parto imediato é uma janela de oportunidade que desponta como uma estratégia interessante na atenção à saúde reprodutiva. Assim, faz-se necessário conhecer os motivos da não aceitação de métodos anticoncepcionais.

Palavras-chave: gestação; anticoncepção; população vulnerável.

\section{CSH - 02 ATIVIDADE EDUCATIVA EM SAÚDE SEXUAL E REPRODUTIVA PARA MENINAS}

Karine Corcione Turke, Victoria Cassioti Teodoro, Camila Sando, Paulo Afonso Ribeiro, Graziella Luciano Antonio, Janete Regina Figueiredo Gomes, Ligia De Fatima Nobrega Reato

\section{E-mail: karineturke@ hotmail.com}

INTRODUÇÃO: O desenvolvimento puberal é acompanhado por um aumento do interesse e da curiosidade sexual em relação ao próprio corpo e os dos demais. Isso acaba por colocar os adolescentes em situações de risco como a prática sexual sem preservativos o que favorece um risco aumentado para as Infecções Sexualmente Transmissíveis (IST) e de gravidez. OBJETIVO: Realizar uma ação educativa sobre o tema sexualidade para crianças e adolescentes do sexo feminino em situação de maior vulnerabilidade social, a fim de esclarecer eventuais dúvidas quanto ao desenvolvimento puberal e uso adequado de preservativos. MÉTODO: As participantes foram divididas em: grupo 1 (8-9 anos) e grupo 2 (10-13 anos). Cada grupo foi orientado por 2 alunos e 1 aluno coordenador. Foi proposta uma dinâmica onde as meninas deveriam desenhar uma boneca e caracterizá-la em aspectos físicos, emocionais e sociais. Houve uma explicação sobre Estadiamento de Tanner e aplicação de questões norteadoras sobre o tema. RESULTADO: Enquanto o grupo 2 se mostrou, a princípio, tímido, o grupo 1 se mostrou curioso e receptivo. No decorrer da dinâmica, o grupo 2 , ao sentir maior segurança, começou a relatar fatos mais íntimos, como relações interpessoais. Já o grupo 1 apresentou dúvidas em relação ao desenvolvimento corporal e processos fisiológicos tal qual a menstruação. DISCUSSÃO: No grupo 1 foi notado um desenho fantasioso, com vestimenta de princesa, festa de 15 anos. A personalidade da boneca correspondia a uma pessoa extrovertida, popular e sem interesse amoroso. A partir das perguntas norteadoras do desenho, verificou-se um maior interesse nas questões fisiológicas femininas e questões relacionadas ao uso de absorvente e sutiã. No grupo 2 percebeu-se uma projeção das jovens na boneca. Durante a realização das perguntas norteadoras foram trazidas questões pessoais. O maior interesse ficou nas relações interpessoais, sobretudo amorosas. CONCLUSÃO: Houve favorável participação de ambos os grupos além de boa receptividade. A ação se tornou efetiva na medida em que dúvidas foram respondidas. Assim, ações como essa se fazem necessárias para promover a saúde e o bem-estar físico e psicológico das jovens em situação de maior vulnerabilidade social.

Palavras-chave: adolescente; sexualidade; educação sexual. 


\section{CSH - 03 CAUSA DE MORTALIDADE DE IDOSOS DEVIDO A CAUSAS EXTERNAS E SUA RELAÇÃO COM O AGRESSOR}

Alexandre Dos Santos Wakim, Carmen Silvia Molleis Galego Miziara

\section{E-mail:ale_wakim@hotmail.com}

INTRODUÇÃO: Com o crescimento global da população idosa específicas questões relacionadas a esse grupo etário do sexo masculino necessitam ser amplamente discutidas e, dentre elas, a morte violenta que desempenha importante papel, pois os maus-tratos, a falta de cuidados e a precária prevenção contra auto lesionamento e acidentes se associam ao aumento da morbimortalidade, causando, assim a necessidade de criação de políticas públicas que possam minimizar ao máximo os danos a essa população vulnerável. OBJETIVO: Verificar a taxa de mortalidade por causa externa de pessoas idosas ocorridas nos anos de 2015 e 2016 nas cidades de São Paulo e de Santo André. MÉTODO: Foi realizado estudo descritivo transversal com dados extraídos de exames necroscópicos realizados nos Institutos Médicos Legais (Central e de Santo André) e dos respectivos Boletins de Ocorrência Nesse estudo foi considerada pessoa idosa aquela acima de 60 anos de idade. RESULTADO: Foram analisados 464 laudos necroscópicos de causas externas de pessoas idosas, sendo que $78 \%$ deles foram de causa acidental e a maioria causada por agente contundente e $78 \%$ delas não foi possível relacionar a um agressor direto. DISCUSSÃO: O estudo demonstra a importância da prevenção primária aos acidentes, em especial as quedas e acidentes automobilísticos (agentes contundentes). Dentro desta prevenção tem especial papel os cuidados que as pessoas próximas às pessoas idosas e as redes públicas e particulares têm com estas pessoas, pois apesar de a maioria das mortes não ter sido atribuída a um agressor direto, acidentes ocorrem, em grande parte, por negligência ou imprudência daqueles que deveriam cuidar desta população. CONCLUSÃO Medidas preventivas para acidentes, suicídios e homicídios em idosos devem ser amplamente implementadas, assim como o melhor manejo dos que sobrevivem à lesão.

Palavras-chave: idosos; mortalidade; acidentes; agressor.

\section{CSH - 04 COMPROVACCÃO DE ESTUPRO POR MEIO DE PROVA TÉCNICO-CIENTÍFICA OBTIDA EM EXAME SEXOLÓGICO: PRINCIPAIS DIFICULDADES}

Camila Fernandes Romeiro, Adriana de Oliveira Camboim, Paola Augusto Gomes, Gabriela de Paiva Ascani, Andreza Resende de Andrade, Michelle Gomes Santos, Karen Akemi Campello Fukuma, Thaina Altarejo Marin, Carmen Silvia Molleis Galego Miziara

\section{E-mail: camilaromeiro17@gmail.com}

INTRODUÇÃO: O conceito de estupro no Brasil (Lei n ${ }^{\circ}$ 12015/2009) possibilita que qualquer pessoa possa ser sujeito passivo ou ativo do crime e inclui nessa categoria a conjunção carnal e ato libidinoso sem o consentimento da vítima Em menores de 14 anos, independentemente do consentimento da vítima, é caracterizando estupro de vulnerável. No Brasil em 2014 foi notificado um estupro a cada 11 minutos, sendo mais prevalente em crianças. Um dos elementos técnico-científicos indiscutíveis de que houve conjunção carnal é a positividade de espermatozóide/sêmen no corpo da vítima. OBJETIVO: Analisar exames sexológicos quanto à positividade técnico-científica. MÉTODO: Estudo descritivo por análise de laudos de exames sexológicos obtidos no banco de dados do IML do Estado de São Paulo no ano de 2017. RESULTADOS: Foram analisados 10621 laudos de exames sexológicos de mulheres por alegação de estupro. Quanto à idade, $61 \%$ das vítimas tinham menos de 14 anos e $73 \%$ de 18 anos. Conjunção carnal foi conclusiva em 5438 pelos sinais himenais, dos quais apenas 245 tinham características de lesão recente. Exame positivo para pesquisa de espermatozoides foi visto em 180 casos. Lesão contundente anal foi descrita em 53 casos. Os 10 principais perpetradores por ordem: pai, conhecido, padrasto, tio, desconhecido, namorado, marido, irmão, vizinho, avô e primo. DISCUSSÃO: Juridicamente, o crime de estupro pode ser conjunção carnal ou ato libidinoso. Conjunção carnal consiste em penetração total ou parcial do pênis na genitália feminina, com ou sem o objetivo de procriação e com ou sem ejaculação, já o ato libidinoso consiste em qualquer manifestação que tende à satisfação do desejo sexual. Diante disso, a confirmação de ato libidinoso se torna muito difícil. Presença de espermatozóide na vagina, rotura himenal ou gravidez comprovam conjunção carnal. A positividade para espermatozóide depende entre outras coisas do tempo entre a agressão e a coleta de material, uso ou não de preservativo e taxa de zoospermia/sêmen. A rotura himenal, mesmo recente, não permite afirmar que houve o estupro, pois a vítima pode ter mantido relação sexual consensual antes da violência. CONCLUSÃO: A comprovação de estupro nem sempre é possível por meio de exame sexológico, pois as vítimas mais atingidas são as crianças e nem sempre a violência se dá por conjunção carnal com vestígios.

Palavras-chave: Estupro; Sexologia; Medicina Legal.

\section{CSH - 05 CONHECIMENTO DA POPULAÇÃO DO MUNICÍPIO DE SANTO ANDRÉ A RESPEITO DO CÂNCER DE PRÓSTATA EM CAMPANHA DE ORIENTAÇÃO DE SAÚDE}

Fauze Camargo Maluf, Clarissa Maria Gomes De Almeida, Feres Camargo Maluf, Guilherme Jose Reche, Leonardo Seligra Lopes

\section{E-mail: fauzecamargo@ hotmail.com}

INTRODUÇÃO: O câncer de próstata $(\mathrm{CaP})$ é o segundo tipo de neoplasia mais comum entre homens no Brasil e em números absolutos é o quarto mais frequente considerando ambos os sexos. Além disso, o CaP possui alta taxa de mortalidade e cerca de $20 \%$ dos casos são diagnosticados em estadios avançados. Por isso é importante que a população brasileira, principalmente masculina, tenha conhecimento do $\mathrm{CaP}$. Para conscientização da população sobre o $\mathrm{CaP}$, existe a campanha internacional nomeada "Novembro Azul" em que todo mês de novembro enfatiza a importância do $\mathrm{CaP}$ e orienta a população em relação a essa neoplasia. OBJETIVO: Esse estudo objetiva avaliar o grau de conhecimento dessa neoplasia na população do município de Santo André. MÉTODOS: Realizada campanha educativa durante a Meia Maratona de Santo André ocorrida no dia 26 de novembro de 2017, período do "Novembro Azul". Eram aplicados questionários aos participantes da prova ou aos acompanhantes no local, que aceitaram participar da pesquisa, e após a entrevista realizou-se orientações e esclarecimentos em relação ao CaP. RESULTADOS: Foram entrevistadas 67 pessoas com idade entre $30 \mathrm{e}$ 89 anos de ambos os sexos. Destes, $82.1 \%$ afirmaram já ter recebido informações sobre CaP. Cerca de $76.1 \%$ apontaram corretamente o intervalo para início dos exames de rotina necessários. Entretanto, $89.6 \%$ não identificaram o principal fator de risco (idade), enquanto $44.7 \%$ desconheciam as opções de tratamento para a doença. DISCUSSÃO: Os dados coletados mostram baixo grau de conhecimento sobre fatores de risco e opções terapêuticas para o $\mathrm{CaP}$ da população estudada. Inclusive, conceitos equivocados como a incidência de $\mathrm{CaP}$ em mulheres foram reportados. Assim, os entrevistados, apesar de, em sua maioria, já terem recebido informações acerca do tema, desconhecem aspectos essenciais para prevenção e tratamento desta doença. CONCLUSÃO: Devido ao baixo grau de conhecimento sobre $\mathrm{CaP}$ da população entrevistada, são necessárias mais campanhas aliadas a outros meios que promovam a informação sobre essa doença de impacto significativo na população brasileira.

Palavras-chave: Câncer de próstata; Novembro Azul; Conscientização.

\section{CSH - 06 CYBERBULLYING NA ADOLESCÊNCIA: A TRANSPOSIÇÃO DA BARREIRA FÍSICA PARA A PRÁTICA DE UMA NOVA VIOLÊNCIA}

Luiza Fernandes Giro, Giane Prata Da Costa Filha, Isabela Saraiva Silva, Danyelle Balduino Sabbag, Beatriz Conti Naves, Laura Cohen Warszawiak, Grazielle Ribeiro Novais, Ligia de Fatima Nobrega Reato

\section{E-mail: luiza.giro@ hotmail.com}

INTRODUÇÃO: A adolescência é um período essencial para a autoafirmação dos jovens e descobertas em geral. A vulnerabilidade nessa fase torna-os um público muito suscetível ao Cyberbullying (bullying aplicado no âmbito virtual). A intenção do agente agressor é impingir sofrimento à sua vítima, repercutindo em sobreposição de poderes e submissão. Sua incidência aumentou proporcionalmente à ampliação do mundo digital. OBJETIVO: Relatar a experiência da atividade educativa realizada em ambiente institucional; levantar a impressão de adolescentes sobre violência virtual; traçar perfil dos que praticam ou sofrem ta ato e avaliar suas percepções sobre as consequências dessa prática. MÉTODO: A ação foi realizada na Instituição Beneficente Irmã Marli, situada na cidade de Santo André-SP. A amostra constituída por 31 adolescentes respondeu a um questionário com 10 perguntas a respeito do contato com o cyberbullying: se já sofreram, praticaram ou presenciaram. Em seguida, realizou-se uma dinâmica de "telefone sem fio" e foram apresentados 3 vídeos abordando o cyberbullying. RESULTADO: A análise dos dados obtidos com os questionários evidenciou que: $41,9 \%$ dos adolescentes não se sentem acolhidos no ambiente escolar; $45,1 \%$ já ofenderam ou foram ofendidos na internet; $64,5 \%$ afirmaram não conversar com seus professores sobre casos de brigas, violência e exclusão; $67,7 \%$ não conversam com os pais sobre o que fazem no computador e $61,2 \%$ já viram algum amigo ofender outra pessoa na internet. A dinâmica do telefone sem fio demonstrou a facilidade de modificação de informações de pessoa para pessoa. DISCUSSÃO: Observou-se a prevalência do cyberbullying na amostra pesquisada e a carência de diálogo sobre o assunto. Muitos adolescentes afirmaram não se sentir confortáveis no ambiente escolar e a falta de diálogo ficou evidente em diversos resultados. É notável o receio em admitir ser o agente agressor comparado a já ter presenciado a cena. CONCLUSÃO: Verificou-se que o cyberbullying faz parte da vida dos adolescentes entrevistados. Detectou-se introspecção, discrição e suscetibilidade, características típicas dessa faixa etária. Também se tornou nítida a hostilidade para manter e estabelecer relações. Conclui-se que há necessidade de projeto educativo de intervenção continuada, tais como discussões e atividades que proporcionem reflexões e possíveis mudanças.

Palavras-chave: cyberbullying; bullying; educação; adolescência. 


\section{DIFERENTES PERCEPÇÕES A RESPEITO DAS AÇÕES DE HUMANIZAÇÃO EM UTIS PEDIÁTRICA E NEONATAL NO HOSPITAL ESTADUAL MÁRIO COVAS (HEMC)}

Marina Quaglio Oinegue Fulfaro, Julia Hoici Brunini, Patricia Andrea Frenk, Maria Laura dos Reis Leitão, Bruna Alejandra Orellana Santos, Marcella Zanini Savordelli, Anna Beatriz Vieira de Lima Veloso, Victor Miranda Borducchi, Luis Ricardo Longo dos Santos

\section{E-mail: marina.fulfaro@ hotmail.com}

INTRODUÇÃO: Ações de humanização no ambiente hospitalar visam tornar menos desconfortável o tratamento médico, tendo impacto nas qualidades do atendimento e em seus resultados. Nas unidades de terapia intensivas (UTI), que são ambientes mais hostis aos pacientes, essas intervenções se tornam mais importantes. Podem incluir desde medidas como o uso do polvo de crochê ou ninhos para recém-nascidos, até o melhor acolhimento do acompanhante da criança ou bebê. OBJETIVO: Detectar práticas de humanização adotadas nas UTIs pediátrica e neonatal do Hospital Estadual Mário Covas (HEMC), caracterizando-as quanto aos meios, intensidade e impactos nos profissionais de saúde, pacientes e acompanhantes. Conscientizar os estudantes de medicina sobre o impacto das ações humanizadas. MÉTODO: Estudo transversal, realizado nas UTIs pediátrica e neonatal do HEMC, através de questionários aos acompanhantes de crianças internadas e profissionais de saúde dos setores. Avaliação das percepções dos entrevistados acerca das práticas de humanização nessas UTIs. RESULTADO A maioria dos acompanhantes afirmou que o HEMC é humanizado, porém, 75\% não souberam exemplificar quando essa prática foi vivenciada. Entre os profissionais entrevistados, $100 \%$ mostrou conhecimento sobre o que é um atendimento humanizado e considerou-se apto a realizá-lo. Ainda assim, $30 \%$ evidenciaram que essa prática poderia ser aprimorada. Além disso, $50 \%$ desse grupo revelaram sentir limitações físicas do ambiente das UTIs pediátrica e neonatal à humanização do atendimento. DISCUSSÃO: Os resultados da pesquisa mostram que, nas UTIs pediátrica e neonatal do HEMC há tratamento humanizado, mas que as ações são melhores percebidas nos casos de hospitalização prolongada. Entre os entrevistados, a maioria estava internada há menos de 30 dias e poucos haviam tido contato com práticas humanizadas. Também há um lapso entre o que é feito e o que é entendido pelos acompanhantes. Bem como, entre o que é idealizado e o que é efetivado pelos profissionais, já que alguns deles sentem que a humanização poderia ser melhor e ter melhores condições para ocorrer. CONCLUSÃO O trabalho de humanização tem sido colocado em prática no HEMC, mas ainda há falha de comunicação entre os envolvidos, de modo que as medidas de humanização não são totalmente aplicadas, compreendidas e percebidas pelos familiares.

Palavras-chave: humanização; terapia intensiva; comunicação com familiares; prática humanizada.

\section{CSH - 08 DILEMA JURÍDICO E ÉTICO A RESPEITO DOS DESTINOS DOS EMBRIÕES EXCEDENTÁRIOS CRIOPRESERVADOS PROVENIENTES DE FIV}

Andreza Resende de Andrade, Maria Laura Jorge Micheletto, Bruna Beatriz Sales Guimaraes Pereira, Paola Augusto Gomes, Elaine Shizue Novalo-Goto, Luan Salguero de Aguiar, Adriana de Oliveira Camboim, Camila Fernandes Romeiro, Carmen Silvia Molleis Galego Miziara, Fabiana Iglesias de Carvalho

\section{E-mail: drezaresende@hotmail.com}

INTRODUÇÃO: A fertilização in vitro (FIV), técnica de reprodução assistida, demonstra o avanço científico na medicina. Contudo, com o avanço desta tecnologia sugiram dilemas éticos e jurídicos ainda não totalmente resolvidos. Um dos problemas mais relevantes apontados pelos atuais métodos da reprodução assistida é a produção de embriões excedentes. FIV congelam embriões excedentes para que, caso de não ocorrer a gravidez a fresco, haja possibilidade realizar transferência dos embriões criopreservados, sem se submeter à nova estimulação ovariana e aspiração folicular. A importância do tema $\mathrm{e}$ necessidade de intensificar discussões é refletido no SisEmbrio - Sistema Nacional de Produção de Embriões na no portal da Agência Nacional de Vigilância Sanitária (Anvisa) que mostra aumento mais que dobrou nos últimos cinco anos sendo em 2017 o número de 78.216 embriões criopreservados. OBJETIVO: Analisar o dilema jurídico e ético nacional que regulou e atualmente pauta os destinos admissíveis para os embriões excedentários criopreservados oriundo de FIV. MÉTODO: pesquisa baseada em artigos publicados no período de 2013 a 2018 em sites como Pubmed, Scielo, Google Scholar, CFM e do Planalto. RESULTADO: Quando esses embriões criados com a finalidade de procriação não são transferidos ao casal, tem-se a alternativa de doação. A outra possibilidade seria o descarte que é uma questão delicada, pois envolve a definição de início da vida humana. O CFM, em 1992, proibiu o descarte de embriões. Em 2013, autorizou o descarte de embriões depois de cinco anos criopreservados. Em 2017, alterou de cinco para três anos o tempo mínimo para descarte. Divergindo da Lei no 11.105/05, Lei de Biossegurança, que aprova o uso de embriões, para pesquisa de células-tronco embrionárias, criopreservados há mais de três anos em clínicas de fertilização e com o consentimento dos genitores, porém, não legisla sobre o descarte desses embriões. DISCUSSÃO: As leis refletem o dilema ético que envolve esse assunto, pois instiga a discutir temas como a origem e o direito à vida. Ação direta de inconstitucionalidade ADI 3510 levou ao STF a discussão da lei 11.105/05. Com resultado de 6 votos a 5 decidiu-se que o uso de células tronco para pesquisa não violava o direito à vida. CONCLUSÃO: Por ser um assunto que envolve ética e direito a vida, carece de maior respaldo jurídico.

Palavras-chave: Embriões excedentários; fecundação in vitro; legislação; biotecnologia

\section{CSH - 09 EDUCAÇÃO EM SAÚDE: EXPERIÊNCIAS DE ALUNOS DE MEDICINA NO ENSINO SOBRE FATORES DE RISCO PARA DOENÇAS CARDIOVASCULARES}

Camila Mika Serikawa, Daniela Gakiya, Beatriz Monteiro Polatti,

Adriana de Oliveira Camboim, Felipe Mingorance Crepaldi,

Joao Fernando Monteiro Ferreira

\section{E-mail: cmikaserikawa@gmail.com}

INTRODUÇÃO: A doença cardiovascular (DCV) é a principal causa de morte no Brasil e no mundo. Logo, a conscientização populacional da prevenção primária dessa doença é fundamental para mudar esse cenário. OBJETIVO: Avaliar o impacto pessoal dos acadêmicos de medicina em campanhas educacionais sobre prevenção da DCV. MÉTODO: Um total de 16 acadêmicos de medicina da Faculdade de Medicina do ABC (FMABC) participaram de 3 atividades educacionais, sendo elas o Projeto Coração de Estudante, o Dia Mundial da Atividade Física e o Dia Nacional da Hipertensão Arterial, todas elas realizadas na região do ABCDM. Ao final dessas atividades foi aplicado um questionário de avaliação aos acadêmicos. RESULTADO: $100 \%$ dos acadêmicos consideraram que adquiriram conhecimento em prevenção às DCV. $93.75 \%$ dos acadêmicos tiveram a percepção de estarem mais confiantes e hábeis para desenvolver ações na comunidade com orientações e esclarecimentos em prevenção às DCV. $81,25 \%$ dos acadêmicos consideraram que houve interação multidisciplinar. Foi observada a percepção de resultados positivos para a comunidade durante as ações em 100\% dos participantes, sendo que $87,5 \%$ consideraram que se tornaram multiplicadores de mensagens de saúde sobre prevenção às DCV. DISCUSSÃO: A atuação de acadêmicos como educadores em saúde representa uma ferramenta necessária para sua formação profissional e pessoal, não se restringindo somente à fisiopatologia das DCV. No papel de multiplicadores de prevenção e promoção à saúde consegue-se observar uma abordagem mais global e empática dos participantes ao lidar com os pacientes, principalmente os que possuem risco de eventos decorrentes de DCV. CONCLUSÃO: Foi possível perceber um empoderamento dos alunos perante os temas abordados. Houve benefício no caráter interdisciplinar das ações, posicionando os estudantes da área de saúde como multiplicadores, ao transmitir informações sobre promoção da saúde, prevenção e controle dos fatores de riscos modificáveis das DCV, para a população leiga de diferentes faixas etárias.

Palavras-chave: doenças cardiovasculares; prevenção primária; promoção da saúde.

\section{CSH - 10 EDUCAÇÃO SEXUAL PARA MENINOS EM SITUAÇÃO DE RISCO: PREVENÇÃO DE AGRAVOS E PROMOÇÃO DA SAÚDE}

Karine Corcione Turke, Anne Gabriele Senne Martinez, Natália Corrêa Gabriel, Livia Restani Dos Santos, Alice Jimenez Koyama, Karola Beserra de Araújo, Juliana Kessar Cordoni, Ligia De Fatima Nobrega Reato

\section{E-mail: karineturke@ hotmail.com}

INTRODUÇÃO: A adolescência é um período de transição entre a infância e a vida adulta caracterizado por uma fase crítica e de vulnerabilidade. É nessa fase que muitos iniciam a vida sexual, cujo início precoce traz mais consequências negativas relacionadas à vida adulta. Meninos adolescentes e pré-adolescentes sofrem determinadas pressões inerentes à condição de masculinidade, buscando afirmar suas identidades e conseguir status no seu grupo social masculino. OBJETIVO: Realizar ação educativa sobre o tema adolescência e sexualidade para crianças e adolescentes do sexo masculino em situação de maior vulnerabilidade. MÉTODO: A ação fo realizada na Instituição Beneficente Irmã Marli, que fornece atividades culturais e esportivas para as crianças e adolescentes de 8 a 15 anos residentes do Morro da Kibon, em Santo André. Os jovens foram divididos em dois grupos, de acordo com a faixa etária e estimulados a desenhar um boneco, sob instruções norteadoras abordando características do mesmo. Após a realização da dinâmica, houve uma apresentação do Estadiamento de Tanner, havendo também uma roda de conversas para esclarecimento de dúvidas. RESULTADO: No total, participaram da dinâmica 30 meninos com idades entre 7 e 13 anos. O grupo de menor faixa etária se mostrou mais receptivo e interessado, precoce no que dizia respeito à sexualidade, com exceções. O grupo de maior faixa etária apresentou resistência e pareciam realizar a atividade apenas por obrigação. De maneira geral, os meninos se demonstraram muito tímidos para fazerem perguntas, e ao mesmo tempo faziam brincadeiras entre os amigos durante a dinâmica. DISCUSSÃO: Constatou-se uma grande heterogeneidade dentro de uma mesma faixa etária. Durante a atividade, foi percebida uma grande projeção dos jovens nos bonecos ao relatarem características próprias e possíveis sonhos. Apesar de algumas discordâncias dos grupos e da relutância de parte do grupo de 10 a 13 anos de idade para participar da dinâmica, a atividade foi realizada com sucesso. CONCLUSÃO: Apesar de a ação ter sido bem-sucedida, para que haja um impacto na redução do risco de ISTs e de gravidez indesejada de parceiras, são necessárias futuras ações de mesma finalidade, procurando consolidar o conhecimento das crianças e adolescentes, particularmente aquelas em situação de maior vulnerabilidade.

Palavras-chave: adolescente; sexualidade; educação sexual. 


\section{CSH - 11 HOMENS: VÍTIMAS SILENCIOSAS DE ESTUPRO}

Luan Salguero de Aguiar, Beatriz Fernandes Diogo Alves, Elaine Shizue Novalo-goto, Karen Akemi Campello Fukuma, Gabriela de Paiva Ascani, Paola Augusto Gomes, Thaina Altarejo Marin, Stephania Morreale, Ivan Dieb Miziara, Carmen Silvia Molleis Galego Miziara

\section{E-mail: luan.salguero@ hotmail.com}

INTRODUÇÃO: Os dados sobre estupro de homens são pouco descritos e, provavelmente, subnotificados. O Estatuto da Criança e do Adolescente determina obrigatoriedade de notificação em casos suspeitos ou confirmados de abuso de crianças/ adolescentes. A partir da Lei 12.015/2009 o estupro (ato libidinoso) também pode ser considerado em vítimas masculinas. Mas os sinais objetivos para confirmação clínica da violência ou para identificação do agressor esvaecem quando o intervalo entre a agressão e o exame sexológico é extenso, principalmente quando a vítima é do sexo masculino. Outro fator envolvido nessa questão é a subnotificação do fato Estima-se que um a cada seis homens foi vítima de violência antes dos 16 anos de idade. OBJETIVO: Mostrar os dados de exames sexológicos realizados em homens por alegada violência. MÉTODOS: Estudo descritivo por levantamento de dados no GDL do IML do Estado de São Paulo no ano de 2017. RESULTADOS: Foram analisados 1675 laudos sexológicos de pessoas do sexo masculino por alegado estupro. A idade das vítimas variou de 1 a 68 anos, sendo a Moda igual a 4 e média de 8,5 anos. Para o grupo com menos de 18 anos a média foi de 8 anos e para maiores de 18 anos foi de 23,7 anos. Quanto aos achados clínicos, 1236 laudos não mostraram elementos comprobatórios de ato libidinoso, 91 descreveram que era possível, mas sem elementos objetivos suficientes para confirmação. Desses 91 casos, 17 tinham diagnóstico de DST, mas sem comprovação de nexo com o abuso relatado. Do total de casos, 29 mostraram sinais objetivos de violência sexual e 315 vítimas não foram submetidas ao exame por impossibilidade de realização ou por escolh da vítima. DISCUSSÃO: A confirmação médica de ocorrência de ato libidinoso em homens não é frequente. Muitas vítimas são examinadas após longo intervalo da agressão e, assim, a positividade em pesquisa de espermatozóide/sêmen se torna improvável. Muitas condições clínicas se sobrepõem aos achados encontrados (megacólon, verminose, fissura anal, obstipação intestinal etc.) dificultando a confirmação do estupro. CONCLUSÃO: Os dados desse estudo mostram que crianças são as vítimas mais frequentes e que os achados clínicos, majoritariamente, não fornecem subsídios técnicos que possam estabelecer nexo entre o que foi alegado pela vítima ou por seu responsável legal com a ocorrência de estupro.

Palavras-chave: Estupro; Prova Pericial; Homens; Sexologia Forense.

\section{CSH -12 HUMANIZAÇÃO: DESENVOLVIMENTO DE HÁBITOS DE HIGIENE EM CRIANCCAS DE 4-6 ANOS DA CRECHE MEIMEI, SANTO ANDRÉ, SP - BRASIL}

Julia Araujo Vigiato, Barbara Gomes Maya, João Vitor Maroneze Porfirio, Julio Santos Teixeira, Marina Sabin de Souza Lima, Gerson Salay, Denise Schoeps

\section{E-mail: juvigiato1@gmail.com}

INTRODUÇÃO: O aprimoramento da visão humanitária é de suma importância na formação médica. Diante da prevenção de doenças, pode-se enriquecer o ensino e promover a saúde. $\mathrm{O}$ trabalho buscou aprimorar essa visão através do ensinamento lúdico das técnicas de lavagem das mãos e escovação dos dentes, em 56 crianças de 4-6 anos na creche Meimei, ABC paulista. OBJETIVO: Orientar as crianças quanto às técnicas de higienização das mãos e escovação de dentes, visando a prevenção de doenças, realização do Exame Parasitológico de Fezes (EPF) para pesquisa de parasitoses intestinais e promoção da humanização na Medicina MÉTODO: Iniciou-se com coleta de dados sobre os hábitos de higiene, entrega dos TCLEs e orientações sobre a pesquisa na reunião de pais na creche, seguida da coleta dos EPFs em três amostras. Realizou-se a atividade de intervenção, com a explicação dos métodos de lavagem das mãos de acordo com o guia da Anvisa escovação dos dentes de acordo com a Colgate, seguida da retirada de tinta guache das mãos com água e sabão e da escovação dos dentes com evidenciador Eviplac pelas técnicas ensinadas. RESULTADO: Observou-se que as crianças não lavavam as mãos, nem escovavam os dentes corretamente, favorecendo a proliferação de in fecções. Observou-se que após a intervenção educativa, houve melhora no modo de higienizar as mãos e os dentes. O ensino correto das práticas e da higiene como hábito e o tratamento de 3 crianças com Giardíase resultou numa visão integral destas. DISCUSSÃO: O foco foram as doenças diarreicas, infecções por parasitas e infecções bucais nas crianças de 4 a 6 anos da creche e mostrou a efetividade do ensino lúdico. $\mathrm{O}$ resultado de giardíase em 3 crianças mostra a precariedade das práticas de higienização e do saneamento básico, evidenciando a importância do trabalho como prevenção. Pôde-se compreender que circunstâncias sociais, éticas e educacionais influenciam no adoecimento. CONCLUSÃO: O estudo, baseado na humanização, permitiu uma intervenção lúdica eficaz para transmitir os conceitos corretos de higienização das mãos e dentes, considerando que as crianças passam grande parte do tempo em creches onde possuem alto risco de infecções. A prática comunitária foi uma estratégia de ensino capaz de desenvolver uma relação integrada com as crianças, mostrando a importância de lidar com pessoas e não doenças e proporcionar a promoção da saúde.

Palavras-chave: Humanização; parasitoses; higiene; creches.

\section{CSH - 13 MORTES POR ACIDENTE DE TRÂNSITO CONTRIBUÍRAM COM O AVANÇO NA TAXA DE TRANSPLANTES REALIZADOS NO ESTADO DE SÃO PAULO?}

Luan Salguero de Aguiar, Stephania Morreale, Paola Augusto Gomes, Maria Laura Jorge Micheletto, Adriana de Oliveira Camboim, Bruna Beatriz Sales Guimaraes Pereira, Michelle Gomes Santos, Ivan Dieb Miziara, Carmen Silvia Molleis Galego Miziara

\section{E-mail: driks_camboim@ hotmail.com}

INTRODUÇÃO: O Estado de São Paulo realiza mais da metade dos transplantes do país. Em 2017 houve um crescimento de 22\% de doadores, mas ainda existe discrepância entre o número de doadores com os de receptores. Em SP de 1980 a 2014 a taxa de mortalidade por acidentes viários era de 15 óbitos/100 mil habitantes, excedendo a do país. A partir de 2015 a taxa baixou, mas mesmo assim continua muito elevada. OBJETIVO: Comparar o número de mortes decorrentes de acidentes de trânsito com o de transplantes realizados no Estado. MÉTODO: Foram obtidas informações em sites governamentais do Estado de 2015 a 2017. Os dados foram submetidos a análise estatística pelo SPSS. RESULTADOS: No triênio estudado foram 15.351 mortes e 22.614 transplantes (incluindo córneas). Os dados foram trabalhados estatisticamente em anos individuais e na totalidade, da mesma forma que foram analisados os diferentes tipos de acidentes. Não foram encontradas diferenças entre mortes de motociclistas, vítimas de acidente de carro (motoristas ou passageiros) e de total de mortes por acidente em geral com doadores efetivos ou potenciais doadores. Os dados de mortes por causas externas gerais (acidentes automobilísticos, armas de fogo, etc.) constam nas bases de dado dos pais, mas ainda não estão atualizados para os anos de 2016 e 2017. DISCUSSÃO: No final de 2017, o CFM publicou nova resolução com orientações atualizadas de morte encefálica, provavelmente haverá maior facilidade no diagnóstico e de viabilização de doações. Vítimas de acidentes de trânsito ou de ferimentos por arma de fogo são consideradas como potenciais doadores, pois são pessoas jovens e sem doenças crônicas. Os acidentes de trânsito assumem importante taxa de mortalidade no Estado, mas não significa que as vítimas evoluam com morte encefálica nem que as famílias concitam com a doação. CONCLUSÃO: Esse estudo não encontrou em relação direta entre o número de mortes em acidentes de trânsito com o número de transplantes realizados no Estado de São Paulo, a justificativa pode ser embasada em três situações: negativa da família; mortes imediatas; ou doadores se tornam inviáveis. Políticas públicas necessitam ser implantadas para estimular a doação, da mesma forma que os médicos necessitam conhecer as novas normas de diagnóstico de morte encefálica as quais provavelmente irão viabilizar mais doadores.

Palavras-chave: Acidentes; Trânsito; Transplantes; São Paulo.

\section{CSH - 14 VIOLÊNCIA NA ADOLESCÊNCIA: FATOR DE RISCO PARA A BAIXA QUALIDADE DE VIDA}

\section{Luan Salguero de Aguiar, Carmen Silvia Molleis Galego Miziara}

\section{E-mail: luan.salguero@ hotmail.com}

INTRODUÇÃO: A adolescência, período de transição da infância para a fase adulta, é caracterizada por grandes transformações, tanto físicas quanto psicológicas, que definirão o indivíduo para o resto da vida. Entretanto, eventos externos podem influenciar negativamente na construção da personalidade pessoal e, dessa forma, comprometer sua transformação em adulto produtivo. Dentre esses fatores a violência assume extrema importância, provocando flutuações negativas que refletirão na vida do indivíduo adulto. OBJETIVO: Descrever a qualidade de vida e o perfil biopsicossocial de pessoas vítimas de violência durante a adolescência; estabelecer fatores de riscos de exposição à violência e comparar seus efeitos em relação ao gênero e ao padrão socioeconômico. MÉTODO: Foram aplicados quatro questionários validados a estudantes universitários: Caracterização da Violência; Critério de Classificação Econômica do Brasil; Inventário de Depressão e Ansiedade de Beck Qualidade de Vida SF-36. RESULTADO: foram selecionados 125 questionários do grupo de estudo (GE) (sofreram violência na adolescência) e 91 do grupo controle (GC). Das formas de violências relatadas, a física foi a mais frequente entre os homens, enquanto para as mulheres foi a sexual e sua associação à física. As análises dos dados demonstraram diferenças significativas entre os grupos, com prejuízo do GE, nos quesitos: depressão e ansiedade; perda de vitalidade; qualidade dos aspectos sociais; nível emocional e nível de dor. Evidenciaram também diferenças entre os sexos, com maior grau de ansiedade nas mulheres. DISCUSSÃO: maus tratos contra a criança e adolescente é um problema de saúde pública, sendo o Brasil o país com as maiores taxas. A violência sexual e a física são as que mais despontam nesse cenário As repercussões negativas desses eventos causam danos mentais e físicos. Os transtornos depressivos, a dependência química e doenças metabólicas são os mais prevalentes nesse contexto e justificam essa queda da qualidade de vida. CONCLUSÃO: Na população pesquisada, as análises demonstram que adolescentes vítimas de violência evoluem com transtornos psíquicos sintomáticos de ansiedade e depressão, sendo a ansiedade ainda mais evidente no público feminino, e com baixos níveis de qualidade de vida, principalmente aqueles de caráter psicoemocional, como a qualidade dos aspectos sociais e os níveis de dor.

Palavras-chave: Violência; Adolescência; Qualidade de vida 


\section{CIR-01 AVALIAÇÃO DO RESULTADO REFRATIVO DE FACECTOMIAS REALIZADAS EM SERVIÇO DE ENSINO}

Maria Leticia Lasca Sales Campos, Glauco Sergio Avelino de Aquino, Carolina Nicolela Susanna, Bianca Nicolela Susanna, Marcela Canato Toloi, Mustapha Mohames Mourad, Gustavo Junges Filiú, Matheus Real Rodrigues, Rodrigo Toledo Mota

\section{E-mail: leticialasca@gmail.com}

INTRODUÇÃO: A facectomia é uma das cirurgias mais realizadas e a evolução técnica dos últimos anos permitiu que, além da resolução da catarata, fosse possível a busca pela emetropia. Sua curva de aprendizado é considerada longa, com a possibilidade de complicações e alterações no resultado cirúrgico. Na maioria dos estudos as taxas de complicações e os resultados visuais são utilizados como indicadores de sucesso. OBJETIVO: Comparar o resultado refracional entre as facectomias realizadas por residentes e preceptores durante um ano no serviço de Oftalmologia da FMABC. MÉTODO: Analisaram-se prontuários de todos os pacientes submetidos à facectomia por facoemulsificação no período de janeiro a dezembro de 2016. Os parâmetros avaliados foram: nível de experiência do cirurgião, refração na consulta de alta do setor de catarata e acuidade visual corrigida. Excluiu-se do estudo pacientes que apresentaram complicações intra ou pós-operatórias, pacientes com doenças oculares de base ou submetidos a procedimentos oculares prévios. RESULTADO: Avaliaram-se 223 olhos de 148 pacientes. Os cirurgiões experientes operaram 31 olhos (13,90\%), desses $4(12,9 \%)$ usaram a fórmula Hoffer-Q e $27(87,1 \%)$ SRK-T, obtendo média de erro refracional de 0,02 (DP 1). Chegaram à acuidade visual (AV) final de 20/30. Os fellows realizaram cirurgia em 119 olhos (53,36\%), usando em 13 olhos (10,92\%) Hoffer-Q, 1 olho $(0,85 \%)$ Barret e em 105 (88,23\%) SRK-T. Obtiveram AV final de 20/30. Os residentes foram responsáveis por 73 cirurgias e apresentaram uma média de erro refracional de -0,02 (DP 0,86). Foram usadas em 8 olhos (10,95\%) a Hoffer-Q e em $65(89,05 \%)$ a SRK-T. Desses, 67 olhos $(91,78 \%)$ tiveram AV final de 20/30 DISCUSSÃO: Com o aumento da exigência dos resultados refracionais dessa cirurgia, exige-se uma técnica cada vez mais precisa dos cirurgiões. Em um ambiente em que operam cirurgiões em treinamento, essa excelência dos resultados pode ser atingida através de boa orientação, uso de bons aparelhos como microscópios, faco-emulsificadores e instrumentais bem produzidos. CONCLUSÃO: Na FMABC obtivemos resultados compatíveis com uma instituição de ensino. É imprescindível haver boa triagem pré-operatória, escolha corretamente do nível do cirurgião, boa orientação em relação à escolha da fórmula e do poder da lente intraocular para cada caso, um orientador preparado durante a cirurgia.

Palavras-chave: catarata; cirurgia; curva de aprendizado.

\section{CIR-02 CIRURGIA CONTRACEPTIVA MASCULINA COM USO DE GRAMPO METÁLICO: DESCRIÇÃO DA TÉCNICA E ANÁLISE DOS RESULTADOS CLÍNICOS}

Matheus Prado Nascimento, Fabio lazzetti Lopes, Sergio Albertini Daiuto Leonardo Seligra Lopes, Fabio Jose Nascimento

\section{E-mail: max_nascimento @ hotmail.com}

INTRODUCÃO: A vasectomia é a forma permanente de controle de natalidade masculina mais utilizada no mundo. Existem diferentes técnicas descritas na literatura mundial, sendo a convencional a mais utilizada no Brasil e nos países em desenvolvimento. Diferentes métodos estão ganhando destaque como a utilização de grampos metálicos para oclusão dos ductos. OBJETIVO: Descrever e analisar os resultados clínicos do método de vasectomia com utilização de grampos metálicos para ocluir os ductos deferentes. MÉTODO: O estudo prospectivo observacional foi realizado no Hospital de Clínicas Municipal José Alencar, onde 31 pacientes foram submetidos a vasectomia com uso de grampos metálicos. Eram utilizados 3 grampos metálicos para ocluir cada ducto deferente ( 2 proximais e 1 distal) Foram avaliados aspectos técnicos como tempo cirúrgico, e os resultados clínicos como a taxa de azoospermia, escala de dor pós-operatória entre outras complicaç̃es. RESULTADO: A mediana de tempo para a realização dos procedimentos fo $09 \min 22 \mathrm{~s}(08 \min 25 \mathrm{~s}-12 \mathrm{~min} 55 \mathrm{~s})$. Foi observado que 4 pacientes $(12,9 \%)$ apresentaram complicações leves e 16 pacientes $(51,6 \%)$ relataram ausência de dor pós-operatória (grau 0). Após 3 meses, todos os pacientes relataram ausência de dor. A taxa de azoospermia foi de $100 \%$. DISCUSSÃO: A técnica com uso de grampos apresentou menor duração da cirurgia quando comparada à técnica convencional. Reduzindo o tempo médio em $40,8 \%$ otimizando a logística do centro cirúrgico e mais conforto ao paciente. Nenhum paciente queixou-se de dor em 3 meses o que pode sugerir segurança do método em relação ao uso de corpo estranho metálico. As complicações pós-operatórias ocorreram em taxas semelhantes a técnica padrão, como hematoma $(9,6 \% \pm 5,4 \%$, IC95 2,9\% - 27,4\%). CONCLUSÃO: A realização da vasectomia com o uso de grampos metálicos mostrou-se de fácil execução, com tempo cirúrgico inferior a técnica convencional $(\mathrm{p}<0,05)$ e taxas de complicações e azoospermia semelhante a técnica convencional, permitindo sugerir uma alternativa segura e eficaz com algum benefício aos pacientes e serviços de saúde. Palavras-chave: Vasectomia; Espermograma, Anticoncepção; Complicações pós-operatórias

\section{CIR-03 CONTINÊNCIA PRECOCE E PROLONGADA PÓS PROSTATECTOMIA RADICAL ROBÓTICA: ABORDAGEM ANTERIOR CONVENCIONAL X ABORDAGEM POUPADORA DE RETZIUS}

Carolina Bistacco Moreira, Maria Claudia Bicudo Furst, Marcos Tobias Machado

\section{E-mail: cahbist@gmail.com}

INTRODUÇÃO: Alcançar a continência precoce pós prostatectomia radical é um controle de qualidade medido por pacientes e cirurgiões. A Retzius sparing é uma técnica nova, porém mais exigente, que apresenta uma racionalização da preservação total das estruturas anteriores à próstata, importantes para o controle da continência urinária. OBJETIVO: Avaliar a taxa de continência pós prostatectomia radical robótica comparando abordagem convencional anterior (CA) X Retzius poupadora (RS). MATERIAL E MÉTODOS: Realizamos uma análise retrospectiva de 100 pacientes que foram submetidos à prostatectomia radical robótica ( $50 \mathrm{CA}$ e $50 \mathrm{RS}$ ) com preservação bilateral conservadora do nervo operado pelo mesmo cirurgião. A CA foi realizada conforme descrito por Menon et al, com poucas modificações e a RS foi realizada conforme descrito por Galfano et al. O cateter de Foley foi removido aos 7-10 dias após a cirurgia. Continente foram considerados pacientes que não usam pads ou 1 pad de segurança após a cirurgia. Avaliação do estado de continência foi realizada no $10^{\circ}$ dia de pós-operatório e 1 , 3, 6, 12 meses após a cirurgia. RESULTADOS: Ambos os grupos são comparáveis considerando a idade, estágio clínico, PSA, risco do grupo D’Amico, volume da próstata, IPSS. A taxa de continência favoreceu RS em 10 dias ( $92 \times 30 \%), 1$ mês (94 x 40\%), 3 meses (96 x 70\%), 6 meses (100 x 86\%). A diferença não foi significativa aos 12 meses com $100 \times 92 \%$. DISCUSSÃO: A preservação da continência envolve a preservação e reconstrução de tecidos. No entanto, todos com impacto na continência precoce, como observado nesta comparação entre as abordagens CA e RS. CONCLUSÃO: O suporte anatômico e a posição da bexiga e da uretra parecem ter importância para alcançar uma continência mais rápida. Aos 12 meses, a cicatrização e a fibrose desenvolvem um novo suporte e retorno de continência na maioria dos pacientes submetidos à prostatectomia radical robótica independente da abordagem.

Palavras-chave: Câncer de próstata; prostatectomia; incontinência.

\section{CIR-04 LINFADENECTOMIA INGUINAL ENDOSCÓPICA POR VÍDEO (VEIL). RESULTADO A LONGO PRAZO DA AMOSTRAGEM DE 110 PACIENTES NA AMERICA LATINA}

Gustavo Luis Ramos Moralejo, Rafaela Oliveira de Sousa, Pedro Ivo Sanches Martins, Giulio Bartie Rossi, Victor Tramonte Pereira, Guilherme Ferrari de Araújo, Vinicius José Andreotti Panico, Marcos Tobias Machado

\section{E-mail: gustavo45m@gmail.com}

INTRODUÇÃO: A linfadenectomia inguinal é o procedimento indicado no manejo linfonodal do câncer de pênis. Esse procedimento clássico é comumente associado a complicações cirúrgicas elevadas. A VEIL é uma alternativa minimamente invasiva, conserva os princípios oncológicos e reduz a morbidade. OBJETIVO: Explicitar a diminuição das morbimortalidades relacionadas à linfadenectomia inguinal no câncer de pênis, e relatar a experiência com a maior experiência da literatura até os dias atuais, focando na satisfação estética, qualidade de vida e resultados oncológicos, associados à diminuição das complicações da VEIL. MÉTODO: Foram analisados 150 procedimentos em 110 pacientes, com contribuição de diversos centros latino-americanos por 6 anos; Todos os centros utilizaram a técnica descrita por Tobias-Machado et al, J Urol, 2007. RESULTADO: Tempo operatório médio: 90 min (60-120), morbidade geral: 20\% (5-30) (Classificação de Clavien-Dindo 3-4 - 2\%), morbidade da pele: $3 \%(0-5)$, morbidade linfática: $15 \%$ (5-25), remoção média de linfonodo: 8 (6-16), conversão para aberto: $0 \%$, internação mediana: 1 dia (1-7), média de dias com drenagem: 7 (3-21), readmissão: 5\%, punção de linfocele: $10 \%$, reoperação: $0 \%,+$ linfonodo: $25 \%$, recidiva inguinal: $2 \%$, sobrevida específica do câncer: $90 \%$, sobrevida global: $85 \%$. DISCUSSÃO: Devido à falha recorrente dos métodos não invasivos, a VEIL mostrou-se mais efetivo evitando recidivas e a progressão da doença. Embasado nos dados, o tempo operatório por ser minimamente invasiva a cirúrgica promove uma baixa morbidade, sendo que o sucesso e a precisão na retirada dos linfonodos, sem atingir nenhuma artéria, veia ou nervo importantes, contribuem para um pós-operatório de tempo mínimo e sobrevida elevada. Para utilizar esse método é necessário ter uma equipe experiente, multiespecializada, com pré-operatório minucioso. Não houve conversão para cirurgia aberta em nenhum dos pacientes e os linfonodos anormais foram mais acessíveis. CONCLUSÃO: Comparado com a técnica aberta, o VEIL mostrou semelhança na ressecção de linfonodos (resultado oncológico), redução da morbidade e menor tempo de recuperação. A técnica foi apropriada para a doença $\mathrm{N} 0-\mathrm{N} 1$ com resultados oncológicos promissores a longo prazo.

Palavras-chave: VEIL; Linfadenectomia inguinal; Cirurgia minimamente invasiva. 


\section{NOVO PARADIGMA DA NEUROTIZACCÃO DO BÍCEPS EM PACIENTES COM MAIS DE UM ANO DE LESÃO DO PLEXO BRAQUIAL. UMA ANÁLISE RETROSPECTIVA E COMPARATIVA}

Henrique Batissoco de Siqueira, Pedro Augusto Soffner Cardoso, Victor Bignatto Carvalho, Isabella Pereira Blanco, Manuela Pereira Blanco, Fernando Towata, Márcio Aita

\section{E-mail: henrique.siqueira45@gmail.com}

INTRODUÇÃO: A lesão do plexo braquial é a afecção neurológica mais grave que acomete o membro superior. Durante muito tempo foi considerada como irreversível, até que, em 1994, Oberlin C et al apresentou uma nova técnica de neurotização, mudando seu prognóstico. Atualmente a literatura demonstra bons resultados mediante intervenção cirúrgica precoce (menos de 1 ano de lesão). OBJETIVO: Avaliar o resultado funcional da intervenção cirúrgica em lesões tardias (1 ano), comparando-as com a intervenção precoce. MÉTODO: Um total de 49 pacientes, submetidos à cirurgia de Oberlin por lesão parcial do plexo braquial entre os ano de 2007 e 2016, foram subdivididos em 2 grupos (A e B). No grupo A, os pacientes operados com um tempo de lesão inferior a 1 ano. E no B, aqueles que ultrapassaram 1 ano de lesão. Todos realizaram reabilitação com terapia ocupacional e foram avaliados ambulatorialmente, medindo o grau de forção de flexão do cotovelo de acordo com a escala internacional de força. RESULTADO: No grupo A (29), aproximadamente $80 \%$ dos pacientes apresentaram resultados bons ou satisfatórios com força de flexão do cotovelo igual a M4 e M3. No grupo B, dos 9 pacientes avaliados, 7 obtiveram bom resultado (M4) e 2, um resultado satisfatório (M3). A análise realizada neste trabalho não demonstra diferença estatisticamente significativa no resultado pós-operatório, quando comparado o grau de força obtido entre pacientes dos grupos A e B. DISCUSSÃO: A literatura mostra bons resultados para pacientes operados até 1 ano de lesão e resultados não satisfatórios para paciente operados após esse prazo. Neste trabalho observamos que os pacientes operados com mais de 1 ano de lesão do plexo braquial apresentaram resultados bons (M4) ou satisfatórios (M3) de flexão do cotovelo em mais de $90 \%$ dos casos. CONCLUSÃO: A neurotização ainda é viável em pacientes com lesões parciais do plexo braquial superiores a 1 ano, visando resultados bons e satisfatórios de flexão do cotovelo. No entanto, são necessários estudos multicêntricos prospectivos e randomizados para obter a resposta definitiva para essa questão.

Palavras-chave: Plexo Braquial; Transferência de Nervo; Membro Superior.

\section{CIR-06 PROSTATECTOMIA SUBCAPSULAR ABERTA, LAPAROSCOPICA OU ROBO ASSISTIDA: ESTUDO COMPARATIVO DAS TÉCNICAS EMPREGADAS EM DIFERENTES ESTÁGIOS DA CURVA DE APRENDIZADO \\ Victor Tramonte Pereira, Rafaela Oliveira de Sousa, Guilherme Ferrari} de Araujo, Gustavo Luis Ramos Moralejo, Giulio Bartie Rossi, Pedro Ivo Sanches Martins, Vinicius José Andreotti Panico, Marcos Tobias Machado

\section{E-mail: victortpereira@icloud.com}

INTRODUÇÃO: A cirurgia é o procedimento padrão para a maioria dos casos sintomáticos de HBP após falha na terapia medicamentosa. Para adenomas maiores que $80 \mathrm{cc}$, a prostatectomia subcapsular aberta (PSA) é o procedimento padrão, sendo a via laparoscópica uma alternativa minimamente invasiva e hoje a abordagem robótica está ganhando espaço em substituí-la. OBJETIVO: Comparar os resultados perioperatórios e funcionais baseados nos dados obtidos durante a curva de aprendizado dos cirurgiões para técnicas aberta, laparoscópica e robótica MÉTODO: Análise de dados coletados em 3 hospitais durante 5 anos. Foram incluídos pacientes com próstata maior que $80 \mathrm{~g}$, retenção urinária refratária, insuficiência renal obstrutiva, falha no tratamento clínico e preferência do paciente. Foram excluídos pacientes com ASA 3 e 4, câncer de próstata, bexiga neurogênica ou estenose uretral. Não houve randomização nas técnicas cirúrgicas. RESULTADO: 90 pacientes submetidos à prostatectomia foram incluídos em nosso estudo; 65 foram tratados com PSA, 15 submetidos à cirurgia Prostatectomia laparoscópica (PL) e 10 operados com auxílio robótico (prostatectomia robótica-PR). Tempo operatório médio foi de 125 min 180 min e 150 min respectivamente. Tempo médio de permanência com sonda e tempo de internação foram maiores nos pacientes submetidos à cirurgia aberta. $\mathrm{O}$ sangramento intraoperatório e necessidade de transfusão foram maiores no grupo de abordagem aberta. Não houve registro de complicações graves entre os grupos com abordagem laparoscópica (PL e PR). DISCUSSÃO: Quando comparado com a PSA, a PL mostrou menor: perda sanguínea, período de cateterismo pós-operatório e internação hospitalar, apesar do tempo operatório mais longo. Ao analisar os casos submetidos a tratamento cirúrgico para HBP, a perda média de sangue no PSA foi aproximadamente $88 \%$ maior do que na PL. PSA teve um tempo médio de sonda de 8,5 dias, enquanto no PL foi de 5 dias, o que representa um período $70 \%$ maior com o sonda. O tempo de internação foi 2x maior no grupo PSA. A amostra limitada, a falta de análise de custos e o formato retrospectivo foram as limitações mais importantes do estudo. CONCLUSÃO: As cirurgias minimamente invasivas podem ser mais seguras e eficazes do que a PSA. Mais estudos serão necessários até que a cirurgia minimamente invasiva seja considerada padrão para o tratamento cirúrgico das próstatas maiores.

Palavras-chave: Hiperplasia Prostática Benigna; Prostatectomia Subcapsular Laparoscopia.
CIR-07 RECONSTRUÇÃO DA MEMBRANA INTERÓSSEA DO ANTEBRAÇO NO TRATAMENTO DA INSTABILIDADE DA ARTICULAÇÃO RADIOULNAR DISTAL

Othon Moritoshi Shiroma, Henrique Batissoco de Siqueira, Giovana Moreira Minchilo, Lucas Alves Dominicano Ferreira, Fernando Towata, Marcio Aita

E-mail: othonshiroma@gmail.com

INTRODUÇÃO: As fraturas de antebraço, punho e cotovelo podem ocorrer isoladas ou em associação. Podem estar associadas à lesão da membrana interóssea do antebraço (MIA). Quando não abordadas adequadamente, alteram a anatomia estabilidade e transmissão de carga, o que pode resultar em dor, diminuição do arco de movimento e da força de preensão palmar, prejudicando a qualidade de vida do paciente. OBJETIVOS: Mensurar qualidade de vida e a clínica-funcional dos pacientes submetidos à reconstrução ligamentar da MIA, por meio do tendão do músculo braquial estilorradial (BR) e descrever essa nova técnica cirúrgica no tratamento da instabilidade da articulação da radioulnar distal (ARUD). MÉTODOS: Por um período de 33 meses, 24 pacientes com lesão longitudinal da ARUD foram submetidos ao tratamento cirúrgico, pela nova técnica proposta. Todos foram avaliados pelo setor de terapia ocupacional em intervalos regulares no período pós-operatório e realizaram a mesma sequência de reabilitação. Foram analisados: arco de movimento (ADM) e qualidade de vida através dos questionários DASH (Disability Arm, Shoulder and Hand) e VAS (Visual Analogue Scale). Foram realizadas radiografias pré e pós-operatórias, e descritas as complicações e o tempo de retorno ao trabalho. RESULTADOS: O arco de movimento foi em média 167,92 . O valor da avaliação subjetiva da dor foi $2 / 10$. A mensuração da qualidade de vida foi de 5,63/100. O tempo de retorno ao trabalho foi de 7,37 meses. Quanto às complicações, apenas um evoluiu com instabilidade da ARUD, solucionado através da técnica de Brian-Adams, e outros três com problemas ao redor do fio, evoluindo de forma satisfatória após sua retirada. DISCUSSÃO: Os resultados deste estudo revelam uma melhoria na mobilidade de $93,29 \%$, quando comparados aos $86,11 \%$ na literatura. Além disso, essa técnica apresenta vantagens como: diâmetro do túnel ósseo pode ser mínimo, evitando fraturas iatrogênicas do rádio ou da ulna; evita abordar outro sítios cirúrgicos, como o joelho; não afeta a capacidade funcional do antebraço doador. CONCLUSÃO: A nova abordagem apresentada é segura e eficaz no tratamento da instabilidade longitudinal da ARUD, já que apresenta resultados radiográficos, clínicos e funcionais satisfatórios e baixas taxas de complicações. Permite o retorno às suas atividades, além de um aumento da qualidade de vida.

Palavras-chave: Essex-Lopresti; membrana interóssea; reconstrução ligamentar; ARUD.

\section{CIR-08 TIMPANOPLASTIA INLAY: UMA COMPARAÇÃO ENTRE A TÉCNICA ENDOSCÓPICA E MICROSCÓPICA}

Livia Alexandre Martins, Gabriel Matos, Carlos Eduardo Borges Rezende

\section{E-mail: li_martins16@hotmail.com}

INTRODUÇÃO: A timpanoplastia é uma cirurgia otológica introduzida em 1950 com o intuito de reconstruir a membrana timpânica (MT) perfurada, principalmente em pacientes com otite média crônica (OMC), por meio da colocação de enxerto, melhorando a audição e protegendo a mucosa da orelha média de infecções. O método inlay, descoberto por Roland Eavey em 1998, proporciona diversas vantagens e, portanto é muito utilizado atualmente. Esse método pode ser realizado por meio de duas técnicas, a microscópica, mais antiga e considerada o padrão ouro durante muitos anos e a endoscópica, mais atual e mais comumente utilizada. OBJETIVO: Comparar as duas técnicas, endoscópica e microscópica, em pacientes submetidos a timpanoplastia inlay, em relação aos limiares auditivos antes e depois da cirurgia e à otoscopia pré e pós operatória. MÉTODO: Foi realizado um estudo de série de casos de corte transversal fundamentado na análise de prontuários de 20 pacientes com OMC simples submetidos a timpanoplastia inlay, 10 pela técnica endoscópica e 10 pela técnica microscópica, no período de 2013 a 2017 atendidos no ambulatório de Otorrinolaringologia da Faculdade de Medicina do ABC. RESULTADO: A técnica endoscópica proporcionou o fechamento completo da MT de todos os pacientes e a redução da perda auditiva em $42,8 \%$ com diminuição de $38,2 \%$ do SRT médio dos pacientes submetidos à essa técnica. Em contrapartida, daqueles pacientes submetidos à técnica microscópica, $20 \%$ permaneceram com a MT perfurada após a cirurgia e $50 \%$ permaneceram com perda auditiva, embora tenha havido uma redução da perda auditiva em 37,5\% com diminuição de 13,2\% do SRT médio. DISCUSSÃO: O endoscópio se mostrou mais eficaz e satisfatório em relação ao microscópio, pois permite a visualização de uma imagem extensa, incluindo áreas atrás da orelha média de difícil acesso, excluindo a necessidade de incisões pós-auriculares, sendo portanto menos invasivo. Além disso, essa técnica proporcionou resultados otoscópicos e audiométricos superiores ao microscópio, considerando o fechamento da MT e a diminuição dos SRT médios, tornando-se a técnica mais utilizada atualmente. CONCLUSÃO: A timpanoplastia inlay endoscópica se mostrou mais vantajosa quanto ao fechamento completo da MT e à melhora da audição dos pacientes com perfuração timpânica como sequela da OMC, quando comparada à timpanoplastia inlay microscópica.

Palavras-chave: timpanoplastia; endoscópio; membrana timpânica; perda auditiva. 


\section{CATEGORIA - CLINIICO}

\section{CLI - 01 AVALIAÇÃO DE COORTE RETROSPECTIVA SOBRE O IMPACTO DA EXPRESSÃO ANORMAL DE ANTÍGENO CD7 LINFÓIDE NA LEUCEMIA MIELÓIDE AGUDA NO SUDESTE DO BRASIL}

Julia Araujo Vigiato, Igor Luiz Argani, Glauco Sergio Avelino de Aquino, Vitor Augusto Queiroz Mauad, Davimar Miranda Maciel Borducchi

\section{E-mail: juvigiato1@ gmail.com}

INTRODUÇÃO: A leucemia mieloide aguda é uma neoplasia mieloproliferativa agressiva, caracterizada pela proliferação patológica de precursor comprometido com a via de diferenciação mielóide. À medida que o conhecimento citogenético aumenta, a abordagem e terapia alvo entram nas matrizes de tratamento. O estudo e a compreensão de um antígeno linfóide $\mathrm{CD} 7$, marcador não usual, pode ser fundamental para o desenvolvimento e melhoria dos tratamentos. OBJETIVO Avaliar o impacto da apresentação do antígeno CD7 como preditor de prognóstico. MÉTODO: Desenvolveu-se uma comparação entre os pacientes $\mathrm{CD} 7$ + e -, com avaliação de sobrevida. RESULTADO: Dos 61 pacientes com LMA, 15 expressaram CD7, enquanto 46 não. A taxa de remissão foi de $40 \%$ e $39,13 \%$, respectivamente. Resultados da Sobrevida (OS): em um mês foi de $66,67 \%$ no grupo CD7 + e 69,67\% no grupo CD7-; em um ano foi de $45,7 \%$ em CD7 + e $23,9 \%$ em CD7-. O OS em três anos revelou $38,1 \%$ em pacientes CD7+ e $21 \%$ em CD7-. O DFS em três anos foi maior nos grupos CD7- $(72,2 \%)$ do que nos grupos $\mathrm{CD} 7+(60 \%)$. A Mediana da Sobrevida Global no grupo CD7 + foi de 8,2 meses, enquanto o CD7- foi de 2,03 meses, quase quatro vezes menor. DISCUSSÃO Neste estudo, esse marcador teve um bom valor prognóstico, pois os pacientes $\mathrm{CD} 7+$ viveram quatro vezes mais que os pacientes CD7- (OS) e apresentavam menor DFS. Ao contrário, outros estudos sustentam que o CD7 + é um marcador de mau prognóstico. Essa controvérsia pode ser explicada por diferenças metodológicas, como a técnica de imunofenotipagem. Não associações entre imunofenotipagem e aberrações genéticas também poderiam contribuir para o valor prognóstico contraditório, como a dificuldade em realizar uma análise multifatorial. CONCLUSÃO: O CD7 é um cluster de diferenciação, expresso na superfície celular das células T e natural killer. É expresso em alguns pacientes com LMA devido a uma mutação cromossômica, indicando imaturidade fenotípica. No presente estudo, a positividade para $\mathrm{CD} 7$ foi um bom marcador prognóstico, embora ainda seja controversa na literatura.

Palavras-chave: LMA; CD7; Prognóstico.

\section{CLI - 02 ESTUDO COMPARATIVO E RANDOMIZADO DOS EFEITOS TERAPÊUTICOS DA BETAMETASONA + HIALURONIDASE TÓPICA COM APLICAÇÕES DO PRODUTO SEM E COM TRAÇÃO DO PREPÚCIO}

Matheus Prado Nascimento, Fabio Jose Nascimento

\section{E-mail: max_nascimento@ hotmail.com}

INTRODUÇÃO: A fimose é uma doença comum na prática diária de urologistas pediatras e cirurgiões infantis, $10 \%$ das crianças após os 3 anos apresentam essa patologia. É definida como a incapacidade de retração do prepúcio (pele que recobre a extremidade do pênis), impedindo assim a exteriorização da glande. O tratamento pode ser clínico, utilizando-se cremes tópicos a base de corticoides ou descolamento das aderências através de manobras digitais com o uso de anestésicos locais. Pode-se ainda realizar um tratamento cirúrgico, a postectomia convencional e a postectomia com dispositivo plásticos. Entretanto, estudos recentes demonstraram que o tratamento clínico em cremes tópicos a base de corticoides pode ser uma alternativa. OBJETIVO: O objetivo desse estudo é comparar os efeitos terapêuticos da aplicação do Valerato de Betametasona $0,2 \%$ + Hialuronidase tópico com e sem tração do prepúcio para o tratamento da fimose. Para demonstrar se há diferença na taxa de cura devido ao método de aplicação escolhido. MÉTODO: Trabalho prospectivo, randomizado e comparativo. A amostra foi de 33 pacientes portadores de fimose, com idade igual ou superior a três anos e inferior a dez anos de idade. As fimoses foram classificadas pela classificação de Kayaba. Foi usado Valerato de Betametazona $0,2 \%$ + Hialuronidase tópico. Um grupo foi orientado a fazer a tração total do prepúcio para a aplicação do medicamento e outro grupo para não realizar a traç̃o. RESULTADO: Dos 33 pacientes submetidos ao trabalho, apenas 13 foram curados da fimose. Desses, 7 não realizavam a tração do prepúcio, sobrando 6 que realizava. Dos 20 pacientes que não foram curados, 11 desses tiveram uma melhora na classificação da fimose, significando uma ação da droga. Os pacientes não curados foram encaminhados para cirurgia. DISCUSSÃO: Com esses dados preliminares é possível notar que dos pacientes curados $54 \%$ não realizavam a tração. A taxa de cura foi baixa comparada com outros trabalhos na literatura, $39 \%$. CONCLUSÃO: Assim, conclui-se que ambas as maneiras de aplicação da pomada levam a cura da fimose, porém não é possível estabelecer com certeza se um método é superior ao outro.

Palavras-chave: Fimose; betametasona; tratamento tópico; corticoide.

\section{CLI - 03 PRESSÃO ARTERIAL DE RECÉM-NASCIDOS EM ALOJAMENTO CONJUNTO}

Cecilia Salgueiro Alvo, Lara Aguiar Marchetti Maia, Simone Holzer

E-mail: cica_alvo@hotmail.com

INTRODUÇÃO: A medida da pressão arterial (PA) é considerada importante na avaliação do recém-nascido (RN). Entretanto, é pouco utilizada na prática diária, principalmente em RN saudáveis em alojamento conjunto. Vários fatores podem influenciar os valores da PA neonatal, como idade gestacional (IG), peso, patologias maternas e eventos perinatais. Há evidências de que determinadas doenças maternas e medicamentos utilizados à gestação e parto associam-se a alterações da PA no RN, sendo tal correlação pouco explorada. A pesquisa pretende ampliar os conhecimentos dessa associação. OBJETIVO: Avaliar os valores de PA em RN em alojamento conjunto e relacioná-los com peso ao nascer e IG; morbidades e/ ou doenças, hábitos e Índice de Massa Corpórea (IMC) maternos. MÉTODO: Esse estudo transversal e controlado é composto por $148 \mathrm{RN}$ termo saudáveis, no qual são avaliadas as pressões arteriais dos neonatos em alojamento conjunto do Hospital Municipal Universitário de São Bernardo do Campo. Coletaram-se informações em prontuários como morbidades e intercorrências durante a gestação e condições ao nascimento e dados antropométricos do RN. RESULTADO: PA sistólica/diastólica média $\mathrm{RN}$ mães hígidas $=72,26 / 28,5 \mathrm{mmHg}$, Peso ao nascer médio $\mathrm{RN}$ mães hígidas $=3432,5 \mathrm{~kg}$, IMC médio mães hígidas $=23,24$ $\mathrm{kg} / \mathrm{m}^{2}$. PA sistólica/diastólica média $\mathrm{RN}$ mães não hígidas $=71,38 / 37 \mathrm{mmHg}$, Peso ao nascer médio RN mães não hígidas $=3610 \mathrm{~kg}$, IMC médio mães não hígidas $=29,12 \mathrm{~kg} / \mathrm{m}^{2}$. Os critérios para mães não hígidas foram: $\mathrm{IMC}>30 \mathrm{~kg} /$ $\mathrm{m}^{2}$ ou hábitos (tabagismo e etilismo) ou doença hipertensiva/endocrinológica. DISCUSSÃO: A análise dos dados obtidos prevê mínima diferença de parâmetros pressóricos entre hígidas e não hígidas, sendo maior disparidade notada nos valores diastólicos. Há significativo contraste das variáveis IMC materno e Peso ao Nascer entre os grupos, assinalando para a real importância do papel da obesidade materna na condição de nascimento. CONCLUSÃO: A inviabilidade de análise mais detalhada se dá pela exigência de casuística maior, o que está sendo realizado pelos pesquisadores. Conforme achados iniciais, nota-se falta de planejamento familiar, concorrendo para adoção de atitudes incorretas pelo desconhecimento da gestação bem como comorbidades não investigadas. Tal fato, associado à medida isolada da $\mathrm{PA}$, pode contribuir para constatação de valores alterados em relação à média da literatura.

Palavras-chave: pressão arterial; recém-nascidos.

\section{CLI - 04 RELAÇÃO ENTRE FUNÇÃO PULMONAR E CAPACIDADE FUNCIONAL MÁXIMA EM PACIENTES COM DPOC}

Paula Elinda Ignacio Gomes, Paulo Roberto Gomes

E-mail: paulinhagomes79@ hotmail.com

INTRODUÇÃO: A DPOC, caracterizada por comprometimento da função pulmonar, é responsável por influenciar negativamente a capacidade funcional de exercício. No entanto a relação da função pulmonar com o comportamento clínico destes pacientes frente a um esforço máximo ainda não está totalmente elucidado. OBJETIVO: Investigar a relação entre variáveis de função pulmonar e capacidade funcional máxima em pacientes com DPOC. MÉTODO: Foram avaliados pacientes com DPOC estável. Todos realizaram avaliação da função pulmonar (espirometria), e teste progressivo exaustivo em esteira (TPEE) com monitorização da frequência cardíaca (FC) e saturação periférica de oxigênio (SatO2) em cada estágio do teste, além de captação constante do consumo de gases (Quark). Para análise da normalidade dos dados foi utilizado o teste de Shapiro-Wilk. Correlações foram realizadas por meio dos testes de Pearson ou Spearman de acordo com a normalidade dos dados. O nível de significância adotado foi de $p<0,05$. RESULTADO: 17 pacientes ( 11 homens e 6 mulheres) com média de idade de $67,29 \pm 9,78$ anos, capacidade vital forçada (CVF) de $73,24 \pm 12,06 \%$ do predito, volume expiratório forçado no primeiro segundo

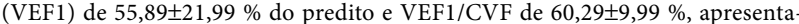

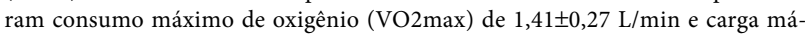
xima alcançada no TPEE de $78,24 \pm 20,07$ watts. A FC e SatO2 ao final do TPEE foram de $134,4 \pm 20,06$ bpm e $89,12 \pm 5,93 \%$ respectivamente. Houve correlação moderada entre CVF e carga máxima de trabalho $(r=0,56 ; \mathrm{p}=0,02)$; VEF1 e carga máxima de trabalho $(\mathrm{r}=0,56 ; \mathrm{p}=0,02)$; VEF1/CVF e VO2max $(\mathrm{r}=0,51 ; \mathrm{p}=0,04)$ e PFE e VO2max $(r=0,58 ; p=0,02)$. A FC e SatO2 no momento da interrupção do TPEE não apresentaram relação com as variáveis de função pulmonar $(p>0,05)$. DISCUSSÃO: A DPOC é uma entidade nosológica que a despeito dos recursos farmacológicos terapêuticos disponíveis, requer um suporte multidisciplinar com ênfase na reabilitação pulmonar e na performance músculo- esquelético. CONCLUSÃO: Quanto melhor a função pulmonar maior a capacidade máxima de exercício em pacientes com DPOC. No entanto o comprometimento pulmonar destes pacientes não está relacionado com o comportamento da FC e SatO2 ao final de um esforço máximo.

Palavras-chave: DPOC; reabilitação pulmonar; função respiratória. 


\section{CLI - 05 SEGUIMENTO TARDIO DO USO DE ANTI-TNF NO TRATAMENTO DAS DOENÇAS INFLAMATÓRIAS INTESTINAIS}

Clarissa Maria Gomes De Almeida, Fauze Camargo Maluf,

Giovana Moreira Minchillo, Pedro Mazzilli Suplicy, Feres Camargo Maluf, Andre Luis Cortez Minchillo, Maristela Gomes de Almeida

\section{E-mail: clarissa_almeida96@ hotmail.com}

INTRODUÇÃO: As doenças inflamatórias intestinais (DII), doença de Crohn (DC) e Retocolite ulcerativa (RCU), são resultantes de processo inflamatório exarcebado da mucosa intestinal, de etiologia ainda a esclarecer. São classificadas em leve, moderada ou grave, dependendo da intensidade dos sintomas e dos achados laboratoriais, radiológicos e endoscópicos. A indicação do uso de infliximabe ou adalimumabe, que são anticorpos contra o fator de necrose tumoral (anti-TNF), tem melhorado bastante a qualidade de vida destes pacientes. OBJETIVO: $\mathrm{O}$ estudo objetiva avaliar, retrospectivamente, pacientes portadores de DC ou RCU moderada a grave, que estão em uso de anti-TNF há mais de 60 meses, observando o comportamento da doença neste período. MÉTODO: Estudo retrospectivo, descritivo, dos prontuários de 10 pacientes que fazem uso de anti-TNF (infliximabe ou adalimumabe) por um período maior de 60 meses. Foram coletados dados demográficos e clínicos, fármacos utilizados, eventos cirúrgicos, efeitos colaterais e resposta clínica e endoscópica ao uso destes medicamentos. RESULTADO: Dentre 74 pacientes portadores de DII, 10 (13,5\%) estavam fazendo uso de anti-TNF há mais de 60 meses. 6 eram do sexo masculino, e 7 pacientes portadores de DC e 3 de RCU, com média de idade de 46,1 anos e tempo médio de doença de 13,3 anos. A média de idade do início dos sintomas foi de 31 anos. 4 (40\%) pacientes já tinham sido submetidos a tratamento cirúrgico. Após início do anti-TNF, nenhum necessitou de tratamento cirúrgico. O tempo médio do uso de anti-TNF foi de 74,8 meses. 8 (80\%) doentes usaram inicialmente o infliximabe e 2 (20\%) o adalimumabe. Alguns pacientes (4) faziam uso esporádico de corticosteroides e 6 usavam inicialmente a associação de anti-TNF com imunossupressor (azatioprina). Nenhum paciente apresentou complicação infecciosa grave. Do ponto de vista endoscópico, 4 (40\%) apresentam cicatrização completa da mucosa e estão totalmente assintomáticos. DISCUSSÃO: A partir dos resultados, observa-se que o uso de anti-TNF é seguro. Os biológicos analisados não apresentam efeitos colaterais graves ao paciente Ademais, a cicatrização da mucosa permite o maior controle clínico da doença. CONCLUSÃO: Percebe-se que o uso de anti-TNF tem mostrado, ao longo do tempo, sua eficácia e segurança, certamente modificando a história natural das DII.

Palavras-chave: Doença de Crohn; retocolite ulcerativa; anti-TNF; tratamento clínico.

\section{SÉRIE DE CASOS DE ASFIXIA NEONATAL TRATADOS SEGUNDO PROTOCOLO DE HIPOTERMIA EM SERVIÇO DA FACULDADE DE MEDICINA DO ABC}

Yasmin Cristina Cesquim, Fernanda Ferreira Banhos, Maria Isabel Sacchi Mendonça, Vanessa Lopes Mathia, Maria Isabel Cardoso dos Passos Carvalho, Da Hye Lee, Gleise Aparecida Moraes Costa

\section{E-mail: yasmin.cesquim@gmail.com}

INTRODUÇÃO: A asfixia neonatal é um importante desencadeante de dano neurológico ao nascimento, responsável por muitos óbitos e graves repercussões sistêmicas. A intervenção terapêutica para esse quadro foi recentemente instalada e tem evoluído consideravelmente. Ao deixar de manejar apenas as complicações e comorbidades, a terapia baseada na hipotermia prolongada tem minimizado danos de forma efetiva e mostrando-se segura e eficaz em recém-nascidos sujeitos a desenvolver encefalopatias decorrentes da anóxia, sendo importante analisar como isso se aplica no contexto do serviço da faculdade de medicina do ABC. OBJETIVO: Os casos exemplificam e elucidam a respeito do tratamento de casos de asfixia neonatal segundo o protocolo de hipotermia recentemente implantado no Brasil, bem como indicam as dificuldades, sucessos e desfechos dos casos assim conduzidos nesse local. MÉTODO: Estudo de coorte retrospectivo, que objetiva descrever a experiência do serviço no uso do protocolo de hipotermia para tratamento da asfixia neonatal nos casos elegíveis para tal e compará-lo com a biografia nacional e internacional existente. Foram coletados dados de 14 pacientes com asfixia perinatal e com indicação ao protocolo de hipotermia referentes à data do nascimento, idade gestacional ao nascer, patologia gestacional materna, hora de início do resfriamento, apgar ao nascer, intercorrências durante a vigência do resfriamento, hora de término do protocolo e desfecho. RESULTADO: quanto à patologia gestacional materna, $14,28 \%$ das mães apresentaram HAS ou Diabetes Mellitus gestacional. 57,14\% elegíveis ao protocolo de hipotermia dentre os nascidos com asfixia perinatal. Quanto ao apgar no primeiro minuto, $42,85 \%$ apresentaram apgar $1,7,14 \%$ apresentaram apgar 2 ou zero, $21,43 \%$ apresentaram apgar 3 e $14,28 \%$ apgar 5 . O principal fator determinante à interrupção do protocolo de hipotermia foi Bradicardia em 14,28\% dos casos. Os desfechos variaram, de boa evolução à morte encefálica. DISCUSSÃO: Sabe-se que as condições mínimas para que o recém-nascido seja submetido ao Protocolo de Hipotermia são idade gestacional $>35$ semanas, peso ao nascer $>1800 \mathrm{~g}$ e que tenha menos de $6 \mathrm{~h}$ de vida. A despeito do relatado na literatura, não são todos os pacientes submetidos à hipotermia terapêutica que permanecem as $72 \mathrm{~h}$ preconizadas. CONCLUSÃO: A hipotermia terapêutica é um avanço importante.

Palavras-chave: asfixia perinatal; hipotermia terapêutica.

\section{SÉRIE DE CASOS DE PACIENTES COM HAIRY CELL LEUKEMIA ATENDIDOS EM SERVIÇOS DE HEMATOLOGIA DA FMABC}

Yasmin Cristina Cesquim, Lisa Maki Umeda, Carolina Doering Neves, Thiago Artioli, Beatriz Ferreira do Prado Bassetti, Vitor Augusto Queiroz Mauad, Davimar Miranda Maciel Borducchi

\section{E-mail: yasmin.cesquim@gmail.com}

INTRODUÇÃO: A Hairy Cell Leukemia (leucemia de células pilosas - HCL) é uma desordem crônica maligna caracterizada por linfoproliferação de linfócitos $\mathrm{B}$ maduros que representa cerca de $2 \%$ de todas as leucemias linfóides do adulto e acomete mais comumente homens (5:1) com idade média de 55 anos. A patogênese da doença, apesar de ainda não totalmente elucidada devido ao fato de haver grande dificuldade em conseguir um número expressivo de amostras desse tipo de célula para análise, parece ter forte associação com a mutação de V600E em BRAF, uma quinase que vem sendo considerada a lesão genética chave no desenvolvimento da HCL. OBJETIVO: Esse trabalho objetiva descrever a experiência dos serviços de medicina do $\mathrm{ABC}$ no diagnóstico, tratamento e acompanhamento de pacientes diagnosticados com HCL, visando entender a população atendida no serviço, suas características e futuras linhas de estudo. MÉTODO: Foi realizada, primeiramente, análise da literatura brasileira e mundial no que se refere ao modo de diagnosticar, tratar e seguir os pacientes identificados como portadores de HCL. Foram então levantados dados retrospectivamente a partir de prontuários. Foram incluídos no estudo pacientes maiores de 18 anos, portadores da Leucemia de Células Pilosas, com diagnóstico e segmento dentro da instituição; o diagnóstico foi considerado apenas mediante confirmação imunofenotípica por citometria de fluxo. RESULTADO: foram levantados 5 casos, 4 homens e 1 mulher, com idade média de 48,6 anos, que foram analisados segundo sintomatologia clínica, diagnóstico, tratamento, desfecho e manejo de recidivas. DISCUSSÃO: Em nossa série, 3 dos 5 pacientes apresentavam sudorese noturna e febre, incomuns no quadro inicial dessa doença; do restante, a apresentação inicial é bastante adequada com o demonstrado em outros estudos. Um dos pacientes, mesmo apresentando DRM por imunofenotipagem positiva, não apresentou recidiva, mesmo com tempo de segmento bastante longo, ao contrário do sugerido na literatura. Outro paciente, que apresentava quadro inicial bastante sintomático e expressões imunofenotípicas anômalas, teve recidiva precoce em menos de 2 meses a despeito de tratamento mais agressivo. CONCLUSÃO: Em doenças raras como essa, esse levantamento de dados é imprescindível para apontar observações e novas ideias que servirão de base para estudos futuros.

Palavras-chave: Hairy Cell Leukemia; linfoproliferação; Leucemia de células pilosas.

\section{CLI - 08 TROPONINA I DE ALTA SENSIBILIDADE COMO MARCADOR PROGNÓSTICO CARDÍACO E DE MORTALIDADE EM PACIENTES COM MIOPATIAS AUTOIMUNES SISTÊMICAS}

Julia Basilio Santoro, Danielle Menosi Gualandro

\section{E-mail: juusantoro@gmail.com}

INTRODUÇÃO: O envolvimento cardíaco nas miopatias autoimunes sistêmicas (MAS) é um dos fatores de mau prognóstico. Portanto, a identificação precoce deste acometimento, mesmo nas fases assintomáticas, é fundamental para a prática clínica. No presente estudo foram avaliados os níveis séricos de troponina I de alta sensibilidade (hs-cTnI) em pacientes com MAS. OBJETIVO: Quantificar a prevalência de níveis elevados de troponina I, mensurados ao diagnóstico, nos pacientes com doenças inflamatórias, assim como determinar o papel da Troponina I na predição de mortalidade e acometimento cardíaco no seguimento. MÉTODO: Estudo de coorte retrospectivo, unicêntrico, em que foram incluídos 171 pacientes consecutivos com MAS ( 98 com dermatomiosite, 32 com polimiosite e 28 com síndrome antissintetase). A hs-cTnI foi dosada em amostras de soro coletadas e armazenadas na ocasião do diagnóstico dessas doenças. A regressão de Cox foi utilizada para associar as variáveis clínicas, ecocardiográficas e laboratoriais e o desfecho primário (óbito e novo diagnóstico de doença arterial coronária ou insuficiência cardíaca). RESULTADO: A mediana de idade dos pacientes foi de 44 anos, sendo $23 \%$ do sexo masculino. O tempo de doença foi 5 meses e o tempo de seguimento ambulatorial foi 4,7 anos (IQR 2,6-8,1). Doze pacientes (7\%) apresentaram o desfecho primário. Em relação à hs-cTnI, $11 \%$ dos pacientes apresentaram valores acima do percentil 99. A mediana de hs-cTnI em pacientes com evento foi maior do que em pacientes sem evento $(9,5 \mathrm{ng} / \mathrm{dL}$ vs. $4,0 \mathrm{ng} / \mathrm{dL}$ respectivamente). A concentração de hs-cTnI (OR 1,5; IC 95\% 1,1-2,1; $\mathrm{P}=0,019$ ), a de hemoglobina (OR 0,59; IC95\% $0,39-0,9 ; \mathrm{P}=0,013$ ) e a idade (OR 1,$05 ;$ IC95\% $1,01-1,1 ; \mathrm{P}=0,021)$ foram relacionadas ao desfecho primário. A alteração ecocardiográfica mais prevalente foi a disfunção diastólica (38\%), que não se relacionou com o desfecho primário. CONCLUSÃO: A concentração sérica de hs-cTnI mensurada na época do diagnóstico da MAS, foi preditora de mortalidade ou aparecimento de nova doença cardíaca, durante o seguimento dos pacientes com MAS.

Palavras-chave: troponina; miopatia; auto-imune; prognóstico. 


\section{CATEGORIA - EPIDEMIOLÓGICO}

\section{EPI - 01 AVALIAÇÃO DO ALEITAMENTO MATERNO DE CRIANCCAS ATENDIDAS NOS AMBULATÓRIOS DE ESPECIALIDADES DA FMABC: PREVALÊNCIA E CAUSAS DE DESMAME PRECOCE}

Karine Corcione Turke, Livia Restani dos Santos, Roseli Oselka Saccardo Sarni

E-mail: karineturke@ hotmail.com

INTRODUÇÃO: O aleitamento materno é essencial para o crescimento e desenvolvimento saudáveis da criança durante os primeiros anos de vida e traz benefícios na promoção à saúde e prevenção de doenças até a idade adulta. De acordo com a Organização Mundial da Saúde (OMS), o aleitamento materno deve começar dentro da primeira hora após o nascimento, prosseguir de forma exclusiva até o sexto mês de vida e continuar até dois anos ou mais, associado à alimentação complementar saudável. Apesar das recomendações nacionais e internacionais, a prevalência do aleitamento mundialmente ainda é considerada insuficiente. No Brasil, apenas $41 \%$ dos lactentes recebem aleitamento materno exclusivo (AME) até os 6 meses de idade. OBJETIVO: Avaliar e descrever a prevalência do Aleitamento Materno na primeira hora, AME até o sexto mês e total até 2 anos ou mais das crianças atendidas nos ambulatórios de especialidades da FMABC, bem como os motivos para interrupção precoce do aleitamento. MÉTODO: Foi aplicado às mães de crianças atendidas nos Ambulatórios de Especialidades Pediátricas da FMABC questionário contendo dados demográficos, informações sobre o parto e aleitamento, incluindo duração e os motivos que levaram à interrupção precoce (desmame). Análise estatística: Testes Exato de Fisher e Wilcoxon-Mann-Whitney $(\mathrm{p}<0,05)$. RESULTADO: Foram incluídas no estudo 100 mães. A média de idade das mães foi de $34.8+7.69$ e das crianças $6+3.5$ anos. Somente $31 \%$ e $26 \%$ das mães realizaram AME e total por 2 anos ou mais. O motivo mais frequente para a parada do aleitamento foi a falta de leite ou de saciedade da criança (23\% nas duas situações de aleitamento). $67 \%$ das mães amamentaram na primeira hora de vida. Foi observado que as mães que realizaram o AME por 6 meses apresentaram maior chance de praticar o total por 2 anos ou mais $(\mathrm{OR}=16.22, \mathrm{CI}=4.58-69.0)$. DISCUSSÃO E CONCLUSÃO: Observou-se na amostra estudada, que a prevalência do AME foi menor que a média nacional e, também que o aleitamento na primeira hora após o nascimento e o total são inferiores às recomendações da OMS. Medidas de conscientização e sensibilização para as famílias e profissionais de saúde são necessárias para que as metas propostas pela OMS sejam atendidas.

Palavras-chave: Aleitamento materno; criança; desmame.

\section{EPI - 02 AVALIAÇÃO DO MANEJO DA DISTROFIA MUSCULAR DE DUCHENNE NO BRASIL ATRAVÉS DE QUESTIONÁRIO REALIZADO COM DOENTES E SEUS FAMILIARES}

Karine Corcione Turke, Alzira Alves Siqueira Carvalho, David Feder

\section{E-mail: karineturke@ hotmail.com}

INTRODUÇÃO: A Distrofia Muscular de Duchenne (DMD) é uma doença de herança recessiva ligada ao cromossomo $\mathrm{X}$ e afeta cerca de 1 em cada 3500 nascidos vivos do sexo masculino. É decorrente da mutação no gene que codifica a proteína distrofina, responsável por garantir a estabilidade da membrana celular de células do músculo estriado esquelético e cardíaco. O quadro é progressivo, com fraqueza muscular a partir dos 3 anos e após a adolescência, aparecem os sinais e sintomas cardíacos e respiratórios. OBJETIVO: Avaliar se os protocolos internacionais de acompanhamento estão sendo aplicados de forma eficaz nos pacientes com DMD no Brasil. MÉTODO: Através das redes sociais voltadas para pacientes com DMD e seus familiares, convidamo-los para responderem um questionário online sobre as condições do diagnóstico, exames e tratamentos realizados. RESULTADO: Foram incluídos no estudo 54 pacientes. A idade média foi de 13,0 +1,2 anos. 40,7\% apresentava algum tipo de alteração cardíaca. Contrariando a recomendação de realização de exames a partir dos 6 anos, o primeiro eletrocardiograma (ECG) e ecodopplercardiograma foi realizado aos 8,4 e 8,8 anos em média, respectivamente. Após os 10 anos, quando os exames devem ser anuais, $23,5 \%$ não fez o ECG e não fez $26,4 \%$ o ecodopplercardiograma. 50\% já realizaram holter e 9,2\% realizaram Ressonância Magnética do coração. Apenas 31,4\% realizaram teste de força a cada 6 meses, A fisioterapia motora regular só ocorreu em $22,11 \%$ dos casos estudados. $79,5 \%$ dos pacientes com mais de 6 anos realizaram espirometria, sendo a idade média do primeiro exame aos 10,5 anos. Para a avaliação do esforço de tosse, o exame foi realizado por apenas $34,7 \%$ dos pacientes com mais de 6 anos. A espirometria anual só foi realizada por $48,1 \%$ dos participantes. $37 \%$ foram avaliados por terapeutas ocupacionais e $31,4 \%$ com nutricionistas no último ano. Somente $57,4 \%$ dos participantes receberam vacina contra influenza no último ano. DISCUSSÃO: Melhorar a divulgação dos protocolos, assim como melhorar o acesso dos pacientes aos serviços de saúde especializados podem contribuir para a melhora do acompanhamento e consequente melhoria da qualidade de vida desses pacientes. CONCLUSÃO: Conclui-se que protocolos internacionais de acompanhamento dos pacientes com DMD não são seguidos no Brasil, o que pode contribuir para maior mortalidade.

Palavras-chave: Distrofia Muscular de Duchenne; sistema cardiovascular; sistema respiratório.

\section{EPI - 03 ASSOCIAÇÃO ENTRE A OCORRÊNCIA DE HIPOTIREOIDISMO PRIMÁRIO E EXPOSIÇÃO DA POPULAÇÃO À POLUENTES INDUSTRIAIS NO ESTADO DE SÃO PAULO, BRASIL}

Marcel Gutierrez, Natália Corrêa Gabriel, Paulo Afonso Ribeiro, Luiza Fernandes Giro, Thais Stahl de Novais, Rafaella Elias Bosco, Karola Bessera de Araújo, Vitoria Cassioti Teodoro, Thalles Zaccarelli Balderi, Maria Angela Zaccarelli Marino

\section{E-mail: marcelgutierrez07@gmail.com}

INTRODUCÃO: O hipotireoidismo primário é a doença tireoidiana mais comum com crescente frequência de diagnósticos. OBJETIVOS: investigar hipotireoidismo primário (HP) em moradores próximos do Complexo Petroquímico de Capuava (CPC) e em áreas industrializadas não influenciadas pelo CPC; avaliar a associação da chance de HP com as concentrações de poluentes atmosféricos: dióxido de nitrogênio, monóxido de carbono, material particulado, dióxido de enxofre e compostos orgânicos voláteis. MÉTODO: Entre 2003 e 2005, 2004 pessoas, de idades entre 8 e 72 anos, foram avaliadas por questionário, sendo incluídos indivíduos com HP sem outras doenças tireoidianas e em uso de hormônio tireoidiano (HT). Os residentes de áreas industrializadas foram divididos em 2 grupos, sendo o A com 1002 residentes próximos $(0,5 \mathrm{a} 2 \mathrm{~km})$ de áreas de poluentes petroquímicos (Região 1), e o grupo B com 1002 indivíduos vivendo longe da região 1 (7,5 a 8,5 km) (Região 2). As concentrações dos poluentes atmosféricos foram obtidas e analisadas em 2017 por simulações numéricas com o modelo AERMOD usando dados meteorológicos do período de 2005 a 2009, correlacionando estes dados com a pesquisa feita em 2003. RESULTADOS: Dos 2004 moradores, 19,41\% apresentavam HP. Entre as regiões 1 e 2 houve diferença no número de moradores com $\mathrm{HP}(\mathrm{p}<0,001)$, sendo $32,34 \%$ na região 1 e $6,49 \%$ na região 2 . Entre adultos, $37,41 \%$ dos moradores da região 1 e 7,95\% dos moradores da região 2 tinham HP. Comparando crianças e adolescentes, a região 1 apresentava $20.40 \%$ moradores com HP e a região 2, 1,35\% moradores com HP $(\mathrm{p}<0,001)$. As análises mostram que as chances de HP na região próxima ao CPC (Região 1) são diferentes da região 2. As concentrações médias de todos os poluentes são maiores na Região 1. DISCUSSÃO: HP é uma doença comum e tratável, mas negligenciada, podendo gerar déficits motores e neurológicos em crianças. Pelas complicações do HP, o estudo sugere que a função tireoidiana deva ser avaliada em trabalhadores das indústrias químicas e moradores locais. CONCLUSÃO: Resultados mostraram diferença na taxa de HP da região 1 (mais próxima do $\mathrm{CPC}$ ) comparada com a região 2 , com concentrações médias maiores de poluentes maiores na região 1 . Sugere que fatores de risco ambientais relacionados com agentes petroquímicos se relacionam com HP.

Palavras-chave: hipotireoidismo; poluição; industrial; Brasil.

\section{EPI - 04 ANÁLISE DO PERFIL GLICÊMICO DE ACORDO COM O TIPO DE INSULINOTERAPIA EM CRIANÇAS PORTADORAS DE DIABETES MELLITUS TIPO 1 SUBMETIDAS POR UM DIA A UMA MESMA ROTINA: UMA ATIVIDADE EDUCATIVA DA ADIABC}

Thaina Altarejo Marin, Maria Isabel Sacchi Mendonça, Leticia Mota de Souza, Jessica Miwa Takasu, Giovanna Milani, Gabriela Fernandes Conrado, Edige Felipe de Sousa Santos, Marcio Krakauer

\section{E-mail: thaina.marin@ hotmail.com}

INTRODUÇÃO: Diabetes mellitus do tipo 1 (DM1) é uma doença autoimune que resulta na perda da capacidade de controlar o nível de glicose circulante, levando à hiperglicemia. Os pacientes devem se atentar em relação à dieta, atividade física e insulinoterapia. O Kids Day é uma Atividade Educativa realizada pela Liga de Controle de Diabetes da FMABC juntamente com a Associação de Diabetes do $\mathrm{ABC}$ (ADIABC). Por um dia, voluntários acompanham a rotina de crianças portadoras de DM1. OBJETIVO: Comparar o perfil glicêmico de crianças portadoras de DM1 submetidas a mesma rotina, de acordo com seu esquema terapêutico. MÉTODO: Foram analisadas 28 crianças DM1, entre 4 e 12 anos. Os dados coletados durante o Kids Day consistiram em: tempo de diabetes, tratamento, diário alimentar. Cada criança teve sua glicemia mensurada quatro vezes, e os valores foram comparados de acordo com o tipo de insulinoterapia: bomba de infusão de insulina (BII), ação longa associada à ultrarrápida (ALAU) e NPH associada à Regular (NPHAR). Foram realizados cálculos estatísticos e projeção em gráficos para análise. RESULTADO: A tendência da glicemia das crianças foi semelhante nas três insulino terapias. O perfil glicêmico com o uso da BII variou na média de 107 a $147 \mathrm{mg} / \mathrm{dL}$; enquanto que com o uso da ALAU variou na média de 102 a $185 \mathrm{mg} / \mathrm{dL}$; por fim, a combinação NPHAR evidenciou tratamento com oscilação glicêmica dentro da média de 91 a $257 \mathrm{mg} / \mathrm{dL}$. DISCUSSÃO: A tendência foi semelhante devido à rotina padronizada, evidenciando queda da glicemia após prática de exercícios físicos. Níveis adequados de glicemia foram alcançados com o uso da BII, mantendo perfil pouco oscilante, ao contrário do que ocorre com o tratamento combinado de NPHAR. A resposta ao uso da insulinoterapia de ALAU mostrou-se eficiente, ainda que sua variação seja maior que a do tratamento com o uso da BII, porém menor do que a do tratamento combinado de NPHAR. O controle do Diabetes é desafiador no cuidado pediátrico, dado que a doença exige disciplina de um público alvo o qual nem sempre compreende a complexidade do quadro. 
CONCLUSÃO: O tratamento que mostrou melhor eficiência no controle glicêmico foi o da BII, sofrendo menor interferência do manuseio do operador. Além disso, há a necessidade de apoio psicológico e familiar à criança com Diabetes, para melhor adesão ao tratamento e compreensão da doença.

Palavras-chave: Diabetes Mellitus tipo 1; crianças; insulina; dieta da carga de carboidratos.

\section{EP| - 05 ASSOCIAÇÃO ENTRE AS PATOLOGIAS DAS VIAS AÉREAS INFERIORES E SUPERIORES E POLUENTES AMBIENTAIS EM MORADORES PRÓXIMOS A ÁREAS INDUSTRIAIS NO ESTADO DE SÃO PAULO, BRASIL}

Mayara de Cassia Benedito, Maria Laura dos Reis Leitão, Liya Serikawa Sato, Felipe Mingorance Crepaldi, Pedro Ivo Sanches Martins, Marina Alvez Pinto, Rafaela Tiemi Vincentin, Maria Angela Zaccarelli Marino, Thalles Zaccarelli Balderi

\section{E-mail: mayara.decassia@icloud.com}

INTRODUÇÃO: A poluição atmosférica de particulados e gases estão sendo estudados e há preocupações significantes, mundialmente, devido aos riscos à saúde. Existem poucos estudos epidemiológicos relacionados à poluição do ar e indústrias químicas. OBJETIVO: Investigar rinite, sinusite, faringite e doenças obstrutivas pulmonares (DOP), como asma e bronquite, nos indivíduos residentes na vizinhança de um polo industrial de subprodutos do petróleo (PIP) e em outra área industrializada não influenciada pelo PIP; avaliar a associação destas patologias com poluentes atmosféricos: dióxido de nitrogênio (NO2), monóxido de carbono (CO), material particulado (MP10), dióxido de enxofre (SO2) e compostos orgânicos voláteis (COVs), no estado de São Paulo, Brasil. MÉTODOS: Entre 2003 e 2005, 2.004 indivíduos de ambos os sexos, de 8 a 72 anos foram avaliados por um questionário; selecionamos residentes com rinite, sinusite, faringite e DOP. Os indivíduos foram divididos em dois grupos. Grupo A: 1002 residentes próximos (0,5 a $2 \mathrm{~km}$ ) do PIP (Região 1); Grupo B: 1002 indivíduos distantes da Região 1 (7,5 a 8,5 km) (Região 2). As concentrações dos poluentes atmosféricos foram analisadas em 2017 por simulações numéricas com o modelo AERMOD usando dados meteorológicos do período de 2005 a 2009, correlacionando estes dados com a pesquisa feita em 2003. RESULTADOS Em ambas as regiões, no total de 2.004 residentes, 648(32,33\%) tinham rinite, 364 $(18,16 \%)$ sinusite e $219(10,93 \%)$ faringite. Nas Regiões 1 e 2 , observamos diferença significante nos residentes com rinite, sinusite e faringite $(\mathrm{p}<0,001): 395(39,42 \%)$ e $253(23,25 \%), 214(21,35 \%)$ e $150(14,97 \%)$ e $143(14,27 \%)$ e $76(07,58 \%)$, respectivamente. Em ambas as regiões, nos 2.004 residentes, 211 (10,53\%) tinham DOP. Nas Regiões 1 e 2, a diferença nos residentes com DOP foi altamente significante ( $\mathrm{p}<0,001)$ : 156(15,57\%) residentes na Região 1 e $55(05,49 \%)$ na Região 2 As concentrações médias de todos os poluentes estudados são maiores na Região 1 . DISCUSSÃO: A Região 1 é única porque os residentes estão próximos das indústrias de produtos petroquímicos e fatores ambientais podem afetar os casos incomuns de rinite, sinusite, faringite e DOP. CONCLUSÃO: Residentes em áreas industriais são mais afetados com rinite, sinusite, faringite e DOP e as concentrações médias de NO2, CO, MP10, SO2 e COVs são mais elevadas na Região 1 .

Palavras-chave: poluentes atmosféricos; indústria química; vias aéreas, Brasil.

\section{EP| - 06 COMPARAÇÃO DA MORTALIDADE POR DOENCAS DO APARELHO CIRCULATÓRIO EM INDIVÍDUOS COM IDADE ENTRE 10 E 29 ANOS RESIDENTES DA REGIÃO NORTE E DA REGIÃO SUL DO BRASIL NO SÉCULO XXI}

Jessica Miwa Takasu, João Victor Ji Young Suh, Henrique de Morais Bernal, Edige Felipe de Sousa Santos

\section{E-mail:miwa takasu@hotmail.com}

INTRODUÇÃO: No Brasil as Doenças do Aparelho Circulatório (DAC) correspondem à primeira causa de morte. Em 2015, a mortalidade proporcional por DAC na população em geral correspondeu a $27,6 \%$. Há lacuna de estudos populacionais sobre mortalidade por DAC em adolescentes e adultos jovens residentes de regiões desenvolvidas e em desenvolvimento como no Brasil, um grande país de renda média e com importantes desigualdades sociais. Assim, é difícil saber se a redução da mortalidade por DAC em adultos jovens no Brasil ocorre de forma semelhante quando estratificado por características clínico-sócio-demográficas. OBJETIVO: Avaliar a mortalidade por Doenças do Aparelho Circulatório em indivíduos com idade entre 10 e 29 anos, residentes da região Norte e da região Sul do Brasil, em ambos os sexos e faixa etária. MÉTODO: Trata-se de estudo ecológico de séries temporais com uso de microdados. Foram consideradas todas as mortes por DAC em indivíduos com idade entre 10 e 29 anos residentes da região Norte e da região Sul do Brasil, registrados no Sistema de Informação sobre Mortalidade (SIM), no período de 01 de janeiro de 2006 a 31 de dezembro de 2015. Doenças do Aparelho Circulatório foram definidas pela CID, 10a revisão em I00-I99. Foi calculada mortalidade bruta (x 100.000 habitantes) discriminando por regiões. Utilizou-se análise de regressão Prais-Winster utilizando software STATA 14.0. RESULTADO: No período estudado, ocorreram 3.304 mortes na região Norte e 3.317 na região Sul. A taxa de mortalidade por DAC foi $32 \%$ maior na região Norte que na região Sul, sendo que na região Norte do Brasil a mortalidade variou de 12,3 para 9,8 (tendência decrescente de $37,9 \%$ ao ano) $(\mathrm{p}=0,005)$ e no Sul variou de 7,9 para 6,2 (tendência decrescente de $28,5 \%$ ao ano) $(\mathrm{p}=0,01)$. DISCUSSÃO: As diferenças na mortalidade entre regiões do Brasil podem ter relação com fatores socioeconômicos, avanços farmacológicos e tecnológicos para o tratamento das DAC, além da expansão da Estratégia de Saúde da Família. Destaca-se que a transição epidemiológica também apresenta padrões distintos nessas regiões, mais avançada na região Sul. CONCLUSÃO: A mortalidade por DAC reduziu em ambas regiões, sendo mais expressiva na região Norte do país.

Palavras-chave: Doenças cardiovasculares; epidemiologia; mortalidade; adulto jovem.

\section{EFEITOS DA TEMPERATURA AMBIENTAL, UMIDADE DO AR E POLUIÇÃO ATMOSFÉRICA NA INCIDÊNCIA DE ADMISSÕES HOSPITALARES POR ACIDENTE VASCULAR CEREBRAL NA CIDADE DE SÃO PAULO}

André Akira Ramos Takahashi, Luiz Vinicius de Alcantara Sousa, Fernando Adam

\section{E-mail: andreakiratakahashi@gmail.com}

INTRODUCC̃̃O: O Acidente Vascular Cerebral (AVC) é uma das maiores causas de morbimortalidade no mundo, de difícil tratamento e recuperação. O risco de desenvolver AVC pode estar associado a fatores ambientais, sendo importante o estudo dessas possíveis associações em um cenário de alterações climáticas. OBJETIVO: Analisar associação entre a temperatura ambiental, umidade do ar e poluição atmosférica com a incidência de admissões hospitalares por AVC na cidade de São Paulo em 2016. MÉTODOS: Trata-se de estudo ecológico, realizado por coleta de dados secundário na cidade de São Paulo no ano de 2016. A definição de Acidente Vascular Cerebral foi de acordo com a décima revisão da Classificação Internacional das Doenças nos códigos: I60, I61, I63 e I64. Os dados sobre incidência de admissões hospitalares por AVC foram obtidos no site do DATASUS. Os dados ambientais foram coletados pela Companhia Ambiental do Estado de São Paulo. Foi realizado uma descrição das variáveis. Para analisar a associação entre a exposição aos poluentes e a incidência de admissões hospitalares por AVC na população da cidade de São Paulo foi utilizado o teste de correlação de Pearson e Spearman. O nível de significância adotado foi de 5\% e o programa estatístico foi o Stata versão $13.0^{\circledast}$. RESULTADOS: Houve correlação positiva entre os poluentes e incidência de admissões hospitalares por AVC nas mulheres, CO (rho:0,22; $\mathrm{p}=0,480$ ), MP10 (rho:0,52; $\mathrm{p}=0,080$ ), SO2 (rho:0,80; $\mathrm{p}=0,002$ ) $\mathrm{MP2,5}$ (rho:0,51; $\mathrm{p}=0,090$ ). Em homens existiu uma correlação positiva entre estas variáveis, $\mathrm{CO}(\mathrm{rho}=0,09 ; \mathrm{p}=0,780), \mathrm{MP} 10$ (rho: 0,27; $\mathrm{p}=0,390), \mathrm{SO} 2$ (rho: 0,570; $\mathrm{p}=0,005$ ) e MP2,5 (rho: 0,24; $p=0,440$ ). Não foram observadas diferenças estatisticamente significantes entre umidade e temperatura com a incidência de admissões hospitalares. DISCUSSÃO: A correlação positiva entre a concentração de $\mathrm{SO} 2$ e a incidência de admissões hospitalares por AVC se justifica graças à absorção desse gás no trato respiratório, o que contribui para constrição brônquica e cardiovascular. $\mathrm{O}$ aumento de $\mathrm{SO} 2$, nos meses mais frios, pode ser entendido como uma consequência da inversão térmica reduzindo a dispersão de poluentes. CONCLUSÃO: Foi observado uma correlação positiva entre a incidência de AVC e a concentração do poluente atmosférico Dióxido de Enxofre, fato importante para a intervenção na dispersão de poluentes.

Palavras-chave: Acidente Vascular Cerebral; Poluição atmosférica; Serviço Hospitalar de Admissão de Pacientes.

\section{INCIDÊNCIA DAS INTERNACÕES POR ACIDENTE VASCULAR CEREBRAL EM ADOLESCENTES, ENTRE $10 \mathrm{E}$ 19 ANOS, RESIDENTES DO ESTADO DO RIO GRANDE DO SUL, NO PERÍODO ENTRE 2010 E 2017}

Henrique de Morais Bernal, João Victor Ji Young Suh, Jessica Miwa Takasu, Edige Felipe de Sousa Santos

\section{E-mail: henriquembernal@hotmail.com}

INTRODUCC̃̃O: O Acidente Vascular Cerebral é a principal causa de internação no Brasil e não é evento raro em populações jovens. Estudo feito em países desenvolvidos, entre 1995 e 2008, mostrou tendência crescente da incidência de AVC nessas populacões. Outros estudos que analisaram essa incidência em adultos jovens em países em desenvolvimento mostraram resultados heterogêneos com taxas padronizadas variando entre 8,70 a 21,02. Especificamente para adolescentes, há lacuna de estudos que avaliem a incidência de internações por subtipos da doença cerebrovascular. OBJETIVO: Avaliar tendência da incidência das internações por subtipos de AVC em indivíduos de 10 a 19 anos residentes do Rio Grande do Sul. MÉTODO: Trata-se de estudo de séries temporais. Foram consideradas todas as admissões por AVC em adolescentes financiadas pelo sistema de saúde público entre 1 de janeiro de 2010 e 31 de dezembro de 2017. Os dados foram obtidos do Departamento de Informática do SUS (DATASUS). AVC foi definido pela Classificação Internacional das Doenças (CID-10) (I60-I64). Utilizou-se análise de regressão Prais-Winster realizada no software STATA 14.0. RESULTADOS: Contabilizou-se 696 internações, das quais 56\% decorreram de AVC hemorrágico, 15\% de isquêmico e $29 \%$ de não especificado. A incidência global variou de 5,46 para $4,04 \mathrm{x}$ 100.000 habitantes. A tendência da incidência por AVC apresentou tendência estacionária? $=-0.01$ IC 95\% (-0,021: 0,001). Avaliando AVC por subtipos, a incidência por AVC hemorrágico apresentou tendência decrescente $\beta=-0,017$ IC $95 \%(-0,023:-0,011)$ com redução de $-3,76 \%$ ao ano; por $\mathrm{AVC}$ isquêmico apresentou tendência estacionária $\beta=-0,014$ IC $95 \%(-0,051: 0,023)$; e por AVC não especificado apresentou tendência estacionária $\beta=0,006$ IC 95\% (-0,031: 0.043). DISCUSSÃO: A incidência por AVC 
hemorrágico em adolescentes correspondeu três vezes à incidência por AVC isquêmico, resultados que divergem da população geral. Isso pode ser atribuído aos diferentes fatores de risco a que está submetida a população jovem, na qual eventos trombóticos são mais raros. Nesta população os riscos estão associados à prevalência crescente de hipertensão, uso de álcool e drogas. CONCLUSÃO: A incidência das internações por AVC em adolescentes apresentou tendência estacionária. A redução na tendência por subtipos de AVC foi verificada apenas para a hemorragia intracraniana.

Palavras-chave: Incidência; AVC; adolescentes; epidemiologia

\section{EP| - 09 PERFIL DAS ADOLESCENTES ATENDIDAS NA MATERNIDADE DO MUNICÍPIO DE SANTO ANDRÉ - SP}

Morganna Alves, Karine Risso Barbosa, Gabriel Faria Medeiros, Jessica Locaspi, Gianna Roselli Venancio

\section{E-mail: morgs.alves@gmail.com}

INTRODUÇÃO: A gravidez na adolescência é um problema de saúde pública e se tornou debate de políticas universais. Dados recentes do MS indicam que os índices são maiores nas regiões NE e SE, e em jovens de baixa escolaridade, devido à falta de conhecimento e dificuldade de acesso a métodos contraceptivos; submissão, violência e expectativa de autonomia através da maternidade precoce. OBJETIVO: Caracterizar a população adolescente atendida em serviço obstétrico de hospital universitário MÉTODO: Estudo transversal feito por levantamento de prontuários de gestantes de 10 a 19 anos atendidas no Centro Obstétrico e Maternidade do Hospital da Mulher de Santo André, SP entre 01/01/2017 e 30/06/2018. Foram analisados dados pessoais, antecedentes ginecológicos e obstétricos, dados do pré-natal, parto e puerpério. RESULTADO: Fizeram parte do estudo 348 pacientes, de 14 a 19 anos de idade (média de 17,4 anos). $45 \%$ não possuíam união estável. $86 \%$ não possuía renda própria. $17 \%$ eram secundigestas: destas, $40 \%$ tinham um abortamento anterior. Pós-datismo foi o diagnóstico mais prevalente, seguido de erro de data e RPMO. A média da menarca foi de 12,5 anos; da coitarca, $14,7.83 \%$ não planejou a gestação; apenas $16 \% \mathrm{fa}$ zia uso de contraceptivo. $41 \%$ tiveram menos de oito consultas de pré-natal. A taxa de cesárea foi de $26 \%$ e, dos partos vaginais, houve episiotomia em $31 \%$. DISCUSSÃO: Mais de $80 \%$ das pacientes teve menarca entre 11 e 14 anos, dentro da normalidade. Grande parte iniciou atividade sexual entre 14 e 16 anos, em idade muito próxima da menarca. O mais preocupante é a baixa taxa de uso de métodos contraceptivos, sendo o método de escolha o anticoncepcional oral. A baixa adesão ao uso de contraceptivo reflete na taxa de gestações não programadas. A maioria apresentou sorologias negativas na rotina de pré-natal. A taxa de cesárea está acima do preconizado pela OMS de 15\%; entretanto, mostra-se melhor que o índice brasileiro, que em 2017 mantinha-se em torno de 55,5\%, uma das taxas mais altas globalmente. CONCLUSÃO: Os índices de gestação na adolescência foram expressivos, principalmente quando associados ao fator socioeconômico e falta de planejamento familiar. Desta forma, justifica o desenvolvimento de ações de atenção primária à saúde da adolescente, visando diminuir as taxas de gestações e, consequentemente, suas complicações.

Palavras-chave: Adolescência; gravidez; perfil; risco.

\section{EPI - 10 ADENOCARCINOMA PANCREÁTICO EM AIDS NA ERA TARV: ALGUMA MUDANÇA?}

Carla Beatriz Veronezi Macedo, Michel Prevital Correia, Ethel Zimberg Chehter

\section{E-mail: carlabvm95@gmail.com}

INTRODUÇÃO: Este estudo tem como objeto de pesquisa analisar a ocorrência do adenocarcinoma pancreático em pacientes HIV positivos na vigência do tratamento antirretroviral (TARV), avaliando uma possível mudança do padrão epidemiológico dessa neoplasia. A hipótese seria um aumento na ocorrência da neoplasia, tendo em vista que os pacientes HIV positivos em uso de terapia antirretroviral têm maior expectativa de vida e têm reconstituição imune. Este grupo seria comparado com pacientes HIV positivos pré-TARV e soronegativos. MÉTODOS: A pesquisa foi realizada através de revisão de literatura indexada a partir de 1996, ano da padronização da terapia antirretroviral (TARV) até $\mathrm{o}$ ano de 2018. Foi feita pesquisa através dos buscadores PubMed. Utilizamos as palavras chave: PÂNCREAS, HAART, HIV e CÂNCER. RESULTADOS: Foram encontrados 15 artigos e destes 7 preenchiam os critérios. Dos 15 artigos encontrados, pudemos verificar que os resultados se mostraram insuficientes para comprovar o aumento da incidência em relação à população soronegativa. Em relação aos soronegativos pudemos verificar que o diagnóstico da neoplasia pancreática em HIV positivos foi encontrado em idade mais precoce e em estágios mais avançados. Já em pacientes HIV positivos sem TARV, o adenocarcinoma pancreático apresentou menor relevância dentre as causas de morte quando comparados aos soropositivos com TARV. CONCLUSÃO Tais resultados abrem oportunidades para diversas teorias: Se soropositivos são diagnosticados numa faixa etária precoce e em estágios avançados, seria possível que a terapia antirretroviral tenha algum efeito oncogênico? Também podemos inquirir se a própria presença de inclusões nucleares do vírus HIV mesmo com cargas virais indetectáveis em células pancreáticas possa ter envolvimento em mutações determinantes do adenocarcinoma pancreático? Além disso, a reconstituição imunológica dos pacientes soropositivos em tratamento antirretroviral, apesar de satisfatória quantitativamente, seria satisfatória qualitativamente? Em suma, esse estudo apontou uma mudança no padrão epidemiológico do adenocarcinoma pancreático após a instituição da terapia antirretroviral, a causa de tais mudanças ainda não foi esclarecida pela literatura.

Palavras-chave: Pancreatic; neoplasm; HIV; HAART.

\section{EPI - 11 AVALIAÇÃO CLÍNICO-DEMOGRÁFICA DE PACIENTES ATENDIDOS EM UNIDADE CRÍTICA CARDIOLÓGICA DE HOSPITAL TERCIÁRIO NA REGIÃO DO ABC}

Karine Corcione Turke, Juliana Daltrino Teodoro, Caio Cesar Ferreira Fernandes, Antonio Carlos Palandri Chagas

\section{E-mail: karineturke@ hotmail.com}

INTRODUÇÃO: A doença cardiovascular é a principal causa de morbimortalidade em nosso meio e corresponde a grande percentual das internações hospitalares. Entender o perfil epidemiológico dos pacientes com doença cardiovasculares estabelecidos atendidos em uma determinada região é importante para traçar metas focadas tanto no âmbito preventivo quanto no terapêutico. OBJETIVO: Analisar o perfil epidemiológico dos pacientes atendidos em unidade crítica cardiológica de hospital terciário na região do ABC. MÉTODO: Foram analisados consecutivamente 229 pacientes admitidos na unidade crítica cardiológica de hospital universitário da região do $\mathrm{ABC}$ no ano de 2016 e 2017. Os dados foram coletados por análise de prontuário eletrônico. A gravidade dos pacientes foi estimada usando escores validados na literatura: escore GRACE para síndrome coronária aguda (SCA) e escore STS para pacientes cirúrgicos. RESULTADO: A idade média dos pacientes foi de 64,36 anos (mediana de 65 anos); 64\% dos pacientes eram homens; o Índice de Massa Corpórea foi calculado em $98,7 \%$ dos pacientes e $60,71 \%$ estava acima do peso. Com relação a fatores de risco: hipertensão arterial $(83,3 \%)$, diabetes $(42,1 \%)$, dislipidemia (37\%), sedentarismo (93,4\%), tabagismo (atual 20,9\% e ex-tabagista $31,9 \%$ ), história de infarto prévio $(40,6 \%)$, revascularização miocárdica prévia $(17,9 \%)$, insuficiência renal crônica (clearance $<60 \mathrm{ml} / \mathrm{min} ; 12,3 \%$ ). O motivo de admissão na UCC foi analisado: pós-operatório de cirurgia cardíaca eletiva (41\%), SCA $(34,4 \%)$, arritmias $(9,6 \%)$, insuficiência cardíaca descompensada $(9,1 \%)$ e causas não-cardiológicas $(5,6 \%)$. Para os pacientes com SCA, a mortalidade média predita pelo score GRACE foi de 7,31\% e a mortalidade observada foi de $11,39 \%$ nos pacientes com SCA. Para os pacientes em pós-operatório de cirurgia cardíaca, a mortalidade média prevista pelo STS foi de $14 \%$, e a mortalidade observada foi de $12,76 \%$. DISCUSSÃO E CONCLUSÃO: O perfil dos pacientes mostra uma população com alta prevalência de fatores de risco para doenças cardiovasculares, principalmente doença coronária. A mortalidade predita pelo GRACE foi menor que a observada nos pacientes com SCA, enquanto a mortalidade prevista pelo STS foi maior que a observada nos pacientes cirúrgicos. O estudo do perfil epidemiológico dos pacientes é importante para traçar estratégias de prevenção primária e secundária em nosso meio.

Palavras-chave: doenças cardiovasculares; hospitalização; perfil de saúde; fatores de risco.

\section{EP| - 12 ESTUDO DESCRITIVO DA MORTALIDADE E INCIDÊNCIA DE NEOPLASIAS DO SISTEMA NERVOSO CENTRAL NA POPULAÇÃO PEDIÁTRICA DO BRASIL ENTRE 2010 E 2015}

André Akira Ramos Takahashi, Amyr Braverman, Leonardo Alfano de Lima, Livia Akemi Ramos Takahashi, Luiz Vinicius de Alcantara Sousa, Fernando Adami

\section{E-mail: andreakiratakahashi@gmail.com}

INTRODUÇÃO: Tumores de Sistema Nervoso Central (SNC) constituem o segundo tipo de câncer mais comum em população pediátrica, sendo a principal causa de morte relacionada a neoplasias em crianças. O tratamento pode prejudicar a qualidade de vida, pelas sequelas que irão comprometer o desenvolvimento das crianças. No entanto, pouco ainda é estudado sobre a associação entre essa neoplasia e as condições sociais dentro das regiões brasileiras. OBJETIVO: Descrever a mortalidade e a incidência de neoplasias de SNC em crianças entre 2010 e 2015 nas regiões brasileiras. MÉTODO: Trata-se de um estudo descritivo que utiliza dados secundários para mortalidade e incidência de tumores de SNC em crianças entre 0 a 14 anos. A definição de Neoplasia de SNC está de acordo com a décima revisão da Classificação Internacional das Doenças nos códigos: C71, C72 e D33. Os dados sobre mortalidade e incidência de neoplasias foram obtidos através do site do DATASUS e população do estudo foi obtida por meio do IBGE. O nível de significância foi de 5\% e o programa estatístico utilizado foi o Stata versão $13.0^{\circledast}$. RESULTADOS: A incidência para meninos decaiu no Norte $(-0,13)$, Nordeste $(-0,47)$ e Centro-Oeste $(-0,41)$ e aumento no Sudeste $(0,08)$ e Sul $(0,20)$. Para as meninas houve diminuição da incidência para o Norte $(-0,14)$, Nordeste $(-0,41)$ e Centro-Oeste $(-0,15)$ e aumento no Sudeste $(0,02)$ e Sul $(0,26)$. A mortalidade masculina reduziu no Norte $(-0,07)$ e Sudeste $(-0,04)$ e aumentou no Centro-Oeste $(0,46)$, Sul $(0,27)$ e Nordeste $(0,12)$ A mortalidade feminina decaiu no Norte $(-0,70)$, Nordeste $(-0,24)$ e Sudeste $(-0,01)$ e aumentou no Centro-Oeste $(0,15)$ e Sul $(0,08)$. DISCUSSÃO: A redução da incidência no Norte, Nordeste e Centro-Oeste pode ser explicada pelo avanço da prevenção primária. O aumento das internações no Sul e Sudeste pode indicar acréscimos de diagnósticos, pela concentração dos centros de saúde nessas regiões. O aumento da mortalidade no Centro-Oeste se relaciona a uma demora no tratamento, pela sobrecarga dos centros de referência da região e pela má adesão ao tratamento pelos doentes. CONCLUSÃO: A incidência de neoplasias de SNC aumentou na região Sul e Sudeste. A mortalidade aumentou nas regiões Centro-Oeste e Sul. Essas alterações dependem do local analisado, pela diversidade de fatores associados a doença. Palavras-chave: neoplasia; sistema nervoso central; criança; epidemiologia. 


\section{EPI - 13 ESTUDO EPIDEMIOLÓGICO DOS SUBTIPOS DE LINFOMAS NOS HOSPITAIS DA REGIÃO DO ABC}

Rafaela Tiemi Iwaoto Vincentin, Thiago Artioli, Beatriz Ferreira do Prado Bassetti, Julia Araujo Vigiato, Pedro Mazzilli Suplicy, Yasmin Cristina Cesquim, Paola Mortean dos Santos, Adriana Wisnik de Campos, Vitor Augusto Queiroz Mauad, Davimar Miranda Maciel Borducchi

E-mail: rafaelatiemi.abc@gmail.com

INTRODUÇÃO: Os linfomas são um grupo heterogêneo de entidades patológicas. Seus subtipos caracterizam-se por malignização e proliferação de linfócitos. Para confirmação do subtipo é necessária a biópsia de gânglio alterado e, a partir desta, pode-se dividi-los em: Linfoma de Hodgkin (LH) e Linfomas Não Hodgkin (LNH). O levantamento epidemiológico de cada subtipo torna-se importante para prognóstico, sobrevida e aperfeiçoamento do manejo clínico nos serviços. OBJETIVO: Avaliação do perfil epidemiológico dos subtipos de linfomas nos servicos de hematologia da Região do ABC. MÉTODO: Análise dos prontuários de 128 pacientes atendidos no serviço de Hematologia do Hospital Estadual Mário Covas entre os anos de 2010 a 2018. Pesquisa do subtipo de linfoma de cada paciente e análise estatística do perfil epidemiológico dos pacientes. RESULTADO: Do total de linfomas, $14,58 \%$ corresponderam ao $\mathrm{LH}$ e $82,29 \%$ ao $\mathrm{LNH}$, sendo 3,8\% anaplásico, $3,8 \%$ células T, 5,6\% zona do manto, $10,13 \%$ zona marginal, $29,11 \%$ folicular, e $48,10 \%$ Grandes Células B (GCB). Referente às idades ao diagnóstico, 58,65 anos foi a média entre os LNH, e 42,44 anos entre os LH. Dentre os subtipos de LNH, 59,57 anos foi a média apresentada pelos pacientes para o Anaplásico, 37,8 para Células T, 57,09 para Manto, 67,26 para Zona Marginal, 62,19 para Folicular e 55,13 para GCB. DISCUSSÃO: Em um estudo realizado no Reino Unido, os LNH revelaram-se $85,6 \%$ dos linfomas e LH $14,4 \%$, comparado a $82,29 \%$ e $14,58 \%$ no $\mathrm{ABC}$, respectivamente. Nesse estudo, o linfoma difuso de GCB foi o mais frequente, revelando coerência com o $\mathrm{ABC}(48,10 \%)$. Na literatura global, a média de idade foi compatível com o marginal e o folicular e incompatível com os demais, que se mostraram menores no ABC. Referente ao anaplásico, ressalta-se um pico bimodal entre pré-adolescentes e idosos, sendo a mínima de 29,68 e máxima de 60,46 anos. CONCLUSÃO: Comparando os dados obtidos nos serviços do $\mathrm{ABC}$ com os da literatura apresentada, pode-se inferir que o perfil epidemiológico se assemelhou nos subtipos de linfoma, mas se diferenciou na média de idade de 3 subtipos de LNH. Devido à semelhança de dados, é possível realizar uma análise comparativa entre os serviços visando adequar o atendimento e tratamento, resultando em seu aperfeiçoamento e o entendimento da morbimortalidade na região.

Palavras-chave: linfoma; subtipos; perfil; epidemiológico.

\section{EPI - 14 INTERNAÇÕES HOSPITALARES POR DOENÇAS DO APARELHO CIRCULATÓRIO EM INDIVÍDUOS COM IDADE ENTRE 10 A 29 ANOS, NA REGIÃO DO NORTE E SUL DO BRASIL, NO SÉCULO XXI}

João Victor Ji Young Suh, Jessica Miwa Takasu, Henrique de Moraes Bernal, Edige Felipe de Sousa Santos

\section{E-mail: miwa_takasu@ hotmail.com}

INTRODUÇÃO: As doenças cardiovasculares (DAC) representam principal causa de hospitalização e custo referente a internações hospitalares no Sistema Único de Saúde do Brasil. OBJETIVO: Avaliar as internações hospitalares por doenças do aparelho circulatório em adolescentes e adultos jovens residentes da região Norte e Sul do Brasil MÉTODO: Trata-se de estudo ecológico utilizando dados secundários. Foram consideradas todas as internações ocorridas por doenças do aparelho circulatório em indivíduos com idade entre 10 a 29 anos, residentes das regiões Norte e Sul do Brasil, contidos nos Sistemas de Informação Hospitalar do SUS, no período de 01 de Janeiro de 2006 a 31 de Dezembro de 2015. Doenças do Aparelho Circulatório foram definidas pela CID, $10^{\mathrm{a}}$ revisão (I00-I99). Os dados foram extraídos do Departamento de Informática do SUS (DATASUS). Foram calculadas as taxas de incidência de internação sendo utilizada regressão de Prais-Winster. Todas as análises foram realizadas no software STATA 14.0. RESULTADO: A incidência de hospitalização por DAC apresentou tendência decrescente em ambas as regiões do Brasil no período de 2006 a 2015. A redução na região Norte foi de 12,06\% ao ano $(\mathrm{p}<0,001)$ enquanto a região Sul apresentou diminuição de $6,4 \%$ ao ano $(p=0,001)$. A redução na região Norte foi $88,43 \%$ maior do que na região Sul. Entretanto, a incidência de hospitalização por DAC em ambas as regiões permaneceram alta. DISCUSSÃO: Nossos achados podem ser justificados pelas mudanças no padrão de morbidade associados a transição epidemiológica. No Brasil, esse fenômeno mostrou acometimento distinto nas macrorregiões, ocorrendo primeiramente nas regiões Sul e Sudeste e posteriormente nas regiões Norte e Nordeste. Vale notar que a prevalência dos fatores de risco para o desenvolvimento de DAC tais como consumo de tabaco, consumo de álcool, inatividade física, sobrepeso e hipertensão arterial têm se mostrado prevalente inclusive na população jovem. CONCLUSÃO: A incidência de internação por DAC em ambas as regiões diminuiu sendo mais expressiva na região Norte. Mesmo sendo referida uma redução da incidência de internações por Doenças Cardiovasculares em adolescentes e adultos jovens durante o início do século XXI, os valores continuam elevados.

Palavras-chave: Hospitalização; Adulto Jovem; Epidemiologia; Doenças Cardiovasculares.

\section{EPI - 15 NEVOS CONGÊNITOS MELANOCÍTICOS INTERMEDIÁRIOS E GIGANTES}

Lia Vineyard Steuer, Débora Terra Cardial, Gabrielle Ellert de Almeida, Francisco Paschoal

\section{E-mail: lia_steuer@hotmail.com}

INTRODUÇÃO: Nevo melanocítico é uma proliferação benigna de melanócitos na epiderme, derme ou outros tecidos. São classificados de acordo com o seu diâmetro em pequenos, intermediários e gigantes. Os nevos melanocíticos como um todo estão presentes em cerca de $1 \%$ dos recém-nascidos, mas os gigantes são mais raros, com uma incidência 1:20.000. O tratamento preferencial é exérese cirúrgica, contudo, se a possibilidade de degeneração maligna for pequena, pode-se optar por acompanhamento com dermatoscopia. OBJETIVO: Avaliar o perfil epidemiológico dos pacientes com Nevos Melanocíticos Congênitos intermediários e gigantes. MÉTODO: Estudo epidemiológico retrospectivo descritivo baseado na análise de prontuários dos pacientes da Dermatologia da Faculdade de Medicina do ABC, de 2008 a 2018. Foram incluídos todos os pacientes que apresentaram nevo melanocítico congênito. Coletaram-se os seguintes dados: idade na primeira consulta tipo de nevo (gigante ou intermediário), localização do nevo, regularidade do acompanhamento, história familiar de nevos congênitos, sexo, tratamento, presença ou não de exames de imagem e desenvolvimento ou não de melanoma. Foi feita uma análise estatística padrão no Stata 11.0. RESULTADO: A frequência de homens e mulheres foi semelhante, com $11 / 52,4 \%$ e $10 / 47,6 \%$, respectivamente. A maioria dos pacientes possuía nevo congênito gigante $(18 / 81,82 \%)$, lesão única $(16 / 80 \%)$, sem história familiar de nevos congênitos (15/93,7\%), nem exames de imagem (18/94,7\%). Nenhum paciente apresentou malignização no período analisado. A maioria dos pacientes foi acompanhada com dermatoscopia anual (9/56,25\%). O local mais acometido foi o dorso (9/36\%). A média da idade na primeira consulta foi de 6,9 anos (DP: 5,53). DISCUSSÃO: Verificamos que a média de idade na primeira consulta foi de 6,9 anos. Na literatura, alguns artigos descrevem a idade menor que três anos como fator de risco para malignização, portanto, os pacientes deveriam chegar ao serviço em uma idade mais precoce. Além disso, nenhum dos nossos pacientes desenvolveu melanoma, enquanto nos artigos refere-se uma incidência que varia de 2,8-8,5\%. Este fato mostra a importância do seguimento. CONCLUSÃO: Praticamente não houve prevalência de gênero. A idade média da primeira consulta foi 6,9 anos. A maioria apresenta lesão única em dorso. Não foi observado nenhum caso com malignização do nevo.

Palavras-chave: Nevos congênitos melanocíticos; nevos gigantes; nevos intermediários.

\section{EPI - 16 NÍVEL DE ESTRESSE EM ACADÊMICOS DE MEDICINA}

Alana Degaspari de Araujo, Adriana Wisnik de Campos, Adelle Bittencourt Abdulmassih, Andreza Resende de Andrade, Carolina Guimarães, Julia Fernanda Pellegrim

\section{E-mail: alana.degaspari@outlook.com}

INTRODUÇÃO: A carga emocional e as responsabilidades resultantes da formação médica tornam os estudantes de medicina mais suscetíveis a apresentar sintomas relacionados ao estresse crônico, transtornos psiquiátricos e até mesmo suicídios. OBJETIVO: Avaliar o nível de estresse em estudantes de medicina da Faculdade de Medicina do ABC, de todas as séries, para medir o possível impacto de altas cargas horárias com intenso ritmo de estudo da graduação médica sobre a saúde mental desses estudantes. MÉTODO: Estudo observacional de corte transversal com uma amostra representativa de 98 estudantes de medicina, de todas as séries. A pesquisa consistiu na aplicação de um questionário sistematizado e na coleta de saliva matinal de jejum, em tubos de ensaio apropriados, para a dosagem dos níveis de cortisol, o melhor indicador bioquímico do nível de estresse. Nenhum desses estudantes havia usado corticosteróides nos 12 meses anteriores à pesquisa. RESULTADO: $90 \%$ dos estudantes consideraram-se com estresse alto ou muito alto, e $69 \%$ relataram pelo menos um episódio de estresse no mês anterior à pesquisa. $39 \%$ consideravam-se cansados ou muito cansados e $86 \%$ dormiam menos de 8 horas por noite em média, com $40 \%$ de sono descansado. Por outro lado, $75 \%$ consideraram ter boa memória e apenas $22,4 \%$ eram sedentários. DISCUSSÃO: A percepção de estresse autorreferida difere do estresse crônico detectado via determinação de cortisol salivar. Uma hipótese provável é a possível confusão feita pelo acadêmico entre momentos de cansaço e de estresse propriamente dito. Além disso, há uma limitação no estudo, já que foi colhida apenas uma amostra de saliva por cada acadêmico. Pretende-se estudar tais acadêmicos durante o decorrer do curso realizando-se assim um estudo comparativo. Os alunos do primeiro e quarto anos apresentaram significância estatística, o que talvez ocorra devido à distribuição disciplinar na matriz curricular do curso. CONCLUSÃO: Os resultados da análise e questionários de cortisol salivar evidenciaram o alto nível de estresse que os estudantes. Estudos de avaliação bioquímica e de autopercepção em acadêmicos da área médica são de extrema importância, pois podem revelar a necessidade de revisão da forma do ensino-aprendizagem e, além disso, podem contribuir para estratégias de planos extra-curriculares adequadas para mitigar essa problemática.

Palavras-chave: cortisol; estresse. 


\section{EPI - 17 PERFIL EPIDEMIOLÓGICO DA TENTATIVA DE SUICÍDIO EM CRIANÇAS E ADOLESCENTES NOTIFICADAS A UM CENTRO DE INTOXICAÇÃO EM SÃO PAULO}

Juliana Jorge Romano, Anthony Wong, Cristina Andrusaitis Sandron

\section{E-mail: julianajromano@uol.com.br}

INTRODUÇÃO: Suicídio é o ato humano de causar a cessação da própria vida, sendo, no mundo, uma das dez principais causas de morte e a segunda causa de morte em jovens. Visto os elevados números de suicídio, juntamente com os impactos sociais, emocionais e econômicos trazidos com ele, o suicídio constitui um problema de saúde pública. As taxas de suicídio variam de acordo com gênero e faixa etária e apresentam alguns fatores de risco como depressão, histórico familiar, doenças psiquiátricas. OBJETIVO: Analisar os aspectos epidemiológicos das tentativas de suicídio em pacientes jovens notificadas ao Centro de Assistência Toxicológica do Hospital das Clínicas de São Paulo, no período de 2015 a 2017. MÉTODO: Estudo descritivo baseado no banco de dados dos atendimentos realizados pelo CEATOX, com a circunstância de tentativa de suicídio em pacientes de até 19 anos. Analisou-se um total de 1573 atendimentos, e caracterizou-se assim o perfil epidemiológico, com os seguintes dados: sexo, faixa etária, tipo de ocorrência, sazonalidade, acompanhamento, substância utilizada e sintomas apresentados. RESULTADO: Em relação ao gênero, a tentativa de suicídio é mais prevalente no sexo feminino $(77,62 \%)$ quando comparado ao sexo masculino (22,38\%). O número de casos entre 2015 e 2017 é crescente, com um aumento progressivo entre os anos. Na grande maioria dos casos $(82,07 \%)$ foram utilizados medicamentos, $6,99 \%$ fizeram uso de rodenticida, $4,58 \%$ fizeram uso de produtos químicos e $3,18 \%$ fizeram uso de pesticidas. Os sintomas apresentados mais observados são sonolência $(29,43 \%)$, seguido de vômito $(11,89 \%)$ e taquicardia (10,04\%). No estudo observou-se certa sazonalidade nos casos, englobando os anos de 2015 a 2017. DISCUSSÃO: É válido atenção pública para a compreensão de como os jovens têm acesso aos medicamentos e substâncias utilizadas na tentativa de suicídio. Atualmente, o tema suicídio está bastante presente na mídia, e alguns estudos revelam certo impacto que essas cenas causam sobre algumas pessoas, podendo também ser um fator de risco de suicídio, fenômeno denominado suicide contagion. CONCLUSÃO: Neste estudo, foi possível caracterizar o perfil epidemiológico dos jovens que tentaram o suicídio. Esse tema é de extrema importância e requer atenção por parte dos profissionais de saúde e familiares, a fim de identificar precocemente os fatores de risco e os comportamentos suspeitos.

Palavras-chave: tentativa de suicídio; crianças; adolescentes.

\section{EPI - 18 PERFIL EPIDEMIOLÓGICO DOS PACIENTES INTERNADOS E ÓBITOS NO SUS POR DOENÇAS CARDIOVASCULARES NO BRASIL NOS ANOS DE 2010 A 2017}

Thiago Artioli, Karine Corcione Turke, Juliana Daltrino Teodoro, Livia Restani dos Santos, Leticia Santos Matsumura, Leonardo Luis Torres Bianchi, Antonio Carlos Palandri Chagas

\section{E-mail: thiago.artioli@ hotmail.com}

INTRODUÇÃO: As doenças cardiovasculares representam a maior causa de mortalidade no mundo e corresponde a uma grande parte das internações hospitalares. Dessa forma, é essencial entender o perfil epidemiológico dos pacientes a fim de criar medidas de prevenção. OBJETIVO: Traçar um perfil epidemiológico nacional das internações e óbitos por doenças cardiovasculares no Sistema Único de Saúde (SUS) no que se refere à ocorrência desses eventos em diferentes faixas etárias, sexo e raça. MÉTODO: Estudo descritivo, observacional e transversal de dados coletados no Sistema de Informações Hospitalares (SIH-SUS) do DATASUS, nos anos de 2010 a 2017. RESULTADO: Em relação às internações do SUS por infarto agudo do miocárdio (IAM) entre 2010 e 2017, é possível observar uma maior frequência de pacientes do sexo masculino $(63,53 \%)$; da raça branca $(40,44 \%)$ e de faixa etária entre 60 e 64 anos (14,94\%). Em relação aos óbitos por IAM, houve maior frequência do sexo masculino (55,72\%); raça branca (39,15\%) e faixa etária de 80 anos ou mais $(22,3 \%)$. Em relação às internações por insuficiência cardíaca, foi notada maior frequência do sexo masculino $(51,24 \%)$, sendo 2016 o ano de maior diferença entre os sexos; raça branca (36,35\%) e faixa etária de 80 anos ou mais $(21,55 \%)$. Nos óbitos por insuficiência cardíaca houve predomínio de mulheres (50,28\%), exceto nos anos de 2012 e 2013; raça branca $(36,47 \%)$ e faixa etária de 80 anos ou mais $(32,63 \%)$. Em relação aos transtornos de condução e arritmias cardíacas, a maioria das internações envolveu pacientes do sexo masculino $(51,29 \%)$, com exceção de 2010; raça branca $(45,94 \%)$ e faixa etária de 80 anos ou mais $(18,88 \%)$. Nos óbitos por arritmia houve predomínio do sexo masculino (52,75\%); raça branca $(42,48 \%)$ e faixa etária de 80 anos ou mais (24,54\%). DISCUSSÃO E CONCLUSÃO: Entre as doenças cardiovasculares, a insuficiência cardíaca é a que mais ocasionou internações e óbitos no SUS no período estudado, sendo responsável por 60,59\% das internações e $60,68 \%$ dos óbitos. É possível inferir que a raça branca e o sexo masculino são as características mais frequentes nas internações e óbitos no SUS por doenças cardiovasculares. A faixa etária de 80 anos ou mais é a mais incidente nas doenças analisadas. Dessa forma, conclui-se que a prevenção pode contribuir para a redução dessa comodidade no Brasil.

Palavras-chave: doenças cardiovasculares; hospitalização; perfil de saúde; fatores de risco.

\section{EPI - 19 PREVALÊNCIA DE HIPERTENSÃO, DIABETES E OUTRAS COMORBIDADES EM PACIENTES HEMODIALÍTICOS NO HOSPITAL ANCHIETA}

Camila Mika Serikawa, Caroline Awoki Ferrandez, Daniela Gakiya, Julia Thiemi Hino, Amanda Carvalho Matsubara, Daniel Rinaldi dos Santos

\section{E-mail: cmikaserikawa@gmail.com}

INTRODUÇÃO: A hemodiálise consiste no principal tratamento final da Doença Renal Crônica (DRC), antes do transplante. Esta doença é um problema de saúde pública crescente cujo diagnóstico é muitas vezes tardio e decorrente de etiologias como hipertensão, diabetes e doenças renais não tratadas. Além disso, a hemodiálise apresenta, ao longo dos últimos anos, uma demanda crescente o que tem implicado em considerável consumo de recursos financeiros. OBJETIVO: Avaliar a prevalência e incidência de hipertensão, diabetes e outras comorbidades como doenças associadas e/ou determinantes de falência renal em pacientes hemodialíticos no Hospital Anchieta para corroborar a importância do tratamento contínuo dessas doenças a fim de evitar a diálise. MÉTODO: Estudo transversal, retrospectivo e observacional com análise quali-quantitativa de dados de 252 prontuários de pacientes hemodialíticos no Hospital Anchieta de São Bernardo do Campo no período de 28 de março até o dia 03 de maio de 2018. As informações coletadas incluem sexo, idade, hipertensão, diabetes, hepatites $\mathrm{B}$ e C e/ou HIV, tabagismo, etilismo, uso de drogas ilícitas, obesidade e etiologia da doença renal crônica. RESULTADO: A análise dos dados demonstrou que há predomínio do sexo masculino (59,5\%) entre os hemodialíticos com uma média de idade global de 54,7 anos. Em relação aos outros dados $10,3 \%$ são obesos; $91,3 \%$ são hipertensos; $38,1 \%$ são diabéticos; $12,3 \%$ são tabagistas; $9,5 \%$ são etilistas; $2,3 \%$ são usuários de drogas; $9,1 \%$ são portadores da hepatite $\mathrm{B}$ e/ou C e 1,5\% são portadores do HIV. Em relação à etiologia da hemodiálise 5,9\% são Glomerulonefrite Crônica (GNC); 14,2\% são Nefropatia Diabética; 14,2\% são Nefroesclerose Hipertensiva; 27,7\% são DRC Indeterminada; 25,7\% são outras causas; $5,5 \%$ são DRC por HAS e DM; 4,3\% são Rins Policísticos; $1,1 \%$ são inconclusivos. DISCUSSÃO: O presente estudo evidenciou que a etiologia de causa indeterminada da doença renal crônica, seguida pela nefroesclerose hipertensiva e nefropatia diabética se destacaram como as mais prevalentes dentre os pesquisados. CONCLUSÃO: O conhecimento da prevalência da DRC entre os brasileiros iria subsidiar melhor o planejamento de ações preventivas e assistenciais.

Palavras-chave: Diálise Renal; Insuficiência Renal Crônica.

\section{PREVALÊNCIA DOS FATORES DE RISCO CARDIOVASCULARES NA POPULAÇÃO ATENDIDA NA 20" CAMPANHA DO DIA MUNDIAL DO DIABETES MELLITUS}

Leticia Pedroso Regis, Giovanna Tiemi Takara, Lucas Olea Madeira, Marina Sabin de Sousa Lima, Thais Salomão Marques Torrado, Juliana Daltrino Teodoro, Fernando Valente

\section{E-mail: letpedrosoregis@gmail.com}

INTRODUÇÃO: A Associação Nacional de Atenção ao Diabetes (ANAD) promove, durante a semana do Dia Mundial do Diabetes, uma campanha, sendo em 2017 a $20^{\mathrm{a}}$ edição. Nela, portadores ou não de Diabetes Mellitus (DM), passam por triagem analisando parâmetros laboratoriais dos valores séricos de triglicerídeos (TAG), colesterol total/frações, hemoglobina glicada (HbA1) e capilar, além da mensuração do perfil antropométrico, pela estatura, peso, Índice de Massa Corporal e circunferência abdominal (CA), que são fatores de risco (FR) para doenças cardiovasculares (DCV), estando intimamente relacionados ao desenvolvimento delas. OBJETIVO: Realizar um estudo sobre a prevalência dos FR para DVC na população triada pela 20 Campanha da ANAD. MÉTODO: O estudo é observacional e transversal. Foram usados: resistência à insulina (glicemia: $>100 \mathrm{mg} /$ $\mathrm{dl} \mathrm{e/ou} \mathrm{HbAlc} \mathrm{>} \mathrm{5,7 \% );} \mathrm{dislipidemia} \mathrm{(HDL}<40 \mathrm{mg} / \mathrm{dl}$, homens e $<46 \mathrm{mg} / \mathrm{dl}$, mulheres e/ou LDL $>100 \mathrm{mg} / \mathrm{dl}$ e/ou TAG $>150 \mathrm{mg} / \mathrm{dl}$ ); obesidade (IMC $>30 \mathrm{~kg} / \mathrm{m}^{2}$ e/ou CA $>102 \mathrm{~cm}$, homens e $>88 \mathrm{~cm}$, mulheres); sexo (masculino); idade (homens $>55$ anos e mulheres $>65$ anos). RESULTADO: Analisados 316 pacientes (158 homens e 158 mulheres), cada parâmetro foi avaliado individualmente observando que, excluindo os pacientes sem dados para análise, 67 apresentaram alterações de HDL, 110 de LDL, 118 de TAG, 200 de CA, 254 de glicemia capilar, 190 de HbAlc e 208 tem idade elevada. Dentre eles, 2 pacientes tinham 1 FR, 22 com 2 FR, 77 com 3 FR, 72 com 4 FR e 37 com 5 FR. DISCUSSÃO: Dos pacientes incluídos, 93,59\% apresentaram valores de $\mathrm{HbAlc}$ elevados, juntamente com 93,04\% da glicemia capilar. Os principais FR para o desenvolvimento de DM Tipo 2 e DCV podem ocorrer isoladamente ou, associados, fato presente nos dados levantados, apresentando $96,33 \%$ dos homens e $79,41 \%$ das mulheres, três ou mais FR. Nos pacientes diabéticos de base, a dislipidemia é considerada o principal FR, principalmente o LDL e $55,55 \%$ dos pacientes apresentavam LDL alterados. Entre os sexos, isso ocorreu em $49,52 \%$ dos homens e $62,36 \%$ nas mulheres. A constituição corporal se relaciona com a etiologia do DM, apresentando $49,36 \%$ dos homens e $77,21 \%$ das mulheres com CA elevadas. A idade, um FR não-modificável teve, no estudo, incidência de 65,82\%. CONCLUSÃO: Os pacientes triados apresentaram alta prevalência nos FR para DVC, sendo, em sua maioria, associados.

Palavras-chave: Diabetes mellitus; Risco Cardiovascular. 


\section{EP| - 21 PRINCIPAIS QUEIXAS DE DISTÚRBIOS DO SONO DURANTE A CAMPANHA DO DIA MUNDIAL DO SONO}

Amanda Ribeiro Battle, Ana Paula Possar do Carmo, Gabriella Clementino da Silva, Marina Longo Machado de Almeida, Fernando Ramos Pellegrini, Franco Chies Martins

\section{E-mail: amanda.rbatlle@gmail.com}

INTRODUÇÃO: O sono influencia em comorbidades de todos os sistemas do corpo humano. Saber mais sobre seus distúrbios em pacientes ambulatoriais pode levar a otimização de recursos de saúde e práticas médicas integradas dirigidas. OBJETIVO: O objetivo do trabalho é apontar a principal queixa em relação ao sono, estabelecendo relação com comorbidades, uso de medicamentos, dados demográficos, em pacientes atendidos em serviço terciário, no Ambulatório de Especialidades da Fundação do ABC. MÉTODO: Foi aplicado questionário próprio a 50 pacientes aleatórios, o qual indagava quanto à identificação do paciente, presença de comorbidades, medicamentos e principal queixa ou dúvida a respeito do sono. As queixas foram agrupadas nas categorias: insônia, ronco/apneia do sono, transtorno do movimento, ritmo circadiano e sonolência excessiva diurna. As comorbidades foram divididas em Sistema Cardiovascular, Endócrino, Respiratório, Digestório, Nervoso e Gênito-Urinário. RESULTADO: Dentre os 50 pacientes, 33 eram mulheres (66\%). 34,8\% das dúvidas relatadas foram sobre insônia, $24,2 \%$ sobre sonolência diurna excessiva, $16,7 \%$ sobre ronco/apneia do sono, $13,6 \%$ sobre transtorno do movimento e $10,6 \%$ sobre ritmo circadiano. 70\% daqueles que responderam ao questionário são procedentes da Região do Grande ABC, $8 \%$ tem procedência em São Paulo e $22 \%$ em outras regiões. A mais prevalente foi do Sistema Cardiovascular. Dentre as mulheres, insônia foi mais comum, e dentre os homens, ronco/apneia do sono. DISCUSSÃO: Os dados estão de acordo com a literatura, na qual a prevalência de sintomas de insônia acomete mais mulheres, enquanto distúrbios relacionados a ronco/apneia do sono são mais relatados por homens, o que denota a importância da abordagem do sono em consultas. Foram mais prevalentes comorbidades do Sistema Cardiovascular, expressando a epidemiologia da unidade de atendimento e salienta a necessidade de exploração diagnóstica principalmente em homens com queixa de ronco e apneia, considerando-se sua associação com lesão endotelial e risco cardiovascular conhecido. CONCLUSÃO A abordagem de queixas relacionadas ao sono e comorbidades em pacientes aleatórios presentes em ambulatório terciário reflete os dados de literatura mundial. Essa informação pode guiar instauração de medidas específicas para essa população visando dirimir os impactos negativos dos distúrbios do sono.

Palavras-chave: Sono; comorbidades; sexo; idade.

\section{EP| - 22 RELAÇ̃̃ DO ÍNDICE DE DESENVOLVIMENTO HUMANO E MORTALIDADE POR CÂNCER NO BRASIL: ESTUDO DESCRITIVO ENTRE OS ANOS DE 2000 E 2013}

Jean Henri Maselli Schoueri, Igor Luiz Argani, Lisa Makki Umeda, Elaine Shizue Novalo-Goto, Luisa Romano Andraus, Raffaela da Costa Oliveira, Isabela Corralo Ramos, William Ferreira Lima Junior, Daniel de Iracema Gomes Cubeiro, Auro Del Giglio

\section{E-mail: jean.schoueri@gmail.com}

INTRODUCC̃̃O: Estudos internacionais recentes apontar para possível associação entre Índice de Desenvolvimento Humano (IDH) e mortalidade por câncer, porém há poucos estudos nacionais sobre o tema. OBJETIVO: Relacionar a mortalidade dos tipos mais frequentes de câncer com o IDH das regiões administrativas do Brasil. MÉTODO: Estudo descritivo de base populacional com dados provenientes do DATASUS entre os anos de 2000 e 2013. Foram obtidos dados referentes às características sociodemográficas e à mortalidade para o câncer de pele não-melanoma, próstata, mama, cólon e reto, traqueia, brônquio e pulmão, estômago e colo de útero para cada região do Brasil. Aplicou-se regressão linear para produzir tendências temporais de mortalidade, estimando-se a inclinação $(\beta)$, probabilidade respectiva $(\mathrm{p})$ e capacidade preditiva do modelo $\left(\mathrm{r}^{2}\right)$. Correlação de Pearson foi utilizada para avaliar a relação existente entre IDH e mortalidade por câncer. RESULTADO: Entre 2000 2013 foram registrados 991.552 óbitos por câncer, dos quais a maioria foi atribuída à população identificada como branca e a minoria ocorreu nas regiões Norte e CentroOeste. Com relação às curvas de tendência de mortalidade, observou-se diferentes padrões relacionados aos diversos tipos de câncer estudados $(\mathrm{p}<0,05)$. Houve forte correlação entre IDH e mortalidade para os cânceres de próstata, cólon e reto, traqueia, brônquio e pulmões e colo de útero $(\mathrm{p}<0,05)$. DISCUSSÃO: Baixo acesso ao sistema de saúde e menor expectativa de vida deve ser responsável pela reduzida notificação de óbito por câncer nas regiões Norte e Centro-Oeste. De modo análogo, melhores níveis socioeconômicos relacionam-se à maior acesso ao sistema de saúde e, consequentemente, maior notificação de óbito de brancos em relação a outras etnias em todo o país. As correlações positivas encontradas entre IDH e mortalidade por câncer devem-se ao aumento da expectativa de vida, favorecendo a ocorrência e morte por câncer devido ao envelhecimento populacional; as correlações negativas presentes em regiões mais ricas devem-se à melhora dos hábitos de vida e ao acesso a tratamentos mais adequados. CONCLUSÃO: Disparidades entre IDH e mortalidade por câncer podem relacionar-se a diferenças de acesso a serviços de saúde ou à diminuição da mortalidade por outras causas.

Palavras-chave: Saúde pública; Câncer; Índice de desenvolvimento humano; Acesso aos serviços de saúde.

\section{CATEGORIA - RELATO DE CASO CIRURGICO}

\section{RCl - 01 ALONGAMENTO/RECONSTRUÇÃO DA MEMBRANA INTERÓSSEA ULNAR NO TRATAMENTO DE OSTEOCONDROMA: RELATO DE CASO}

Rafaela Elias Bosco, Rafael Segundo Ferreira das Neves, Beatriz Galvez Magnoni, Karola Beserra de Araujo, Matheus Real Rodrigues, Ana Carolina Bertelli, Fernando Augusto Reginatto Roberto, Márcio Aita

\section{E-mail: rafaboscoelias@gmail.com}

INTRODUÇÃO: A exostose cartilaginosa múltipla (ECM) é uma desordem do crescimento ósseo endocondral de herança autossômica dominante, caracterizada pelo desenvolvimento de várias proeminências ósseas revestidas por cartilagem anormal. Frequentemente evolui com deformidade severa dos ossos do antebraço com perda de rotação do antebraço, mau funcionamento do pulso e do cotovelo acompanhada, às vezes, de dor em juvenil. O presente trabalho relata tratamento cirúrgico bem sucedido de jovem com ECM resultando em boa recuperação de arco de movimento. RELATO DE CASO: Menino de 11 anos visitou nosso instituto com deformidade congênita, em seu antebraço dominante e direito. Apresentava limitação de flexão do punho, pronação e supinação do antebraço com ulna deslocada com escore DASH de 42 e VAS de 5. Como tratamento cirúrgico foi realizado alongamento ulnar associado à ressecção de exostose e estabilização da articulação radioulnar distal (DRUI) com reconstrução da membrana interóssea distal, utilizando o tendão do músculo braquiorradial (BR). O fixador externo monolateral foi posicionado da ulna proximal à ulna distal, e através de diferentes ângulos de colocação dos pinos foi possível a correção da deformidade angular e rotacional da ulna. Após alongamento da ulna, foram realizadas ressecção da exostose e reconstrução da banda oblíqua distal (DOB) da membrana interóssea. $\mathrm{O}$ antebraço foi fixado em posição neutra com fio de Kirschner transversal no rádio e ulna por seis semanas. Após adequado alongamento da ulna com formação óssea satisfatória, o fixador externo foi removido. O movimento dos dígitos era normal. Escore DASH de 5 , VAS de 0 e força de preensão de $92 \%$ em comparação com o lado não afetado foram obtidos. As radiografias indicaram alongamento da ulna com boa congruência na articulação DRUJ e rádio-capitelo e bons parâmetros radiográficos. DISCUSSÃO: Os osteocondromas são predominantemente localizados nas regiões metafisárias dos ossos longos, contribuindo para deformidades do osso longo em jovens. As diferentes deformidades do antebraço são classificadas de acordo com a escala de Masada sendo o tratamento dessas deformidades de alta complexidade e dependentes da classificação das fraturas. No caso, o uso da técnica cirúrgica descrita propiciou bons resultados clínicos sem complicações, contudo paciente requer acompanhamento em razão da idade. Palavras-chave: osteocondroma; tratamento cirúrgico.

\section{$\mathrm{RCl}$ - 02 ANASTOMOSE DUODENAL DIAMOND-SHAPE COMO TRATAMENTO DE MEMBRANA DUODENAL COM MANIFESTAÇÃO ATÍPICA}

Ana Paula Possar do Carmo, Marcella Zanini Savordelli, Katie Caterine Scarponi Senger, Mario Guilherme A. Brasileiro, Bárbara Miyake Queiroz, Luis Ricardo Longo dos Santos

E-mail: anapaulapossar@hotmail.com

INTRODUÇÃO: Malformações congênitas são causas de obstrução ou sub oclusão duodenal, decorrentes da incompleta recanalização da luz intestinal. O diagnóstico pode ser sugerido por USG pré-natal, mas é confirmado apenas após o nascimento em função dos sintomas de distensão abdominal e vômitos biliosos e dos achados radiológicos com sinal da dupla bolha. A atresia duodenal é classificada em tipo I (membrana obstrutiva), II (cordão fibroso) e III (separação completa dos cotos). Em alguns casos a membrana duodenal pode ter uma abertura, sendo então a manifestação clínica de suboclusão duodenal, com diagnósticos diferenciais de pâncreas anular e vício de rotação intestinal, não de atresia duodenal. Relatamos a evolução de paciente com membrana duodenal com manifestação atípica. RELATO DE CASO: RN masculino transferido para HEMC no 2.o dia de vida, por suspeita de obstrução duodenal. Nascido de parto normal com bolsa rota há 6 horas, IG 35 semanas, peso de 1800 g, Apgar 9-9, tinha USG pré-natal sugerindo obstrução duodenal. Admitido na UTI neonatal em jejum, SOG aberta com débito bilioso e antibioticoterapia. Exame físico na admissão apresentava distensão abdominal em epigástrio. Radiografia simples de abdome com sinal da dupla bolha sem aeração distal, compatível com atresia duodenal. Realizada laparotomia no $3^{\circ}$ dia de vida, com achado intra-operatório de grande dilatação de estômago e $1^{\mathrm{a}} \mathrm{e} 2^{\mathrm{a}}$ porções do duodeno, com alças distais de calibre diminuído, porém preenchidas por mecônio, sugerindo membrana duodenal com pertuito. Duodenotomia transversa na 2.a porção permitiu identificação da membrana obstrutiva, mas não foi visualizado nenhum pertuito comunicando com duodeno distal. Realizada duodenotomia longitudinal na porção distal e duodeno-duodeno anastomose diamond-shape. No PO2 ( $2^{\circ}$ pós-operatório) paciente evoluiu com sepse de origem pulmonar, respondendo bem após modificação da antibioticoterapia. Iniciou dieta oral no PO13, nutrição parenteral suspensa no PO16 e alta hospitalar no PO23. DISCUSSÃO: A sobrevida de bebês com malformações duodenais depende do diagnóstico precoce, realizado com base nas manifestações clínicas e radiografia simples de abdome, e do tratamento cirúrgico adequado. O planejamento pré-operatório é importante, mas a técnica cirúrgica depende dos achados intra-operatórios. Palavras-chave: Atresia duodenal; Cirurgia pediátrica neonatal; Membrana duodenal; Obstrução intestinal neonatal. 


\section{$\mathrm{RCl}$ - 03 CATARATA SUBCAPSULAR BILATERAL E DERMATOSE IGA LINEAR INFANTIL COM USO PROLONGADO DE CORTICOSTERÓIDE SISTÊMICO}

Philipe Franco do Amaral Tafner, Bianca Nicolela Susanna, Carolina Nicolela Susanna, Rodrigo Scabora, Michelle Fu Min Tong, Rodrigo Goldenstein Schainberg, Victor Harasawa Uno, Maria Leticia Lasca Sales Campos

\section{E-mail: p_tafner@hotmail.com}

INTRODUÇÃO: O uso prolongado de altas doses de corticosteroides é comum no tratamento dermatites e seus efeitos colaterais são descritos na literatura. Dentre as repercussões oftalmológicas mais comuns destaca-se a catarata subcapsular bilateral e o glaucoma. Entre as afecções cutâneas na infância, a dermatite atópica possui relação importante com a oftalmologia. Esta doença dermatológica pode ser diretamente causa de catarata subcapsular e esta particularidade não é descrita em outras dermatites, que se relacionam indiretamente a catarata pelo efeito colateral do uso crônico de corticoide. Em 1979 o padrão histológico de cristalinos com catarata foi descrito por Greiner e Chylac, através da análise de microscopia convencional e microscopia eletrônica, comparando a catarata induzida por corticoide com a catarata senil. Questiona-se a falta de estudos para compreender melhor a relação entre dermatites e manifestações oculares. RELATO DE CASO: VGF, 8 anos com perda progressiva da acuidade visual no período de 1 ano. Diagnóstico de Dermatose IgA Linear aos 2 anos. Uso de betametasona $10 \mathrm{ml} / \mathrm{dia}(4 \mathrm{mg} / \mathrm{dia}$-prednisona $30 \mathrm{mg})$ sem acompanhamento médico por 05 anos. Exame Físico: Biomicroscopia anterior: Catarata posterior subcapsular $3 / 4+$, sem outras alterações. Fundo de olho: feito com dificuldade por opacidade de meios, porém mostrando papila fisiológica e retina saudável. DISCUSSÃO: Após cirurgia do primeiro olho, realizou-se análise microscópica convencional e eletrônica do cristalino com catarata. A comparação do padrão histológico convencional com estudos anteriores sugere que a causa desta catarata está relacionada à afecção dermatológica do paciente, contudo, a análise pela microscopia eletrônica evidenciou lesões de uso crônico de corticoide, além de áreas com padrões incaracterísticos, que podem estar relacionadas a causa dermatológica. Evidencia-se a importância do acompanhamento oftalmológico. Ainda não há clareza da verdadeira causa da catarata nas patologias dermatológicas, mas sem dúvida o medicamento é um fator de confusão. Entretanto, independente causa, o acompanhamento oftalmológico tanto em dermatites como em pacientes com uso prolongado e de altas doses de corticoide pode prevenir a cegueira e a catarata. A análise microscópica sugere como causa da catarata a afecção dermatológica somada ao uso prolongado do corticoide.

Palavras-chave: Catarata Subcapsular; Dermatite Corticoide.

\section{RCl - 04 CORREÇÃO ENDOVASCULAR DE ANEURISMA DE AORTA TORÁCICA COM ENDOPRÓTESE EM CHAMINÉ COM RECONSTRUÇÃO DO ARCO AÓRTICO E REVASCULARIZAÇÃO DA ARTÉRIA SUBCLÁVIA ESQUERDA}

Camila Mika Serikawa, Julia Piana do Amaral, Sidnei José Galego

\section{E-mail: cmikaserikawa@gmail.com}

INTRODUCÃO: O aneurisma de aorta torácica tem incidência de 6-10 casos/10000 habitantes e menos de $10 \%$ acometem o arco aórtico. No caso apresentado, o paciente foi vítima de trauma torácico contuso, com lesão de aorta torácica, que evoluiu com aneurisma de arco aórtico diagnosticado 10 anos após o trauma e apresentou-se sintomático somente no último ano. Esse tipo de lesão está relacionado a um alto índice de mortalidade no ambiente pré-hospitalar, com uma taxa de sobrevivência de $25 \%$ até a chegada ao hospital e destes, apenas $50 \%$ sobrevivem às primeiras 24h. RELATO DO CASO: Homem de 40 anos, deu entrada à emergência do Hospital Estadual Mário Covas com quadro de dor torácica e de região cervical de forte intensidade, com irradiação para o dorso há 8 meses com piora progressiva há 1 mês. Paciente hipertenso há 7 anos e tabagista, apresenta história de trauma torácico contuso há mais de 10 anos, pneumotórax e traumatismo crânio-encefálico leve por acidente automobilístico (colisão moto x muro). Ao exame físico, apresentava massa pulsátil em região supraclavicular esquerda. Evidenciou-se uma dilatação aneurismática, na angiotomografia, em topografia de arco aórtico e rotura da artéria subclávia esquerda (ASE). Devido a esse quadro complexo, optou-se pelo tratamento endovascular com aplicação de endoprótese em chaminé, associada à reconstrução do arco aórtico através de confecção de enxertos extra-anatômicos e revascularização da ASE. Esses procedimentos foram realizados com sucesso e sem apresentar complicações significativas. DISCUSSÃO: O tratamento das doenças do arco aórtico, com reconstrução de seus ramos, continua sendo um dos procedimentos mais complexos do sistema vascular. Muito se evoluiu no tratamento das doenças que acometem o arco aórtico nas últimas duas décadas. As novas técnicas possibilitam o tratamento dos pacientes com múltiplas comorbidades e clinicamente instáveis. Este caso mostra-se, assim, relevante pelo trauma e a lesão de aorta torácica por ele ocasionada, em que seu diagnóstico foi tardio; pela evolução do doente e sua sobrevida, e pela tática empregada para correção da lesão complexa do arco aórtico.

Palavras-chave: Aneurisma Aórtico; Procedimentos Endovasculares.
RCl - 05 DUPLA RECONSTRUÇÃO ARTERIAL DA ARCADA PANCREATODUODENAL NO TRANSPLANTE DE PÂNCREAS

Tiago Genzini de Miranda, Emanuela Yumi Fugisawa de Mello, Fernanda Folla Pompeu Marques, Natallia Meira Gonsalez, Isabella Pereira Blanco

\section{E-mail: tiago_genzini@hotmail.com}

INTRODUÇÃO: O transplante de pâncreas (TP) impõe diversos desafios técnicos desde a retirada do órgão até na cirurgia de mesa e implante no receptor. Relata-se caso de TP, cujo enxerto pancreático apresentava artéria hepática direita (AHD) anômala originando-se da artéria mesentérica superior (AMS) e que pode ser aproveitado graças a reconstrução arterial atípica e complexa na cirurgia de mesa. RELATO DE CASO: Paciente de 43 anos, diabética tipo 1 há 34 e doença renal crônica, submetida a transplante renal de doador vivo no ano de 2016 e pâncreas após rim (TPAR) em abril de 2017. Evoluiu com boa função inicial, porém após episódio de rejeição aguda tratada, apresentou perda do enxerto pancreático por trombose venosa, sendo reinscrita na fila de TP. Submetida a Re-TPAR em março de 2018 após oferta de doador de 19 anos, vítima de ferimento por arma de fogo, com órgão de excelente aspecto macroscópico. Durante a retirada do pâncreas, notou-se AHD originária da AMS. Na cirurgia de mesa do pâncreas, verificou-se teste de irrigação deficitário para a porção cefálica e duodeno, o que poderia inviabilizar o órgão de ser aproveitado. Além disso, a artéria pancreatoduodenal inferior (PDI) originava-se da AHD e fora seccionada para que a equipe do fígado retirasse esta artéria junto com o enxerto hepático. Para viabilizar o uso do pâncreas, utilizou-se o tradicional enxerto arterial em Y de ilíaca para reconstrução, mas com três anastomoses no segmento da ilíaca externa: uma com a AMS, outra com a gastroduodenal e a terceira com a PDI seccionada do enxerto pancreático. Desta forma, as duas arcadas da pancreatoduodenal foram revascularizadas, a superior via anastomose com a gastroduodenal e a inferior, através de anastomose com a PDI seccionada. $\mathrm{Na}$ cirurgia do receptor, o pâncreas foi implantado com drenagem venosa na cava e exócrina na bexiga do receptor. A reperfusão revelou ótimo aspecto do órgão, particularmente na área de maior preocupação da região duodeno-cefálica. A paciente evoluiu normoglicêmica e boa função do enxerto, recebendo alta no nono dia pós-transplante. DISCUSSÃO: A dupla reconstrução arterial da arcada pancreatoduodenal mostrou-se manobra técnica factível, apesar de mais complexa, e que pode permitir o aproveitamento de enxertos pancreáticos onde a irrigação da porção duodeno-cefálica possa estar comprometida.

Palavras-chave: Transplante de pâncreas; Irrigação do pâncreas Revascularização do pâncreas; Artéria gastroduodenal.

\section{RCl - 06 HAMARTOMA FIBROSO DA INFÂNCIA: DIAGNÓSTICO RARO DE TUMOR AXILAR NA CRIANÇA}

Nattaly Kolle Pereira, Giovanna Altafini Nasser Ribeiro Nogueira, Hanny Caroline Villavicencio da Cunha, Carolina Doering Neves, Luis Ricardo dos Santos

\section{E-mail: nattalykolle@outlook.com}

INTRODUÇÃO: Hamartoma Fibroso da Infância (HFI) é uma rara neoplasia benigna de partes moles. A maioria dos casos são de meninos com até 2 anos de idade, com lesão sólida subcutânea, isolada e indolor, menor que $5 \mathrm{~cm}$, localizada em braços, axilas, parede torácica e região inguinal. O ritmo de crescimento da lesão é variável, podendo ser inicialmente rápido. Ultrassonografia ou tomografia, definindo nódulo sólido, permite descartar tumores subcutâneos mais comuns (adenomegalias, cistos dérmicos, lipomas), mas o diagnóstico definitivo é anatomopatológico: tumor trifásico contendo fascículos de tecido fibrocolagenoso denso, tecido adiposo maduro e áreas de tecido mesenquimal primitivo ou de células basílicas imaturas, ou ainda de tecido mixóide com células arredondadas. O tratamento é exclusivamente cirúrgico. Foram descritos na literatura mundial menos de 200 casos, o que ressalta a importância deste relato. RELATO DE CASO: EBR, masculino, 16 meses de idade, há 5 meses com nódulo subcutâneo axilar E, de consistência firme, aderido à pele mas não a planos profundos, móvel e sem sinais flogísticos, com crescimento rápido no primeiro mês. Ultrassonografia descreveu nódulo sólido heterogêneo, predominantemente hipoecogênico com $1,9 \mathrm{~cm}$. Indicado tratamento cirúrgico, com ressecção completa do tumor e do retalho cutâneo aderido a ele, sem intercorrências. Peça cirúrgica enviada para anatomopatológico, culturas e pesquisas de fungos e BAAR. Resultado de culturas negativo. Laudo anatomopatológico como Neoplasia Mesenquimal Fusocelular Benigna, com áreas nodulares de células fusiformes envoltas por componente de células de núcleos ovoides hipercromáticos dispostas em estroma mixoide, presença de traves fibrosas e tecido adiposo maduro. Marcadores imuno-histoquímicos (CD34+ focal, EMA, Desmina, S100, AML) e achados morfológicos definiram diagnóstico de Hamartoma Fibroso da Infância. Paciente em seguimento pós-operatório há 2 meses, sem complicações e sem recidiva. DISCUSSÃO: HFI é um diagnóstico raro com excelente prognóstico e deve ser corretamente diferenciado de patologias malignas (Fibromatose Juvenil e Sarcomas) que necessitam tratamentos mais agressivos. Relatos de anormalidades citogenéticas no HFI e os pouquíssimos casos descritos na literatura mundial justificam a importância de novos estudos e seguimento tardio de pacientes com HFI. Palavras-chave: Hamartoma fibroso da infância; neoplasias de tecidos moles neoplasia mesenquimal fusocelular. 


\section{RCl - 07 HEPATECTOMIA ESQUERDA COM DERIVAČ̃̃O BILEODIGESTIVA EM Y DE ROUX POR COLEDOCOLITÍASE E LITÍASE BILIAR EM VIA INTRA-HEPÁTICA: RELATO DE CASO}

Paola Mortean dos Santos, Mateus Lima Silva, Gabriela Anzai Pavoni, Fauze Camargo Maluf, Alexia Dias Fontes Rosa, Fabio lazzetti Lopes, David Eduardo Zuluaga Liberato, Sandra Di Felice Boratto

\section{E-mail: paola.morteansantos@gmail.com}

INTRODUÇÃO: A síndrome ictérica é definida como um conjunto de sinais e sintomas relacionado à coloração amarelada clinicamente aparentes em níveis de $2 \mathrm{mg} /$ dL de bilirrubina sérica. Diversas são suas etiologias, sendo a alteração da excreção biliar por obstrução extra-hepática em decorrência de coledocolitíase e a litíase intra-hepática algumas delas. O USG é o exame inicial de escolha, sendo comum o achado de dilatação da via biliar, indicando processo obstrutivo, além da visualização de cálculos. O diagnóstico diferencial dessas síndromes é fundamental para adequação da conduta. O objetivo do relato é descrever a abordagem terapêutica de um caso raro de litíase intra-hepática e revisar a literatura. RELATO DE CASO: MRSA 45 anos, feminino, obesa, multípara, diabética, é internada no Centro Hospitalar de Santo André em Abril com queixa, há um mês, de dor abdominal em cólica em hipocôndrio direito acompanhada de náuseas e vômitos, com piora à ingestão de gordura presença de icterícia $++/ 4$. Ao exame físico, abdome globoso e doloroso à palpação, sem sinais de peritonite. Estabelecida síndrome ictérica, vias biliares com dilatação intra e extra-hepática na TC; no USG, vesícula biliar hiper estendida sem presença de cálculos; na colangiorressonância, cálculos vesicais e nas vias biliares intra e extra hepáticas. Realizada hepatectomia esquerda com derivação bileodigestiva em y de Roux por coledocolitíase e litíase biliar em via intra-hepática. DISCUSSÃO: Dentre os fatores de risco para a doença, a paciente se enquadra na faixa etária de maior incidência (42,5\%), é do sexo feminino, multípara (incidência de 39,9\%), além de ser obesa e diabética. A paciente foi submetida inicialmente à colecistectomia e devido a presença de cálculos intra-hepáticos, levando a vazamento biliar e obstrução por estenose, houve indicação de hepatectomia esquerda, retirada dos segmentos II e III, com derivação bileodigestiva em y de Roux. Sabe-se que a litíase intra-hepática é uma condição que, devido à sua raridade, pode ter diagnóstico tardio e com complicações, como o colangiocarcinoma. Sendo assim, a percepção dos diagnósticos diferenciais, como a doença de Caroli, em que se têm dilatações saculares dos ductos intra-hepáticos, e o colangiocarcinoma são fundamentais. Por estar associada a resultados satisfatórios, a ressecção hepática é o tratamento de escolha para litíase intra-hepática.

Palavras-chave: litíase; hepatectomia; coledocolitíase.

\section{$\mathrm{RCl}-08$ OCLUSÃO VASCULAR RETINIANA PÓS FACECTOMIA: UM CASO RARO}

Glauco Sergio Avelino de Aquino, Clarissa Maria Gomes de Almeida, Anna Carolina Miscolty e Silva, Flávia Nóbrega, Marcella Canato Toloi, Roberta Ferraz Salles Kesselring, Brian Vicente, João Vitor Yudi Miazaki Villanova, Rodrigo Toledo Mota

\section{E-mail: glauco.aquino@uol.com.br}

INTRODUÇÃO: A catarata é a principal causa de cegueira reversível. Seu tratamento se dá pela facectomia, procedimento considerado seguro. Ainda assim, como toda intervenção cirúrgica, não está isenta de complicações. Entre as principais estão rotura de cápsula posterior, perda vítrea e endoftalmites. Outras condições são mais raras com poucos casos descritos na literatura, como a ocorrência de oclusão vascular retiniana (OVR). Relatamos o caso de uma paciente com OVR pós facectomia. RELATO DE CASO: Paciente de 71 anos, feminino, hipertensa, com queixa de baixa acuidade visual (BAV) há 3 anos, principalmente em olho direito (OD). Ao exame físico, havia diminuição da acuidade visual (AV) e catarata em ambos os olhos. Foi submetida à Facectomia em OD, sem intercorrências. No $7^{\circ}$ dia de pós-operatório (PO), apresentava melhora da AV em OD, com pressão intraocular elevada, sendo prescrito tratamento tópico. No $21^{\circ} \mathrm{PO}$, paciente procura pronto socorro com queixa de perda de campo visual inferior súbito e indolor há 1 dia, sendo avaliada e, por não apresentar alterações ao exame, foi re-encaminhada ao ambulatório. No retorno mantinha queixa de escotoma inferior e BAV em OD, com AV de 20/250, sem alterações do segmento anterior. Ao exame fundoscópico apresentava alteração da coloração, manchas algodonosas próximas às arcadas temporais inferiores e êmbolo na emergência dos vasos no disco óptico. Foi indicado estudo com exame contrastado que evidenciou diminuição do enchimento venoso da arcada temporal inferior com quadro compatível com oclusão de ramo venoso. Não apresentava edema macular Optou-se por conduta expectante com acompanhamento com a cardiologia. No $42^{\circ}$ PO, paciente apresenta melhora da visão, com AV (com correção) de 20/25, com melhora parcial dos escotomas. O novo exame de angiofluoresceinografia demonstrava reperfusão da área afetada sem sinais de isquemia. DISCUSSÃO: A OVR é uma complicação rara, geralmente transitória, de etiopatogenia incerta e que causa hipoperfusão retiniana. Está relacionada à presença de fatores de risco como hipertensão arterial e pode ter como origem a embolia em artéria central da retina por fragmento de placa aterosclerótica de carótida. Há estudos que demonstram associação entre presença de OVR e risco aumentado de morte súbita. O relato de complicações raras é importante para o conhecimento científico e melhor manejo dessas.

Palavras-chave: Oclusão da Veia Retiniana; Catarata.

\section{RCI - 09 PRIMEIRA DISCECTOMIA ENDOSCÓPICA REALIZADA NO HOSPITAL ESTADUAL MÁRIO COVAS}

Paola Augusto Gomes, Julia Hoici Brunini, Lucas Abdo Pereira, Natália Marques dos Santos, Reinolds Amiraldo Corrêa Junior, Desiree Elizabeth Pasqualetto Antikievicz, Gustavo Ferrareto Pires, Alberto Domingos Rancan Filho, Leonardo Yukio Jorge Asano, Luciano Miller Reis Rodrigues

\section{E-mail: paola-rosa@ hotmail.com}

INTRODUÇÃO: Hérnia de disco é um deslocamento do conteúdo central do disco. É a causa mais comum de radiculopatia. Para quadros severos em que o tratamento conservador é ineficaz, indica-se cirurgia. Nesses casos, uma opção é a discectomia endoscópica, técnica minimamente invasiva de retirada da hérnia que pode ser realizada com anestesias local, geral ou sedação e tem entre suas vantagens menores lesão tecidual, tempo cirúrgico e índice de infecção. RELATO DE CASO: Mulher, 20 anos, com dor e parestesia em região lombar irradiadas para toda face lateral do membro inferior esquerdo. No exame físico, tinha teste de elevação da perna estendida positivo, com reflexos preservados, sem déficit motor ou de sensibilidade. Pela ressonância lombar, evidenciou hérnia de disco em L4-L5, mais acentuada no lado esquerdo. Neste caso, indicou-se a discectomia endoscópica. Com a paciente sob anestesia geral, em decúbito ventral, na mesa radiotransparente, fez-se o portal de entrada a $10 \mathrm{~cm}$ da linha mediana em nível discal L4-L5. Introduziu-se uma agulha até o disco e realizou-se uma discografia, confirmando o nível com fluoroscopia. Com azul de metileno, dentro do disco, identificou-se o fragmento herniado. Por meio de uma cânula, inseriu-se um endoscópio até o espaço discal. Removeu-se o núcleo pulposo e o fragmento herniado e, por fim, retirou-se o endoscópio e os instrumentais e suturou-se a incisão. Após a cirurgia, a paciente acordou sem déficit motor ou sensitivo e, 12 horas depois, recebeu alta hospitalar. Com uma semana de pós-operatório, demonstrou melhora completa. DISCUSSÃO: O objetivo deste tratamento é a descompressão suficiente com redução do trauma. Estudos mostraram resultados clínicos de cirurgia endoscópica semelhantes em comparação com a microdiscectomia convencional. Mas a discectomia endoscópica mostrou reabilitação mais precoce. É menos invasiva, com bons resultados, menores sangramentos, tempos cirúrgico e de reabilitação.

Palavras-chave: cirurgia minimamente invasiva; fluoroscopia; fragmento herniado; reabilitação precoce.

\section{RCI - 10 RELATO DE CASO: IAM COMO MANIFESTAÇÃO EXTRAINTESTINAL DE DOENÇA DE CROHN}

Marina Ribeiro Maeji, Daniel Aparecido Alvarenga Silva, Rodrigo Barbosa Novais

\section{E-mail: mamaeji@ hotmail.com}

INTRODUÇÃO: A Doença Inflamatória Intestinal (DII) é uma desordem crônica imunomediada que está associada não só a lesões entéricas, mas também a diversas manifestações extra-intestinais que contribuem para a morbimortalidade da doença. Um crescente número de estudos tem indicado que pacientes com DII possuem maior risco de desenvolver doença cardiovascular por mecanismos fisiopatológicos comuns, decorrentes de processo inflamatório crônico. Os altos níveis de citocinas, proteína C-reativa e homocisteína podem levar à disfunção endotelial, um sinal precoce de aterosclerose. RELATO DE CASO: TGV, 33 anos, tabagista 10 anos/maço, com Doença de Crohn em tratamento há 15 anos, em uso de sulfassalazina e prednisona, é internado dia 08/05/2017 por infarto agudo do miocárdio com DII em atividade. $\mathrm{Na}$ admissão apresentava troponina de 12,43 , BNP de 532 e níveis crescentes de plaquetas (558 - 799 mil), além de eletrocardiograma típico. No exame físico observava-se três orifícios fistulosos pré-sacrais com saída abundante de secreção purulenta e sinais flogísticos, com intolerância ao toque retal pela dor. Paciente foi abordado com cateterismo e angioplastia, além de introdução de monocordil, ciprofloxacino e metronidazol, ticagrelor e AAS, bem como sinvastatina, enalapril e carvedilol para prevenção de novo evento cardiovascular. Após início da dupla antiagregação evoluiu com hemorragia digestiva baixa, sem sucesso de investigação colonoscópica por estenose de reto. Evoluiu com melhora do quadro inflamatório após uma semana. Enteroscopia de junho/2017 evidenciava alteração fibrocicatricial sacral e trajeto fistuloso posterior acometendo o músculo elevador do ânus. Atualmente, em uso de Certulizumab mensal com boa resposta clínica. DISCUSSÃO: A associação entre DII e doenças coronarianas ainda é incerta. Estudos estabelecem relação entre os níveis elevados de IL-6 e TNF-a com indução de aterosclerose precoce e lesão da camada média e íntima arterial, que poderiam predispor ao evento cardíaco. Outros estudos reafirmam essa relação em decorrência de anormalidades plaquetárias, que elevam o risco tromboembólico em 3 a 6 vezes. Uma metanálise publicada no JAHA (Journal of the American Heart Association) indica que observação cuidadosa e terapia efetiva para pacientes com DII pode reduzir o processo inflamatório crônico e, por consequência, o risco de síndrome coronariana aguda.

Palavras-chave: Crohn; IAM; inflamação crônica. 


\section{RCl - 11 RESSECÇÃO CORNUAL UTERINA E SALPINGECTOMIA DIREITA LAPAROTÔMICA SEGUIDA DE CURETAGEM UTERINA VIA VAGINAL POR GESTAÇÃO HETEROTÓPICA: UM RELATO DE CASO}

Nathalia Basile Mariotti, Bárbara Elza Silveira Canto, João Mateus Júnior

\section{E-mail: basile.nathalia@gmail.com}

INTRODUÇÃO: Gravidez heterotópica é a coexistência de gravidez ectópica e tópica, cuja incidência tem apresentado aumento nas últimas décadas (atribuído às técnicas de reprodução assistida), variando de 1:3.889 a 1:6.778. Gravidez ectópica cornual ou intersticial é caracterizada pela implantação do concepto na junção da tuba com o corpo uterino. Representa 2 a $4 \%$ do total das gestações ectópicas e está associada a 2 a 3\% da taxa de mortalidade materna. RELATO DE CASO: É relatado caso de paciente primigesta, 25 anos, admitida no Pronto Socorro de Ginecologia e Obstetrícia do HMU-SBC, em amenorréia, assintomática, com história prévia de sangramento vaginal e BHCG quantitativo ascendente, cuja Ultrassonografia Transvaginal demonstrou saco gestacional tópico e sem embrião (gestação anembrionada) associado a imagem cornual direita sugestiva de saco gestacional, interrogando-se uma gestação heterotópica ou corno uterino rudimentar. Foi internada no setor de Patologia Obstétrica para esclarecimento do caso com Ressonância Nuclear Magnética e controle de BHCG que já se encontrava em declínio. Evoluiu no $2^{\circ}$ dia de internação com quadro de abdome agudo e importante dor à mobilização uterina. Optou-se por laparotomia exploratória, na qual foi realizada salpingectomia com ressecção cornual direita, seguida de curetagem uterina via vaginal. Sendo assim, a ultrassonografia teve papel fundamental no diagnóstico dessa paciente, assim como é o exame padrão ouro para detecção precoce da patologia para todas as pacientes com essa suspeita, tendo uma sensibilidade de $87 \%$ e especificidade de 99\% para gestações ectópicas. DISCUSSÃO: Com o objetivo de apresentar uma patologia rara, com possíveis repercussões maternas de emergência e, portanto, de importância na detecção precoce e resolução assertiva. A gestação intersticial apresenta risco aumentado para complicações hemorrágicas, visto sua proximidade anatômica dos vasos uterinos e consequentemente maior mortalidade associada e sua incidência vem crescendo nas últimas décadas, pois os fatores de risco para essa patologia também aumentaram. O caso exemplifica uma patologia de importância médica, pois a deteç̧ão precoce altera significativamente o prognóstico.

Palavras-chave: Gestação heterotópica; ectópica; cornual.

\section{RCl - 12 TRANSPLANTE RENAL COM DRENAGEM PARA A VEIA GONADAL EM PACIENTE COM TROMBOSE DO SISTEMA ILÍACO-CAVA: RELATO DE CASO}

Natallia Meira Gonsalez, Tiago Genzini de Miranda, Emanuela Yumi Fugisawa de Mello, Isabella Pereira Blanco, Fernanda Folla Pompeu Marques, Juan Rafael Branez Pereira, Marcelo Perosa de Miranda

\section{E-mail: natalliagonsalez@yahoo.com}

INTRODUÇÃO: O transplante de rim (TR) é o tratamento de escolha para a doença renal terminal. A técnica padrão de TR usa as veias ilíacas (externa ou comum) ou cava para drenagem venosa do enxerto. Em pacientes com doença renal crônica, em hemodiálise de longa data, o achado de estenose ou trombose da veia ilíaca ou cava pode ocorrer e representa desafio cirúrgico para o implante do enxerto renal. Relata-se caso de TR com drenagem para a veia gonadal em que a situação clínica acima foi diagnosticada no intraoperatório. RELATO DE CASO: Paciente do sexo feminino, 59 anos, portadora de insuficiência renal crônica há 10 anos secundária a hipertensão arterial sistêmica. Iniciou hemodiálise há três anos e submeteu-se a fístula arterio-venosa três vezes e punção para diversos cateteres. Foi priorizada para TR devido à dificuldade de acesso para diálise. Nos exames pré-operatórios, doppler colorido dos vasos ilíacos sem alteração. Recebeu oferta de enxerto renal de doador falecido de 32 anos, vítima de hemorragia subaracnóidea, com creatinina de $0,7 \mathrm{mg} / \mathrm{dl}$ no momento da captação de órgãos. Durante a cirurgia do receptor, identificou-se trombose de veia cava e ilíacas, além de exuberante circulação colateral. Optou-se por realizar anastomose venosa do enxerto na veia gonadal da paciente, que se encontrava bastante dilatada. A paciente apresentou boa evolução pós-operatória com diurese no quarto dia pós-TR. Recebeu alta hospitalar no $15^{\circ}$ dia e atualmente encontra-se estável, com creatinina de $1,4 \mathrm{mg} / \mathrm{dl}$ e em seguimento ambulatorial. DISCUSSÃO: Apesar de incomum, a trombose do sistema ilíaco e cava pode ocorrer em candidatos a TR por motivos como uso pregresso de catéteres femorais, estado de hipercoagulabilidade ou trauma. Nesses casos, alternativas para a drenagem venosa do enxerto são necessárias e representam desafio maior. Estratégias foram utilizadas para contornar esta situação como anastomose na veia mesentérica superior, veia esplênica ou TR ortotópico. A utilização da veia gonadal possui vantagens como fácil exposição, localização próxima a artéria ilíaca e mobilidade que permite anastomose sem tensão. Apesar de ser opção de exceção, a drenagem venosa para a veia gonadal constitui alternativa interessante para pacientes com escassez de veias patentes, quando o TR se impõe de modo mais urgente como único tratamento capaz de oferecer maior perspectiva e qualidade de vida.

Palavras-chave: transplante renal, trombose venosa, veias ilíacas, veia gonadal.

\section{RCl - 13 TRATAMENTO CIRURGICO DE ESOTROPIA ASSOCIADA AO ALTO MÍOPE}

Maria Leticia Lasca Sales Campos, Carolina Nicolela Susanna Gustavo Junges Filiú, Michelle Fu Min Tong, Elaine Shizue Novalo-Goto, Victor Harasawa Uno, Othon Moritoshi Shiroma, Rodrigo Goldenstein Schainberg, Rodrigo Toledo Mota

\section{E-mail: leticialasca@gmail.com}

INTRODUÇÃO: Há associação entre alta miopia e esotropia (ET) em 3 a $8 \%$ dos casos, onde o paciente geralmente apresenta restrição na elevação e abdução do olho acometido gerando diplopia. O tratamento utilizando as técnicas cirúrgicas convencionais é difícil e geralmente associado a grande taxas de recorrência. Em 2002 Yamada descreveu uma nova técnica cirúrgica mais eficaz do que as anteriores a fim de retornar o olho próximo a posição ortotrópica. OBJETIVO: Apresentar a técnica cirúrgica descrita por Yamada et al realizada no Hospital Estadual Mário Covas em Santo André, SP. MÉTODO: A cirurgia idealizada por Yamada et al consiste na hemitransposição dos músculos reto superior (RS) e reto lateral (RL) com a ressecção do reto medial (RM). Os músculos RS e RL são separados longitudinalmente pela metade por $15 \mathrm{~mm}$ de extensão. As faixas lateral do RS e superior do RL são fixados na esclera juntas, no meio de suas inserções originais, a $7 \mathrm{~mm}$ do limbo. A ressecção do músculo RM é feita em extensão variável com o desvio da paciente, no caso apresentado foi realizada ressecção de $4 \mathrm{~mm}$. RESULTADO: A hemitransposição do RS e do RL e a ressecção do RM são benéficas para centralizar o globo posterior. Comparando exames prévios com a alta cirúrgica, é possível observar uma redução de ET de 50DP para 30DP, bem como HT de 35DP para 15DP direito sobre esquerdo acompanhado de um bom resultado estético sem a presença de diplopia e outras queixas visuais. DISCUSSÃO: A fisiopatologia da esotropia do alto míope ainda não foi esclarecida mas teorias sugerem que há, em consequência de alterações esclerais, o deslocamento dos músculo extraoculares gerando ET de grande ângulo associado a desvio vertical. Diversas técnicas cirúrgicas foram descritas na tentativa de restabelecer a posição do olhar, porém todas com baixa taxa de sucesso e alto índice de recidivas. A técnica descrita por Yamada permite a normalização do trajeto dos músculos associado a centralização do globo posterior apresentando na literatura bons resultados estéticos e baixa taxa de recidiva. CONCLUSÃO: A técnica de Yamada se apresenta como alternativa no tratamento da esotropia do alto míope com boa taxa de sucesso e menores taxas de recidiva.

Palavras-chave: Esotropia alta; miopia; tratamento cirurgia.

\section{RCI - 14 TUBERCULOSE INTESTINAL: RELATO DE CASO DE DIFÍCIL DIAGNÓSTICO}

Marina Ribeiro Maeji, Fernanda Mello de Oliveira e Silva, Larissa Oliveira Berti, Daniel Aparecido Alvarenga Silva, Rodrigo Barbosa Novais

\section{E-mail: mamaeji@ hotmail.com}

INTRODUÇÃO: A tuberculose do trato intestinal e a Doença de Crohn são patologias crônicas de caráter granulomatoso com apresentação semelhante. Em países com endemia de tuberculose a incidência de casos com acometimento intestinal aumenta progressivamente, tornando o diagnóstico diferencial um desafio de alta importância para definição da conduta terapêutica. RELATO DE CASO: RJS, 31 anos, masculino, ex-usuário de cocaína e ex-etilista, em janeiro/2017 tem início a quadro de dor abdominal associada a febre vespertina, dores no corpo e sudorese. Em maio/2017 apresentou permanência dos sintomas, além de dispneia, tosse secretiva e diarréia por um mês, sendo internado e tratado por 17 dias por pneumonia e encaminhado ao posto de saúde para realização de endoscopia e colonoscopia. Paciente sem alteração do quadro internado no Hospital Mário Covas em julho/2017 para realização de exames. Realizada tomografia de tórax, com infiltrado intersticial retículo micronodular, comprometendo os lobos superiores, sugestivo de tuberculose. Levantada a hipótese de doença inflamatória intestinal por colonoscopia com ileíte ulcerativa em atividade e lesão ulcerativa de válvula ileocecal. Na biópsia foi constatada a presença de granulomas tuberculoides e pesquisa de BAAR negativa. Prescrito mesalazina e corticoide, com alta para acompanhamento ambulatorial. Paciente retornou em agosto/2017 sem melhora, com dor em hipocôndrio e flanco direito e hipogástrio, em aperto, de forte intensidade, irradiada para epigástrio, emagrecimento de $17 \mathrm{~kg}$ e episódios de febre não aferida. Nessa internação realizou pesquisa para BK em escarro, com primeira amostra com resultado negativo. Após um mês em uso de mesalazina sem melhora dos sintomas, a medicação foi suspensa e optou-se por iniciar o tratamento com esquema RIPE por 9 meses. Em maio/2018 paciente apresenta melhora do quadro clínico, com ganho ponderal de 14kg. DISCUSSÃO: O diagnóstico diferencial entre tuberculose intestinal e Crohn em locais de alta prevalência é um desafio. A biópsia intestinal com granuloma tuberculoide e os exames para isolamento do Mycobacterium podem não definir um diagnóstico. Uma boa anamnese associada a seguimento clínico são importantes para essa elucidação. Em quadros refratários, em dúvida diagnóstica ou complicações, a abordagem cirúrgica pode ser o tratamento de escolha paras ambas.

Palavras-chave: Doença de Crohn; tuberculose intestinal. 


\section{$\mathrm{RCl}-15$ TUMOR GASTROINTESTINAL EM PACIENTE PORTADOR DE ANGIOMIOLIPOMA RENAL}

Gustavo Costa Santos, Willany Veloso Reinaldo, Guilherme Jose Reche, Pedro Henrique Ogata Kodama, Lucas Abdo Pereira, Feres Camargo Maluf, Thomas Yi Teh Lee, Karine Corcione Turke, Zelia Maria de Sousa Campos, Felipe Augusto Ferreira Oliveira

\section{E-mail: Gustavo_c_santos@hotmail.com}

INTRODUÇÃO: O angiomiolipoma é uma neoplasia renal composta de elementos de gordura, vascular e de músculo liso. Tem acometimento raro na população, sendo mais frequente em mulheres. Na grande maioria dos casos é detectado como um incidentaloma em um exame de ultrassom, tomografia ou ressonância. Na grande maioria dos casos os angiomiolipomas não causam sintomas e apenas acompanhamento. Já os tumores estromais gastrointestinais (GISTs) são raros, entretanto, são as neoplasias mesenquimais mais frequentemente identificadas no trato gastrointestinal (TGI) e representam 0,1 a $3 \%$ de todos os tumores gastrointestinais. Seu diagnóstico é baseado no quadro clínico. Na maioria das vezes, são assintomáticos, descobertos incidentalmente por exames de imagem. RELATO DE CASO: Masculino, 45 anos, encaminhado pela cirurgia de urgência ao Hospital Mário Covas com queixa de melena associado à história de lipotimia, para a realização de endoscopia digestiva alta (EDA). Realizou-se EDA por queixa de hemorragia digestiva alta exteriorizada por melena, sob intubação orotraqueal com sedação. Na EDA o estômago apresentou lesão elevada, arredondada recoberta, com ulceração central, endurecida ao toque, medindo cerca de $4 \mathrm{~cm}$, compatível com tumor gastrointestinal. Observou-se um sangramento, realizando-se um clipe metálico. Realizou-se Tomografia Computadorizada de Tórax, Abdome e Pelve, Eletrocardiograma e Raio-X de Tórax. Paciente foi submetido a um procedimento cirúrgico de gastrectomia em cunha/enuclearão de tumor gastrointestinal de corpo gástrico, além de herniorrafia umbilical. No Intra Operatório observou-se tumoração palpável na pequena curvatura do estômago em parede anterior e corpo médio, de aproximadamente $5 \mathrm{~cm}$ em seu maior diâmetro. Paciente ainda apresentava como consequência do angiomiolipoma renal sinais e sintomas típicos como dor em loja renal, Infecção urinária frequente e aumento da pressão arterial. DISCUSSÃO: É importante descrever casos de baixa incidência na literatura como este, com o intuito de elucidar prognóstico e cada vez mais aprimorar a conduta a ser adotada. Como descrito anteriormente, se trata de uma paciente com um duplo acometimento, uma vez que possui uma tumoração gastrointestinal, associado a um angiomiolipoma renal. É rara sua associação, e vale ressaltar que o diagnóstico por imagem tem papel complementar em todo o estadiamento e achados.

Palavras-chave: Tumor gastrointestinal; angiomiolipoma; radiologia.

\section{CATEGORIA - RELATO DE CASO CLÍNICO}

\section{RCL - 01 A CIRURGIA BARIÁTRICA PODE CAUSAR HIPOGAMAGLOBULINEMIA? PRIMEIRO RELATO DE CASO}

Marcel Gutierrez, Natália Corrêa Gabriel, Anete Sevciovic Grumach

\section{E-mail: marcelgutierrez07@gmail.com}

INTRODUÇ̃̃O: A obesidade atinge cerca de 1,7 bilhões de pessoas no mundo Pode associar-se à hipertensão arterial, doenças cardiovasculares, dislipidemias, diabete mellitus (DM) e apnéia obstrutiva do sono. A cirurgia bariátrica é considerada o método mais efetivo para perda de peso, além de melhorar significativamente ou resolver parte das doenças crônicas. Por outro lado, pode gerar regurgitação crônica, hiperparatireoidismo, osteoporose, alterações renais, deficiência alimentar crônica e estresse oxidativo. Não há relatos prévios de pacientes com hipogamaglobulinemia associada à cirurgia bariátrica na literatura. Neste relato, descrevemos uma paciente com hipogamaglobulinemia diagnosticada pós-cirurgia bariátrica, apresentando deficiências imunológicas celulares e humorais. RELATO DE CASO: Paciente do sexo feminino, submetida à cirurgia bariátrica em 2006, quando começou a apresentar infecções de repetição. As manifestações clínicas relatadas foram: sinusopatia levando a tosse persistente, artralgia, sibilância e astenia. Foi encaminhada para avaliação imunológica e verificou-se: $\operatorname{IgG}=445 \mathrm{mg} / \mathrm{dL}$ (normal - 672-1440 mg/dl), IgM=42 mg/dL (normal - 57-285 mg/dl) e IgA=126 mg/dL (normal- 59-396 mg/dl); células $\mathrm{B}=14$ / mm3 (0,9\%) (normal- 90-680/ $\mathrm{mm}^{3} ; 6-17 \%$ ); células $\mathrm{NK}=3,73 \%$ (normal - 7-22,8\%) e células T CD $3+=889 / \mathrm{mm}^{3}$ (normal $-1000-3900 \mathrm{~mm}^{3}$ ), T CD $4+=492 / \mathrm{mm}^{3}$ (normal $-570 ? 2700 / \mathrm{mm}^{3}$ ), T CD8 $+=402 / \mathrm{mm}^{3}$ (normal $-330-1400 / \mathrm{mm}^{3}$ ). A produção de anticorpos antipneumococo mostrou-se prejudicada após imunização vacinal (S4, S6B, S23F $<0,5 \mu \mathrm{g} / \mathrm{dl}$ (normal - $>1,3 \mathrm{ug} / \mathrm{dl}$ ). Foi iniciado o tratamento específico com a infusão de Imunoglobulina Intravenosa (27,5g/dose), mensalmente, atingindo melhora dos níveis séricos e dos sintomas apresentados. DISCUSSÃO: A efetividade da cirurgia bariátrica tem sido observada no que se refere a perda de peso e ao controle de doenças crônicas, como a diabetes mellitus. Entretanto, a deficiência nutricional e as alterações na absorção de fatores antioxidantes provenientes da alimentação, devido às alterações anatômicas do trato gastrointestinal geradas pela cirurgia, e a intensa perda de peso podem gerar alterações na sinalização imune, predispondo a ocorrência de infecções no pós-operatório. Não há descrição prévia na literatura sobre o desenvolvimento de hipogamaglobulinemia pós cirurgia bariátrica, recomendando-se atenção especial para este aspecto.

Palavras-chave: Cirurgia bariátrica; hipogamaglobulinemia; imunoglobulina; tratamento
RCL - 02 CATARATA SUBCAPSULAR BILATERAL RELACIONADA AO USO DE CORTICOIDE TÓPICO POR 3 ANOS EM UM PACIENTE ADULTO MASCULINO: UM RELATO DE CASO

Carolina Scaff Haddad Bartos, Gustavo Costa Santos, Francisco Zacari Brito, Carolina Nicolela Susanna, Mustapha Mohamed Mourad, Giulianna Nasi Domingues de Oliveira, Sandra Carina Lopez Calcines, Rafael Cunha de Almeida

\section{E-mail: carolina.scaff.haddad@gmail.com}

INTRODUÇÃO: O papel dos corticosteroides é bem conhecido na oftalmologia, tanto seu uso no pós-operatório ou seu papel terapêutico em diversas patologias, como também sua associação com o aparecimento de diferentes tipos de catarata. Esta correlação entre o uso de corticoides orais, usados em altas doses e por tempo prolongado, e a indução de catarata é bem estabelecida na literatura, tanto em adultos quanto em crianças. Entretanto, existem dúvidas em relação ao uso de corticoides dermatológicos tópicos e o desenvolvimento de catarata, por estes apresentarem menor absorção sistêmica. O trabalho relata um caso de catarata subcapsular relacionada ao uso apenas de corticoide tópico dermatológico, sem uso de corticoide oral. RELATO DE CASO: Masculino, 52 anos, procedente de Santo André - SP, Brasil. Encaminhado ao serviço por queixa de baixa acuidade visual (BAV) há 6 meses, após fazer uso tópico dermatológico de propionato de clobetasol, um corticosteróide, por 3 anos de forma inadequada para tratamento de micose. (sic). Ao exame: Acuidade visual (AV) Olho direito (OD): 20/320, AV olho esquerdo (OE) 20/125, sem melhora com correção. Biomicroscopia anterior (BMA): OD: Conjuntiva clara, córnea clara e transparente, catarata subcapsular 3+/4 difusa, nada corando ao teste de fluoresceína, demais sem alterações. BMA OE: Conjuntiva clara, córnea clara, transparente, catarata subcapsular de $2 / 3+/ 4$ difusa, nada corando ao teste de fluoresceína, demais sem alterações. Pressão Intra-Ocular (PIO) OD $14 \mathrm{OE}$ 15. Mapeamento de retina: Ambos os olhos: opacidade de meios, papila de bordas, contornos e coloração aparentemente normais, escavação aparentemente fisiológica, aumento da tortuosidade vascular, mácula aparentemente livre, retina colada $360^{\circ}$, difícil visualizar detalhes. DISCUSSÃO: É importante relatar casos de catarata associados ao uso de corticoides nas suas variadas formas. Ainda que por um período de tempo não tão longo, o uso de corticoide tópico dermatológico pode contribuir para o aparecimento da catarata tipo Sub-capsular Posterior.

Palavras-chave: corticoide, catarata, oftalmologia, dermatologia

\section{RCL - 03 DIAGNÓSTICO DE FIBROSE CÍSTICA EM PACIENTE ADULTA COM APRESENTAÇÃO ATÍPICA}

Leticia Goncalves Silva, Julia Araujo Vigiato, Maria Vitoria Mareschi Barbosa, Maria Fernanda Botelho Hernandez Perez, Elie Fiss

\section{E-mail: leticia.gonc.silva@gmail.com}

INTRODUÇÃO: A Fibrose Cística (FC) é causada pela mutação de um gene no cromossomo 7, o CFTR, alterando a produção do canal de cloro das células epiteliais, gerando o aumento da viscosidade das secreções. Clinicamente, apresenta-se por insuficiência pancreática, dissabsorção de nutrientes, hipovitaminose, infecções respiratórias e infertilidade. São conhecidas mais de 2.000 mutações do gene, conferindo à FC uma variedade de fenótipos. O diagnóstico ouro é o sequenciamento genético. A expectativa de vida depende da precocidade do diagnóstico. RELATO DE CASO: Paciente feminina, encaminhada aos 51 anos, com história de tosse produtiva desde a infância, sem internações. Evoluiu, nos últimos meses, com dispneia aos pequenos esforços, sem alteração de trato gastrointestinal ou dificuldade de ganho ponderal. É quartigesta, tercípara e um abortamento. Não apresenta consanguinidade na família, tem 8 irmãos, sendo um irmão tossidor sem diagnóstico. Resultados dos exames: TC de tórax com bronquiectasias císticas e de tração nos lobos superiores; teste do cloro no suor de $125 \mathrm{mmol} / \mathrm{L}$; teste genético com mutações, F508 e c.3140-26A>G. DISCUSSÃO: Os exames confirmaram o diagnóstico de FC, tendo um dos alelos a mutação, F508, mais frequente entre os portadores que, numa escala de 1 a 7 , por ordem decrescente de gravidade, classifica-se como 2, por não produzir canais de cloro na membrana das células. A outra mutação tem escala 5 , com apresentação fenotípica mais leve. Nesta classe de mutações há a produção de canais de cloro, porém em quantidade reduzida. A combinação destas mutações de diferentes classes resultou em um fenótipo mais brando da doença, com suficiência pancreática, adequado ganho ponderal, fertilidade e sintomas respiratórios que se agravaram apenas no último ano de vida. Também permitiu a sobrevida além da $5^{\text {a }}$ década de vida, apesar do diagnóstico tardio e falta de tratamento específico. O diagnóstico tardio de FC em paciente adulta com manifestações clínicas atípicas ilustra a necessidade dos profissionais de saúde conhecer os sinais e sintomas da doença, objetivando o diagnóstico precoce e tratamento multidisciplinar dos pacientes.

Palavras-chave: Fibrose Cística; Atípica; Fenótipo. 


\section{RCL - 04 EPITELIOPATIA PAQUICORÓIDE TRATADO COM ESPIRONOLACTONA}

Maria Leticia Lasca Sales Campos, Carolina Nicolela Susanna, Michelle Fu Min Tong, Victor Harasawa Uno, Elaine Shizue Novalo-goto, Rodrigo Goldenstein Schainberg, Othon Moritoshi Shiroma, Gustavo Junges Filiú, Rodrigo Toledo Mota

\section{E-mail:leticialasca@gmail.com}

INTRODUCC̃̃: A paquicoróide compreende um espectro de doenças caracterizadas pelo espessamento da coróide, entre elas, a Coriorretinopatia Serosa Central, Epiteliopatia Paquicoróide (EPP) e Neovasculopatia Paquicoróide. A EPP apresenta além do espessamento da coróide e alterações do pigmento do epitélio pigmentar da retina (EPR) causados pela compressão da camada de Haller contra a membrana de Bruch. Acomete duas vezes mais mulheres que homens, especialmente acima dos 50 anos. RELATO DE CASO: JTR, feminina, 48 anos, com queixa de baixa de acuidade visual há 6 meses. Ao exame oftalmológico acuidade visual (AV) 20/25 em olho direito e 20/32 em olho esquerdo com biomicroscopia e tonometria normais. Fundoscopia apresentava em ambos os olhos $(\mathrm{AO})$ áreas hipopigmentadas na região macular superior, fóvea e aumento de tortuosidade vascular. Foi realizada tomografia de coerência óptica (OCT-EDI) onde se observou espessamento da coróide em AO associado a descolamento do epitélio pigmentado da retina (DEP) compatíveis com diagnóstico de EPP. Foi iniciada terapia com espironolactona 50mg/ dia via oral e avaliação trimestral através de exame oftalmológico e OCT-EDI. Após 6 meses de terapia, apresentou melhora da AV, desaparecimento completo do DEP e diminuição da espessura coroideana em AO. DISCUSSÃO: A EPP foi descrita em 2013 e como no caso acima, apresenta associação entre espessamento da coroide e alteração do EPR na região macular. Deve-se sempre considerar como diagnóstico diferencial a degeneração macular relacionada a idade, neste caso descartada, por além de ser um paciente jovem, não estarem presentes outras alterações características da doença. Diversos estudos demonstraram o benefício do uso da espironolactona no tratamento das doenças paquicoróides. Sua indicação precisa permite, além de melhorar a anatomia e função visual, impedir a cronificação do quadro. É uma droga considerar segura, de administração oral, bem tolerada e com poucos efeitos colaterais comparada às outras alternativas terapêuticas, como injeções intravítreas de fatores antiangiogênicos, que além de apresentarem resultados inferiores aumenta o risco de infecção e descolamento de retina. O diagnóstico precoce associado ao uso adequado de espironolactona pode ser benéfico para o restabelecimento visual e anatômico.

Palavras-chave: retina; coróide; edema macular; doença vascular.

\section{RCL - 05 GESTAÇ̃̃O EM PACIENTE COM ANGIOEDEMA HEREDITÁRIO E MUTAÇÃO DE MTHFR: PRIMEIRO RELATO NA LITERATURA}

Ana Paula Possar do Carmo, Amanda Ribeiro Batlle, Nirelcio Aparecido Galão, Anete Sevciovic Grumach

\section{E-mail: anapaulapossar@hotmail.com}

INTRODUÇÃO: O angioedema hereditário (AEH) é uma doença de caráter autossômico dominante, caracterizada por crises de edema provenientes de uma deficiência quantitativa e/ou funcional do inibidor de $\mathrm{Cl}$ (C1-INH), podendo acometer diversos órgãos. O C1-INH atua no controle do sistema complemento, coagulação fibrinólise e de contato. A exacerbação destes sistemas resulta na diminuição dos níveis circulantes da calicreína e conversão com acúmulo de bradicinina. Além disso a trombofilia está relacionada a uma deficiência da enzima metilenotetrahidrofolato redutase (MTHFR), situação que acarreta aumento de homocisteína, acúmulo de placas de ateroma e tromboses tanto arteriais quanto venosas. A associação destes dois defeitos em sistemas relacionados pode trazer maior risco clínico ao paciente. Descrevemos a evolução de paciente com AEH e mutação homozigota de MTHFR primeiro caso descrito na literatura. RELATO DE CASO: Paciente do sexo feminino, 23 anos, G2A1, com AEH com crises desde primeira infância. Primeira gestação com abortamento por descolamento de saco gestacional. Na segunda gestação, com 5,1 semanas apresentou sangramento e descolamento parcial do saco gestacional sem afetar embrião. Medicada com Progesterona (200mg/dia). Exames de pesquisa de trombofilia confirmaram homozigose para a enzima MTHFR. Iniciou tratamento com enoxaparina $(40 \mathrm{mg} / \mathrm{dia}$, subcutâneo), AAS $(100 \mathrm{mg} /$ dia até 32 semanas), ácido fólico (5 $\mathrm{mg} / \mathrm{dia})$, Carbonato de cálcio (500 mg) e Vitamina D (400UI). Recebeu plasma fresco (1 vez), durante a gestação, por crise de angioedema. A gestação progrediu a termo, recém-nascido feminino (38,2 semanas; $3,2 \mathrm{~kg})$, parto cesariano, após profilaxia com inibidor de $\mathrm{C} 1$ esterase derivado de plasma (C1-INHdp) (1000UI). Alta hospitalar em 48 horas mantendo enoxaparina $(40 \mathrm{mg})$ até $15^{\circ}$ dia do puerpério. Durante a amamentação recebeu profilaxia com C1-INHdp a cada 7 dias. DISCUSSÃO: O curso do AEH durante a gestação pode agravar-se. Há estudos que discutem a ocorrência de abortamento decorrente de crises de angioedema. A paciente apresentava associação com mutação homozigota de MTHFR, provável causadora do abortamento apresentado. É importante o controle de ambas situações clínicas para o sucesso da gestação, assim um plano de ação combinado entre obstetra e especialistas aptos a tratar o AEH é essencial. Palavras-chave: Gravidez; Trombofilia; Mutação; Angioedema hereditário.

\section{RCL - 06 INFARTO COM SUPRADESNIVELAMENTO DO SEGMENTO ST EM PACIENTE COM FATOR V DE LEIDEN MUTANTE: RELATO DE CASO}

Juliana Daltrino Teodoro, Thiago Artioli, Leonardo Luís Torres Bianchi, Antonio Carlos Palandri Chagas

\section{E-mail: juliana.daltrino@gmail.com}

INTRODUÇÃO: A trombofilia causada pelo Fator V de Leiden (FVL), doença hereditária resultante da mutação do gene $\mathrm{F} 5$, é relativamente frequente e corresponde a 40-50\% dos casos desse grupo de doenças. É caracterizada pela ocorrência de tromboses, principalmente venosas, sendo a trombose arterial evento mais raramente descrito. Relatamos abaixo um caso de infarto agudo do miocárdio (IAM) em paciente jovem com FVL. RELATO DE CASO: Paciente do sexo feminino, 43 anos, tabagista 10 anos maço, com FVL diagnosticado quando apresentou trombose venosa profunda de membro inferior, sem anticoagulação atual, procurou atendimento por dor torácica típica. Durante a avaliação inicial apresentou parada cardiorrespiratória sendo reanimada por 10 minutos. Após retorno da circulação espontânea foi visto eletrocardiograma com supradesnivelamento de segmento ST de parede ântero-lateral e realizada trombólise. A paciente foi então encaminhada para cineangiocoronariografia que mostrou lesão excêntrica de $60-70 \%$ em terço proximal de artéria descendente anterior. As artérias circunflexa e coronária direita não tinham lesões e o ventrículo esquerdo apresentava discinesia apical e acinesia anterior. Foi optado por realização de cintilografia miocárdica que evidenciou fração de ejeção limítrofe, área de hipocaptação acentuada e persistente em região ântero-apical, sem evidência de isquemia, sendo então optado por tratamento clínico com dupla antiagregação. DISCUSSÃO: Ainda não se conseguiu estabelecer evidência suficiente entre a mutação e os eventos de trombose arterial, apesar da relação entre FVL e eventos trombóticos venosos, Um estudo mostrou aumento na frequência do FVL em mulheres jovens que sofreram IAM, aumento do risco de IAM em mulheres jovens com outros fatores de risco cardiovasculares, além de um aumento de 30 vezes do risco de IAM nas mulheres tabagistas heterozigotas para o FVL, sugerindo sinergismo entre fatores genéticos e comportamentais. Estudo mais recente mostrou associação entre o FVL e risco duas vezes maior de IAM antes dos 45 anos de idade. Este tem a intenção de reforçar a necessidade de mais estudos direcionados às trombofilias como contribuintes de eventos trombóticos arteriais, principalmente coronários, já que pode haver implicações na prevenção primária, métodos diagnósticos e, inclusive no tratamento, como uso de anticoagulação prolongada.

Palavras-chave: Infarto agudo do miocárdio; Fator V de Leiden; Trombofilia; Isquemia miocárdica.

\section{RCL - 07 INSUFICIÊNCIA CARDÍACA POR MIOCARDIOPATIA CHAGÁSICA REFRATÁRIA AO TRATAMENTO CONVENCIONAL}

Henrique Forcinetti Marques, Carolina Doering Neves, Isabela Corralo Ramos, Aline Rodrigues Loreto, Glauco Cesar Faria

\section{E-mail: henriqueforcinetti@gmail.com}

INTRODUÇÃO: A doença de Chagas é uma importante etiologia e o pior prognóstico dentre as causas de Insuficiência Cardíaca (IC). A forma chagásica promove distúrbios elétricos, como os bloqueios divisional antero-superior, de ramo direito e átrio ventricular de $1^{\circ}$ grau. A forma descompensada em geral é perfil B pela classificação clínica-hemodinâmica da IC aguda sendo tratada com diurético de alça, vasodilatador, uso contínuo de IECA ou BRA, beta bloqueador e Espironolactona, que reduzem mortalidade do paciente com ICC. RELATO DE CASO: A paciente MAMC, 59 anos, natural de Minas Gerais. Nega diagnóstico de IC prévia. Diabética há 20 anos, hipertensa há 15 e em tratamento de depressão. Faz uso irregular de Furosemida, Enalapril, hipoglicemiante oral e Sertralina. Internada 27/03/18 até 26/04/18 no Hospital de Clínicas de São Bernardo do Campo, por queixa de anasarca e edema de pálpebra. Iniciadas medidas de IC aguda perfil B. Peso habitual de $88 \mathrm{~kg}$, internada pesando $96 \mathrm{~kg}$ e oligúria (diurese de $600 \mathrm{ml}$ ), evoluiu com ganho de peso, até $114 \mathrm{~kg}$ apesar das medidas para ICC. Evoluiu com insuficiência renal aguda. Administrada solução hipertônica, sem melhora. Adicionada bomba de Furosemida $15 \mathrm{ml} / \mathrm{h}$, resultando em uma diurese de $4,5 \mathrm{~L}$ e perda de $2 \mathrm{~kg}$ progressivamente até alcançar 6,6L de diurese. A seguir, diminuído o fluxo de Furosemida para $8 \mathrm{ml} / \mathrm{h}$ até atingir $88 \mathrm{~kg}$, quando iniciou Furosemida dose fracionada e evoluiu com peso final de $78 \mathrm{~kg}$. Melhorou a função renal após perda de peso (creatinina de 2,4 para 1,1mg/dl). Cursou com leucopenia de 900 leucócitos por 5 dias. A avaliação da Hematologia diagnosticou agranulocitose de origem medicamentosa. Substituiu Sertralina por Fluoxetina e iniciou Granulokine 5000UI. Evoluiu com 13500 leucócitos após 2 dias, suspendendo o Granulokine. Recebeu alta com Furosemida 1cp/ dia VO e substituiu Enalapril por Losartana, devido rash cutâneo, hiperemia, edema periorbital significativos e suspeita de angioedema; manteve Espironolactona e Carvedilol. Teve alta com 79,9 kg e retorno ambulatorial em 7 dias. DISCUSSÃO Nesse caso, a refratariedade ao tratamento da IC chagásica foi significativa, necessitando uso de solução hipertônica e bomba de infusão de furosemida com doses acima do permitido e sem efeitos colaterais. A última foi essencial na resolução do caso, o que não se encontra relatado em outros trabalhos que abordam tal terapia. Palavras-chave: Insuficiência cardíaca; Furosemida; Miocardiopatia Chagásica; Bomba de infusão. 


\section{RCL - 08 LEUCEMIA MIELÓIDE CRÔNICA NA INFÂNCIA}

Adriana de Oliveira Camboim, Rafaela Oliveira de Sousa, Helaine Cristina de Castro

\section{E-mail: driks_camboim@ @otmail.com}

INTRODUÇÃO: A Leucemia Mielóide Crônica (LMC) é uma neoplasia que se caracteriza pela proliferação anormal de células da linhagem mielóide. Essa proliferação anômala está associada a uma translocação balanceada entre os braços longos dos cromossomas 9 e $22 \mathrm{t}(9 ; 22)$ (q34;q11), que leva à fusão dos genes BRC e ABL dando origem ao cromossomo Philadelphia $(\mathrm{Ph})$. Este rearranjo leva à formação de uma nova proteína com atividade tirosino quinase desregulada. A LMC é uma patologia rara na infância, representando apenas $2 \%$ a $3 \%$ das leucemias em crianças e adolescentes menores de 15 anos. RELATO DE CASO: B.C.L.V, sexo masculino, deu entrada no serviço em fevereiro de 2012, aos 12 anos de idade, com história de trauma no joelho. Ao exame físico observava-se esplenomegalia importante. $\mathrm{O}$ hemograma mostrava anemia, hiperleucocitose com desvio escalonado e plaquetose. A medula óssea apresentava hipercelularidade com predomínio granulocítico e escalonamento maturativo, relação G:E 31:1, 1\% de blastos, compatível com doença mieloproliferativa crônica. O cariótipo revelou translocação entre braços longos dos cromossomas 9 e 22 e a biologia molecular mostrou a fusão BCR-ABL. O tratamento foi iniciado com inibidor de tirosino quinase, mesilato de imatinibe, e mantido até os dias atuais devido a boa resposta apresentada pelo paciente e evolução com remissão clínica, hematológica, citogenética e molecular. DISCUSSÃO: O transplante de células tronco hematopoiéticas (TCTH) é a única modalidade terapêutica curativa para a LMC, porém depende da disponibilidade de um doador compatível, e a mortalidade associada ao procedimento é elevada (ao redor de $20 \%$ ). Os inibidores de tirosino quinase são uma alternativa para o tratamento, visto que têm proporcionado altos índices de remissão sem grandes efeitos adversos, apesar do curto tempo de seguimento. Hoje em dia para a escolha da terapia considera-se além da existência de doador compatível, a idade do paciente e a resposta do mesmo ao inibidor de tirosino quinase. Neste caso, tudo isto foi considerado e optou-se pelo tratamento com mesilato de imatinibe, apesar da existência de doador aparentado compatível. Esta escolha se mostrou, por hora, uma excelente opção, pois o paciente se mantém bem e em remissão após 6 anos do diagnóstico

Palavras-chave: Leucemia; Mielóide; Crônica; Imatinibe; Philadelphia.

\section{RCL - 09 NEUROSSÍFILIS COM BAIXA DE ACUIDADE VISUAL SEM OUTROS SINAIS OU SINTOMAS: UM RELATO DE CASO}

Sandra Carina Lopez Calcines, Carolina Nicolela Susanna, Mustapha Mohamed Mourad, Giulianna Nasi Domingues De Oliveira, Gustavo Costa Santos, Francisco Zacari Brito, Carolina Scaff Haddad Bartos, Rafael Cunha de Almeida

\section{E-mail: sandracarinalopez@hotmail.com}

INTRODUCC̃̃O: A Śf́ilis é uma doença infecciosa cuja incidência sofre notório aumento nos últimos anos e chama a atenção das organizações regionais e mundial de saúde. Seus sinais e sintomas são diversos e complexos, o que torna fácil a confusão com outras doenças e lhe rende a descrição de "a grande imitadora". Dentre os possíveis sintomas, pode-se citar o acometimento ocular que pode ocorrer em qualquer estágio, incluindo sífilis primária ou secundária. Apesar de existir levantamentos de estimativas da quantidade de casos na população brasileira e no mundo, pouco se sabe do número de casos de manifestação ocular nessa mesma doença. O conhecimento desse possível comprometimento oftalmológico está se tornando cada vez mais importante, pois, segundo a Organização Mundial da Saúde (OMS), há uma estimativa de 12 milhões de novos casos oculares a cada ano no mundo, sendo $90 \%$ em países desenvolvidos. RELATO DE CASO: LAS, 42 anos, feminino, procedente de Santo André, dona de casa. Procurou e atendimento oftalmológico com queixa de baixa de acuidade visual (BAV) súbita há 3 meses em olho direito, relatou que dormiu enxergando e acordou sem enxergar do olho direito. Negou dor ou outras queixas. Ao exame: Acuidade Visual: OD conta dedos a 4 metros, sem melhora com refração. OE: 20/50, com refração $+0,75 \mathrm{DE}$ 20/32. Após exame de angiofluoresceinografia, apresentou achados compatíveis com neurorretinite. Foram solicitados exames para investigar causas inflamatórias e infecciosas e foi diagnosticada com neurossífilis com envolvimento ocular. A paciente foi hospitalizada para antibioticoterapia intravenosa, apresentando melhora da acuidade visual, alcançando AV no OD de 0,1 e no OE de 0. DISCUSSÃO: Atualmente o que é possível encontrar em relação a estatísticas desse acometimento são publicações de estimativas na população de países desenvolvidos, talvez por isso que se acredita $90 \%$ ocorram nesses Estados. Assim, o que pode ser feito para reduzir as consequências oftalmológicas é, como primeiro passo, conhecer a sífilis, saber identificar, notificar e tratar a patologia. Também é conhecido que, se tratada adequadamente, é possível reverter perdas visuais importantes como no caso apresentado, onde o objetivo maior é lembrar-se da sífilis ocular como diagnóstico diferencial em casos oftalmológicos mesmo sem as manifestações clássicas da sífilis primária, secundária ou terciária.

Palavras-chave: oftalmologia; neurossífilis; infectologia.

\section{RCL - 10 REDUÇÃO DE SEQUELAS NEUROLÓGICAS E MORTALIDADE PERINATAL POR MEIO DE PROTOCOLO DE HIPOTERMIA: UM RELATO DE CASO}

Fernanda Ferreira Banhos, Da Hye Lee, Maria Isabel Cardoso Dos Passos Carvalho, Yasmin Cristina Cesquim, Maria Isabel Sacchi Mendonça, Vanessa Lopes Mathia, Gleise Aparecida Moraes Costa

\section{E-mail: fernandabanhosismart@gmail.com}

INTRODUÇÃO: A asfixia perinatal é um importante desencadeante de dano neurológico ao nascimento, responsável por muitos óbitos e graves repercussões sistêmicas. A intervenção terapêutica para esse quadro foi recentemente instalada e tem evoluído consideravelmente. Ao deixar de manejar apenas as complicações e comorbidades, a terapia baseada na hipotermia prolongada tem minimizado danos de forma efetiva, mostrando-se segura e eficaz em recém-nascidos sujeitos a desenvolver encefalopatia hipóxico-isquêmica. RELATO DE CASO: Recém-nascido de ICS, feminino, parto cesárea, a termo, pesando $3625 \mathrm{~g}$, com Apgar 1, 3 e 5 no primeiro, quinto e décimo minuto de vida, respectivamente. Nasceu em mau estado geral, hipotônico, bradicárdico e em apneia, sendo iniciadas manobras de reanimação para reversão do quadro. Após estabilização o RN foi encaminhado à UTI neonatal para suporte intensivo. Devido ao apgar de 5 no $5^{\circ}$ minuto de vida, gasometria arterial acidótica na primeira hora, e $\mathrm{BE}<-16$, associado ao quadro convulsivo precoce $(<6$ horas de vida), foi indicado protocolo de hipotermia terapêutica pela equipe multidisciplinar. RN permaneceu por 72 horas sob temperatura $<34{ }^{\circ} \mathrm{C}$ e reiniciado aquecimento lento após esse período. Apesar de episódios convulsivos, sugerindo evolução para encefalopatia hipóxico-isquêmica, houve boa recuperação clínica e aos 34 dias de vida, pesando 3665 g, o paciente teve alta hospitalar. DISCUSSÃO $\mathrm{Na}$ tentativa de minimizar os efeitos provocados pela asfixia, reduzindo-se as sequelas neurológicas e a mortalidade, surgiu a hipotermia terapêutica. Sugere-se que sua aplicação no período de latência, portanto, nas primeiras seis horas inibe os mecanismos de lesão do SNC decorrentes da fase tardia da encefalopatia hipóxico-isquêmica. Os efeitos protetores da hipotermia têm sido associados à inibição de proteases e à ativação da calpaína, perda de potencial de membrana e falência mitocondriais, dano de radicais livres, peroxidação lipídica e inflamação, o que reduz a extensão da lesão cerebral. O avanço nos cuidados neonatais, exemplificado pela instauração e aperfeiçoamento do Protocolo de Hipotermia, tem se refletido na redução significativa da mortalidade dos pacientes dessa faixa etária de alta morbidade associada às lesões neurológicas decorrentes da asfixia.

Palavras-chave: Asfixia Perinatal; Hipotermia; Encefalopatia; Hipóxia.

\section{RCL - RELATO DE CASO: DIAGNOSTICO ETRATAMENTO DE PACIENTE COM DIAGNÓSTICO DE MODY5}

Maria Isabel Cardoso dos Passos Carvalho, Fernanda Ferreira Banhos, Marina Longo Machado de Almeida, Juliana Daltrino Teodoro, Ana Paula Possar do Carmo, Maria Carolina Martins Smanio, Augusto Cezar Santomauro Júnior

E-mail: isacar2013@gmail.com

INTRODUÇÃO: O Maturity-Onset type Diabetes of childhood or of Young people (MODY) consiste em uma forma de diabetes ocasionada por mutações gênicas de transmissão autossômico-dominante associadas a defeitos no padrão de secreção de insulina. Essas alterações podem ocorrer de duas maneiras: em genes que codificam a enzima glicoquinase ou em fatores de transcrição que têm sua expressão nas células beta pancreáticas. Atualmente são conhecidos vários subtipos e o que os difere da Diabetes Mellitus tipo 1 (DM1) é a presença de três gerações de mesma família afetadas, ausência de anticorpo positivo e função variável de célula beta pancreática. Os MODY2 e MODY3 representam mais de $80 \%$ dos casos diag nosticados, sendo o subtipo 5 de incidência significativamente baixa na população. RELATO DE CASO: GFG, 19 anos, feminino, procurou endocrinologista em 2014 por valor de glicemia capilar em jejum 112 (vr $100 \mathrm{mg} / \mathrm{dL}$ ) e hemoglobina glicada 5.6\% (vr < 5,7\%). Mãe e avó materna portadores de DM. Resultado de teste de tolerância oral à glicose $212 \mathrm{mg} / \mathrm{dl}$ após 120 minutos $(\mathrm{vr}<140 \mathrm{mg} / \mathrm{dl})$, sendo compatível com diagnóstico de DM. Iniciou uso de Sitagliptina 50mg. Três meses depois, laboratório mostrou glicemia $91 \mathrm{mg} / \mathrm{dL}, \mathrm{HbAlc} 5,2 \%$, anticorpos ant GAD e anti-ilhota negativos, peptídeo C 1,9 (vr 1,1 a 4,4 ng/ml). Conduta mantida e amostra de sangue encaminhada para estudo genético molecular de MODY devido a exames laboratoriais, antecedente familiar e perfil compatíveis com essa forma de DM. Estudo genético confirmou mutação no gene HNF-1 - compatível com MODY 5. Solicitado USG de abdome e pelve para investigar malformações do aparelho urinário e genital e família convocada para realização de pesquisa genética. DISCUSSÃO: Estima-se que $1-2 \%$ dos pacientes portadores de DM possuem, na verdade, a forma monogênica da doença. No caso relatado a hipótese de MODY foi levantada devido a valores de glicemia próximos à normalidade. Por ser uma doença de herança genética, é importante pesquisar mutações em familiares, o que possibilitaria o diagnóstico correto. A depender do subtipo de MODY, é possível escolher a terapêutica apropriada, que de maneira geral possui boa resposta clínica apenas com medicamentos, diferente do quadro de DM1 que necessita de insulinoterapia para se ter um controle glicêmico adequado. $O$ tratamento precoce viabiliza um melhor prognóstico e evita complicações futuras.

Palavras-chave: MODY5; Diabetes mellitus; Monogênica; Glicemia 


\section{RCL - 12 RELATO DE CASO: SÍNDROME DE KEARNS-SAYRE}

Mayara de Cassia Benedito, Mário Guilherme Aparecido Brasileiro, Carolina de Arruda Garcia, Alzira Alves Siqueira Carvalho

\section{E-mail: mayara.decassia@icloud.com}

INTRODUÇÃO: A Síndrome de Kearns-Sayre (SKS) é uma doença genética causada por alterações estruturais e bioquímicas na mitocôndria. As primeiras manifestações frequentemente surgem antes dos vinte anos de idade. A apresentação clássica envolve a tríade: oftalmoplegia externa progressiva, degeneração pigmentar retiniana e bloqueio de condução cardíaca, sendo este a maior causa de mortalidade. Estima-se que a prevalência da doença seja de 1,6 para cada 100.000 indivíduos. As características clínicas estão diretamente relacionadas à quantidade de mitocôndrias afetadas e nos sistemas em que elas se encontram fenômeno denominado heteroplasmia. O diagnóstico é altamente sugerido pela presença de alterações morfológicas das fibras musculares chamadas Ragged-red Fibers (fibras vermelhas rasgadas), encontradas na biópsia de tecido muscular, e é confirmado por teste genético através de sequenciamento do DNA mitocondrial. Não existe tratamento específico para a SKS O tratamento sintomático é feito com coenzima Q10 e carnitina, substratos para a produção de adenosina trifosfato. RELATO DE CASO: Paciente do sexo masculino, 12 anos, com queixa de queda da pálpebra bilateral há 2 anos. Referiu ainda dificuldade na motricidade ocular. O paciente possui atraso de crescimento (está em uso de hormônio do crescimento), hemibloqueio cardíaco anterior esquerdo e escoliose. Os pais são primos de segundo grau. O exame físico mostrou ptose palpebral e paresia ocular nos sentidos horizontal e vertical para cima em ambos os olhos. O paciente foi submetido a biópsia muscular, cujos resultados mostraram alterações musculares primárias com presença de Ragged-red fibers. DISCUSSÃO: A Síndrome de Kearns-Sayre é muito rara e grave, e pode se manifestar em vários sistemas do corpo. É importante que os profissionais de saúde tenham conhecimento sobre a doença, uma vez que as alterações cardíacas podem levar à morte.

Palavras-chave: Síndrome de Kearns-Sayre; doença mitocondrial; oftalmoplegia; bloqueio cardíaco.

\section{RCL - 13 RELATO DE CASO: SÍNDROME DE PRUNE BELLY}

Pedro Henrique Ogata Kodama, Guilherme Jose Reche, Lucas Abdo Pereira, Gustavo Costa Santos, Karine Corcione Turke, Thomas Yi Teh Lee, Fauze Camargo Maluf, Pedro Mazzilli Suplicy, Claudio Campi De Castro, Murillo Salles Mattos Nogueira

\section{E-mail: g_reche@ hotmail.com}

INTRODUÇÃO: A Síndrome de Prune Belly (SBP) ou Síndrome de EagleBarret ou Síndrome do Abdome em Ameixa Seca é uma malformação urogenital congênita rara que acomete 1:50.000 nascimentos, sendo em 95\% dos casos homens. Possui etiologia indefinida e as hipóteses são um possível defeito do mesoderma ou uma obstrução ureteral. A SBP é caracterizada pela tríade clássica de anormalidades congênitas que consiste em criptorquidia bilateral, anormalidades do trato urinário e ausência ou deficiência da musculatura da parede abdominal. As mulheres acometidas terão defeitos na genitália externa além das duas últimas anormalidades da tríade. O diagnóstico pode ser feito por ultrassom gestacional, através de radiografias, testes sanguíneos e pielograma intravenoso. RELATO DE CASO: Paciente masculino, 10 anos, diagnosticado com SBP no periparto, apresentando abdome em ameixa, criptorquidia bilateral, má formação da musculatura abdominal junto ao fator mais incomum de alteração do trato urinário, a persistência do úraco. Foi realizado vesicostomia. Aos 6 meses veio ao Hospital Estadual Mário Covas em pós-operatório tardio de vesicostomia por discinesia vesical, apresentando perda de sonda em persistência do úraco que foi repassada. O paciente foi acompanhado semestralmente até os 4 anos. Neste período apresentou episódios de hematúria e infecções urinárias recorrentes. Após estabilização, foi solicitado avaliação videolaparoscópica para correção da criptorquidia bilateral pela orquidopexia. Não houve intercorrências e foi orientado sobre cuidados gerais e uso de dipirona se dor Aos 8 anos o paciente foi submetido à ureteroplastia associado ao reimplante ureteral esquerdo à politano mais passagem de cateter duplo J, visando a reconstrução do trato urinário. Aos 9 , foi realizado o reimplante uretral direito. Sem intercorrências em ambas as cirurgias. DISCUSSÃO: Devido à gravidade e aos diversos sistemas acometidos, o diagnóstico precoce, ainda intraútero, é de extrema relevância. Os profissionais da saúde, sobretudo os das áreas da Neonatologia, Obstetrícia, Radiologia, Pediatria e Urologia, devem estar aptos para identificar, diagnosticar e tratar o mais precoce possível com a finalidade tanto da melhora clínica e da qualidade de vida do paciente quanto do conforto e assistência à família.

Palavras-chave: Criptorquidia Bilateral; Anormalidades Congênitas; Persistência do Úraco; Síndrome de Prune Belly.

\section{RCL - 14 RELATO DE CASO DE LEISHMANIOSE CUTÂNEA COM APRESENTAÇÃO ESPOROTRICÓIDE ATÍPICA}

Débora Terra Cardial, Lia Vineyard Steuer, Roberta Ferraz Salles Kesselring, Vinicius Gomes Lippi

\section{E-mail: lia_steuer@hotmail.com}

INTRODUÇÃO: Na América, a leishmaniose cutânea (LC) é causada por sete diferentes espécies de Leishmania com uma diversidade de manifestação clínica dependente da espécie envolvida e da resposta imune do hospedeiro. A forma mais comum é a cutânea localizada (LCL), caracterizada por lesão única, ulcerada, com bordos bem delimitados, localizada em áreas expostas, especialmente face e membros. A espécie mais importante é a L. brasiliensis, que pode se manifestar sob a forma LCL, mucosa (desfigurante) ou atípica, como a forma esporotricóide (LE), mimetizando a esporotricose. A LE tem uma incidência de 2,3 a 4,7\% dos casos de LC. É caracterizada por uma úlcera primária combinada com linfangite e nódulos e/ou lesões ulceradas ao longo do trajeto linfático. A LE parece acometer mais mulheres de idade avançada e membros superiores. Dependendo da forma clínica e da Leishmania envolvida, o tratamento é baseado no uso de antimonial pentavalente, anfotericina b lipossomal (ABL) ou pentamidina. RELATO DE CASO: Feminino, 72 anos, procedente de Gandú-Bahia. Relata aparecimento de nódulo único em terço distal de antebraço direito, assintomático, que ulcerou. Houve progressão da lesão primária para face lateral e anterior do antebraço, com ocorrência de nódulos subcutâneos eritematosos, ulcerados e lineares ao longo dos trajetos linfáticos. O anatomopatológico evidenciou dermatose nodular granulomatosa ulcerada e detecção de formas amastigotas de Leishmania. A Cultura de Leishmania foi positiva. A Reação em Cadeia da Polimerase detectou presença de DNA de L. braziliensis. Foi tratada com ABL. Houve melhora progressiva das lesões após término do tratamento. DISCUSSÃO: A forma clínica apresentada é caracterizada como LE, com boa resposta ao ABL. O caso apresenta características clínicas e agente etiológico semelhantes à literatura. Diferentemente da literatura, a manifestação linfática ocorreu antes do início do tratamento. O caso chama atenção pela exuberância clínica das cadeias linfáticas que progrediram a partir da lesão primária. Normalmente, a linfangite nodular é recoberta por pele íntegra ou eritematosa, com eventuais úlceras no trajeto. A divulgação deste caso clínico é de suma importância para alertar os profissionais da saúde, pois o comprometimento linfático exuberante não é comum na LC e pode dificultar o diagnóstico ou causar tratamento inadequado.

Palavras-chave: Leishmaniose cutânea; forma esporotricóide.

\section{RCL - 15 SÍNDROME DE GRISCELLI - RELATO DE CASO}

Vanessa Lopes Mathia, Marina Sabin De Souza Lima, Natalia D'amore Marciano, Gabrielle Ellert De Almeida, Sophia De Souza Tosta, Elisa Couto Peres Ribeiro

\section{E-mail: vanessamathia@gmail.com}

INTRODUÇÃO: A Síndrome de Griscelli é uma doença rara autossômica recessiva e resulta na hipopigmentação da pele e cabelo, presença de agregados de pigmento nas hastes capilares e acúmulo de melanossomas maduros nos melanócitos. É causada por mutações no gene MYO5A, o tipo 1 da síndrome, ou no RAB27A, o tipo 2. A mutação no RAB27A provoca hiper ativação descontrolada de macrófagos e linfócitos T, resultando na Síndrome Hemofagocítica, caracterizada por infiltração celular em linfonodos, cérebro, fígado, baço e medula óssea, e ativação policlonal de células $\mathrm{T}$ (CD8) e macrófagos, gerando modificações multissistêmicas. Os afetados estão propensos a infecções recorrentes devido a alterações do sistema imune. RELATO DE CASO: K.G.A., 16 anos, iniciou em Março/2015 quadro de febre, sudorese noturna e hepatoesplenomegalia, diagnosticado com leishmaniose visceral. Em Julho evoluiu com plaquetopenia devido à leishmaniose reativada. Após 1 semana reiniciou quadro e apresentou em biópsia de medula óssea reação inflamatória linfocitária e histiocitária de padrão granulomatoso. Biópsia de linfonodo axilar por PAAF indicou linfoma não Hodgkin de grandes células B, rico em células $\mathrm{T}$ e histiócitos, confirmado com biópsia excisional. Iniciou tratamento com protocolo LNH 2010 risco intermediário (Ciclofosfamida, Doxorrubicina, Vincristina, Prednisona, Metotrexate e Leucovorin) de Fevereiro a Maio/2016. Sequenciamento genômico do painel de hematofagocitose familiar identificou duas mutações no gene RAB27A e uma no UNC13D, diagnosticando Síndrome de Griscelli tipo 2. Foi indicado transplante de medula óssea enquanto a doença está controlada mas paciente é resistente ao transplante. Faz seguimento ambulatorial na FMABC. DISCUSSÃO: A síndrome hemofagocítica associada a malignidade ocorre principalmente com Linfomas Não-Hodgkin de origem em células T e NK. As manifestações podem ser modificadas pelo processo maligno e por medidas terapêuticas, atrasando o diagnóstico. Em geral possuem ruim prognóstico, com sobrevida de 3 anos, mas o diagnóstico precoce e conduta adequada podem alterar a evolução. Apesar das complicações do paciente, através do tratamento adequado atingiu-se estabilidade da doença, abrindo a oportunidade de realização de transplante de medula óssea, imprescindível para o sucesso do tratamento e possível cura e deve ser feito no período estável da doença para maior sobrevida.

Palavras-chave: Síndrome Griscelli; Síndrome hemofagocítica; linfoma. 


\section{CATEGORIA - MONOGRAFIA}

\section{MON - 01 ALTERAÇÕES GESTACIONAIS CAUSADAS POR DROGAS DE ABUSO}

Fernanda Folla Pompeu Marques, Mércia Tancredo Toledo

\section{E-mail: fernandamarques23@hotmail.com}

INTRODUÇÃO: A gravidez é um período fundamental de crescimento e desenvolvimento fetal e, por isso, necessidade de grande cuidado médico com suas pacientes. Agentes químicos, físicos e biológicos podem ter caráter teratogênico. Na classe de agentes químicos, são abordados o uso persistente de tabaco, maconha e cocaína durante a gestação. OBJETIVO: Motivados por grande número de atendimentos a usuárias de drogas, os autores objetivaram revisar a literatura sobre as alterações, fetais e nas gestantes, decorrentes do uso de tabaco, maconha e cocaína. MÉTODO: Revisão crítica das publicações nas seguintes bases de dados: MEDLINE, SciELO, LILACS e Google acadêmico, entre o período de 2007 a 2017 em inglês e português. Diretrizes e manuais do SUS também foram revisados. RESULTADO: Frente ao conhecimento dos efeitos das principais drogas psicoativas utilizadas durante a gravidez foi construído um infográfico educativo que foi apresentado e entregue a gestantes da Unidade Básica de Saúde Centro de Saúde Escola de Sorocaba. DISCUSSÃO: $\mathrm{O}$ abuso de drogas não é um problema exclusivo do Brasil e as mulheres em idade fértil são maioria no uso de tabaco, maconha e cocaína. A Cannabis sativa é a droga ilícita de maior abuso entre as gestantes, afetando o desenvolvimento do sistema nervoso com má-formação do tubo neural e possíveis anencefalias. Neonatos de mães usuárias apresentaram baixo peso ao nascer e maior probabilidade de uso da unidade de terapia intensiva neonatal. A cocaína tem caráter lipossolúvel e atravessa a barreira placentária por difusão simples. Causa malformação fetal, descolamento prematuro de placenta, aumento da pressão arterial materna e diminuição da circulação fetal. O tabagismo pode causar hipóxia fetal, elevando o risco de infarto cerebral no neonato e funcionamento deficitário da placenta. Prematuridade, abortamento, descolamento prévio da placenta e menor peso do neonato ao nascer também são citados. CONCLUSÃO: $\mathrm{O}$ abuso de drogas durante a gestação causa teratogenia. Diante de escassos estudos e programas governamentais há necessidade de uma maior atenção acerca deste problema de saúde pública a fim de capacitar os agentes promotores de saúde a dar informações as gestantes durante o pré-natal.

Palavras-chave: gravidez; teratogenia; drogas de abuso.

\section{MON - 02 ANÁLISE DA RELAÇÃO EM DIABETES MELLITUS TIPO 2 E DOENÇA DE PARKINSON: REVISÃO SISTEMÁTICA}

Fauze Camargo Maluf, David Feder, Alzira Alves Siqueira Carvalho

\section{E-mail: fauzecamargo@ hotmail.com}

INTRODUÇÃO: No começo de 1960 iniciou-se a discussão entre associação da Doença de Parkinson (DP) e Diabetes Melito tipo 2 (DMT2). Entretanto, ainda existem dúvidas sobre essa relação. OBJETIVO: Essa revisão tem como objetivo analisar as duas doenças quanto as relações causais e tratamento. MÉTODOS: Foram encontrados 58 artigos que analisaram a relação entre DMT2 e DP. RESULTADOS E DISCUSSÃO: Os estudos demonstraram que DMT2 causou alterações neurológicas que podem estar associadas à DP como desregulação da via dopaminérgica, menor expressão de PGCl $\alpha$ (gene proliferadores de peroxissoma gama), aumento da expressão da proteína PED/PEA-15 (fosfoproteína enriquecida em diabetes / fosfoproteína enriquecida em astrócitos 15), neuroinflamação e aumento na velocidade da formação de amilóides de $\alpha$-sinucleína. Além disso, evidenciou-se a piora dos sintomas parkinsonianos após o desenvolvimento de DMT2 e sete genes desregulados no sangue de pacientes com DMT2 e DP. CONCLUSÃO: Em relação ao tratamento, encontrou-se a ação de medicamentos antiglicemiantes capazes de promover neuroproteção para DP, principalmente, os fármacos da classe dos Incretinomiméticos. Portanto, é certo que existem interações entre essas doenças e são necessárias mais pesquisas para elucidá-las.

Palavras-chave: Diabetes Melito tipo 2; Doença de Parkinson; Resistência à Insulina; $\alpha$-sinucleína.

\section{MON - O3 HEMOCROMATOSE E HEPCIDINA: UMA REVISÃO DA LITERATURA}

Pedro Mazzilli Suplicy, Giovana Moreira Minchillo, Glauco Sergio Avelino de Aquino, Vitor Augusto Queiroz Mauad, Davimar Miranda Maciel Borducchi

E-mail: pmsupla@gmail.com

INTRODUÇãO: A hemocromatose hereditária (HH) é a mais frequente doença relacionada ao excesso de ferro no organismo causada pela disfunção de sua regulação, sendo caracterizada pelo aumento do depósito parenquimal de ferro em órgãos vitais como fígado, coração e pâncreas. Pode ocorrer por uma gama de alterações genéticas, mas a maior parte dos pacientes sofre com mutações que prejudicam o funcionamento da hepcidina. Por ter significativa prevalência e morbimortalidade, seu estudo é de grande importância. OBJETIVO: O objetivo desta revisão literária é investigar e elucidar os mecanismos moleculares de regulação do ferro no organismo e o papel desses na hemocromatose hereditária. MÉTODO: O tema foi pesquisado na base de dados PubMed utilizando os filtros "hepcidin or hemochromatosis", e foram obtidos 13201 artigos em inglês, que foram reduzidos a 82 uma vez incluídos apenas os artigos de revisão dos últimos 10 anos compatíveis com o tema. Desses, foram selecionados 31 para revisão final, dos quais 17 foram incluídos para análise qualitativa. DISCUSSÃO: A homeostasia do ferro no organismo é feita por processos controlados em sua maioria pela hepcidina, um hormônio hepático responsável pela regulação negativa da absorção e reciclagem do ferro, através da internalização e degradação da ferroportina, o único exportador celular de ferro conhecido. A regulação da síntese de hepcidina pode ser alterada pelo nível sérico de ferro, infecção, inflamação, anemia e alterações da eritropoiese. A desregulação da homeostasia do ferro no organismo por fatores genéticos pode levar à hemocromatose hereditária, cuja clínica é inespecífica e geralmente ausente em estágio iniciais da doença, podendo aparecer letargia, artralgia, astenia e impotência na evolução. O diagnóstico de HH é confirmado pelos aumentos dos níveis de ferritina sérica e saturação de transferrina, e sua classificação em subtipos é feita com base nas alterações genéticas presentes. $\mathrm{O}$ tratamento requer flebotomia na maioria dos casos. CONCLUSÃO: A hemocromatose hereditária é uma doença de transmissão genética, de alta prevalência, principalmente em europeus caucasianos, e cujo impacto sistêmico é elevado e, se não tratada, pode conduzir à morte. Seu estudo é importante na tentativa de melhorar a qualidade de vida do paciente, ampliar as opções de tratamento e reduzir a mortalidade por complicações. Palavras-chave: Hemocromatose hereditária; hepcidina; ferro.

\section{MON - 04 O USO DO ALISQUIRENO COMO DROGA ANTI- FIBRÓTICA: UMA REVISÃO SISTEMÁTICA}

Thaina Altarejo Marin, Bruno Machado Bertassoli, David Feder

\section{E-mail: thaina.marin @ hotmail.com}

INTRODUÇÃO: O alisquireno é o primeiro fármaco oral para o tratamento da hipertensão arterial que age inibindo diretamente a renina. Altos níveis de renina e de pró-renina provavelmente ativam a via de sinalização patológica da fibrose. $\mathrm{O}$ alisquireno reduz o estresse oxidativo que pode acarretar o início de fibrose. A droga tem sido pouco utilizada no tratamento da hipertensão arterial, por ocasionar em estudos clínicos alguns efeitos adversos em pacientes diabéticos. Apesar disso ela pode apresentar um potencial benéfico antifibrótico em diferentes doenças. OBJETIVO: Analisar os estudos experimentais que demonstram as ações do alisquireno sobre a fibrose. MÉTODOS: Foram utilizadas as bases Pubmed e Lilacs, usando as palavras chave: aliskiren; fibrosis. Foram encontrados 66 artigos no Pubmed e 62 no Lilacs. Foram excluídos 13 artigos por não se adequarem ao objetivo da revisão. Dessa forma, foram analisados 53 artigos. RESULTADOS Em tecido cardíaco, o fármaco atenuou o remodelamento e a hipertrofia reduziu citocinas inflamatórias, deposição de colágeno e estresse oxidativo. Houve menor degeneração dos miócitos e a função cardíaca foi melhorada. Nos rins, houve redução da fibrose túbulo-intersticial, da infiltração de células inflamatórias, da apoptose, da proteinúria e do recrutamento de macrófagos. Em modelos diabéticos, observou-se melhora na relação albumina e creatinina, benefícios à função pancreática e à tolerância à glicose e melhora na sinalização do metabolismo da insulina na musculatura esquelética. No fígado, o alisquireno reduziu a fibrose, a esteatose, as citocinas inflamatórias e a deposicão de colágeno. Em tecido pulmonar e peritoneal, reduziu a fibrose. DISCUSSÃO: Diversos estudos retrataram o efeito benéfico do alisquireno em função endotelial e rigidez arterial. A redução da fibrose em diversos órgãos é citada por inúmeros autores, e corroboram os resultados obtidos nesta revisão. Entretanto, os estudos divergem quanto à utilização da droga em pacientes diabéticos, pelo aumento de hipotensão, hipercalemia e piora da função renal. CONCLUSÃO: O alisquireno apresenta potencial antifibrótico em diversos modelos experimentais, interferindo nos níveis de citocinas fibrogênicas e no estresse oxidativo, podendo sugerir que possa ser útil em diversas doenças nas quais a fibrose tem um papel patofisiológico importante.

Palavras-chave: Alisquireno; fibrose; stress oxidativo; revisão.

\section{MON - 05 PADRÃO DE LESÕES OROMAXILOFACIAIS EM MULHERES VÍTIMAS DE VIOLÊNCIA INTERPESSOAL: ESTUDO DE CASOS PERICIADOS NO IML CENTRAL DO ESTADO DE SÃO PAULO}

Michelle Gomes Santos, Daniela Mieko Abe, Carmen Silvia Molleis Galego Miziara

\section{E-mail: mi.aster@ hotmail.com}

INTRODUÇÃO: A violência física contra a mulher é problemática recorrente, presente em todas as classes sociais, que repercute na saúde da vítima e em outros aspectos da vida diária. A região orofacial é considerada uma das mais afetadas em situações de violência interpessoal não fatal, entretanto estudos dessas lesões e suas consequências, anatômicas e funcionais são escassos. OBJETIVO: Descrever danos anatômicos e/ou funcionais oromaxilofaciais de mulheres vítimas de violência interpessoal (GE) e comparar os resultados com grupo controle formado por homens. MÉTODO: Foi realizada análise de informações obtidas em banco de dados do Núcleo de Odontologia Legal do Instituto Médico Legal do Estado de São Paulo - Central - entre janeiro de 2014 e dezembro de 2016. O grupo controle (GC) foi composto por homens que também sofreram o mesmo tipo de violência. 
RESULTADOS: O tempo entre agressão e a avaliação pericial variou de horas a nove dias (63\%); foram analisados 148 laudos, 71 mulheres (GE) e 77 homens (GC). A maioria das vítimas era de raça branca ( $64 \%$ GE e $73 \%$ GC), a faixa etária entre 18 e 40 anos (nos 2 grupos), com ensino fundamental ou médio completo (GE $41 \%$ e 66\% GC), solteira (GE 60\% e GC 66\%), 30\% relataram agressão anterior (GC 2\%) ocorrida na residência (56\%) e pelo parceiro conjugal (54\%), enquanto no GC maioria ocorreu em via pública (61\%) e por desconhecido (69\%). A motivação da agressão no GE foi conflito familiar com o parceiro ou ex-parceiro (63\%) e no GC por desentendimento (66\%); nos 2 grupos a agressão foi causada por instrumento natural (mãos) e as fraturas (completas ou incompletas) e avulsões dentárias predominaram (46\%), sendo gravidade considerada leve (GE 63\% e GC 53\%) de acordo com o Código Penal. DISCUSSÃO: A região facial, predominantemente os dentes, é uma área facilmente atingida na agressão interpessoal, com possíveis sequelas anatômicas e funcionais, com repercussões estéticas e emocionais. A violência doméstica vitimiza mulheres diariamente, mas apesar de legislações protecionistas muitas mulheres ainda são vítimas diariamente. CONCLUSÃO: Mulheres jovens e solteiras são agredidas na própria residência por parceiros íntimos. As lesões dentárias repercutem de forma negativa na função da mastigação e na estética das vítimas. A violência doméstica é o principal fator. Medidas públicas ainda precisa Palavras-chave: Violência contra a Mulher; Violência Doméstica; Traumatismos Faciais.

\section{MON - 06 USO DE ANTICOAGULANTES PARA PREVENÇÃO DE TROMBOEMBOLISMO VENOSO APÓS CIRURGIAS BARIÁTRICAS: É POSSÍVEL ESTABELECER UM PROTOCOLO?}

Cinthia Emy Endo Amemiya, Beatriz Martinelli Casulli, Marina Ribeiro Maeji, Rodrigo Barbosa Novais

\section{E-mail: cinthia.ea@gmail.com}

INTRODUÇÃO: Segundo a Organização Mundial de Saúde (OMS), a obesidade se tornou uma doença epidêmica e um desafio para o sistema público de saúde, aumentando o número de cirurgias bariátricas. Apesar de ser considerado um procedimento seguro, pode gerar complicações. A mais comum e preocupante delas é o tromboembolismo venoso (TVE), provocando alta morbidade e mortalidade. Para minimizar riscos de TVE, mecanismos de profilaxia são usados de forma conjunta, sendo a terapia anticoagulante uma das formas utilizadas. Contudo, não há especificações quanto à dose e o tipo de anticoagulante a ser usado. OBJETIVO: Identificar na literatura médica um protocolo seguro a ser adotado em estudos do uso da enoxaparina, tanto da dose adotada, quanto do momento de início de infusão e seu tempo de manutenção. MÉTODOS: Revisão de literatura, sendo adotados estudos observacionais que comparam diferentes tipos de profilaxia farmacológica com enoxaparina para TVE em pacientes que realizaram cirurgia bariátrica, além de estudos de revisão sistemática e metanálises na base de dados PubMed. RESULTADOS E DISCUSSÃO: Atualmente, não consta na literatura qual é o nível I de evidência em relação a dose, duração e uso do fármaco como profilaxia de TVE na cirurgia bariátrica. Dessa forma, essa profilaxia é realizada de acordo com a preferência do cirurgião e diretrizes em relação a esse assunto. Os estudos selecionados comparam diferentes métodos de profilaxia com enoxaparina, sendo que métodos não farmacológicos (deambulação precoce, compressão pneumática dos membros inferiores) foram também associados. A deambulação precoce foi considerada na maioria dos estudos um método eficaz e imprescindível para prevenir TVE. Em relação a doses de enoxaparina, estudos diferem opiniões quanto à dose ideal a ser empregada, sendo que $40 \mathrm{mg}$ e $60 \mathrm{mg}$ apresentaram menor incidência de TVE no pós-operatório de cirurgia bariátrica. CONCLUSÃO: A literatura mostra que o uso pode ser realizado com segurança, 0-24h após a cirurgia. Porém, não existem grandes estudos randomizados comparando o tempo na população da cirurgia bariátrica, devendo assim ser instituídos trabalhos prospectivos randomizados estabelecendo uma maior eficácia

Palavras-chave: cirurgia bariátrica; enoxaparina.

\section{MON - 07 USO DE ENXERTOS RENAIS DE DOADORES FALECIDOS COM LESÃO AGUDA POR RABDOMIÓLISE É POSSÍVEL?}

Fernanda Folla Pompeu Marques, Emanuela Yumi Fugisawa de Mello, Tiago Genzini de Miranda, Natallia Meira Gonsalez, Isabella Pereira Blanco, Marcelo Perosa de Miranda

\section{E-mail: fernandamarques23@ hotmail.com}

INTRODUÇÃO: O transplante de rim (TR) é a terapêutica de escolha para a doença renal terminal. A universal desproporção entre demanda para TR e doadores disponíveis exige o desenvolvimento de novas estratégias para aumento da oferta de enxertos renais. Entre estas, citam-se o aumento dos TR intervivos e o uso de doadores falecidos com critérios expandidos (DCE). Os enxertos com lesão renal aguda (LRA) representam uma das situações de DCE e sua utilização persiste tema controverso diante da incerteza da reversão da lesão renal após o TR. A rabdomiólise (RB) é a causa de 7 a 10\% dos enxertos com LRA e decorre da liberação de mioglobina na circulação e consequente lesão tubular por mecanismos diversos. OBJETIVO: Motivados por oferta recente de enxerto renal com RB e posterior não autorização para uso pela Central de Transplantes de São Paulo, os autores objetivaram revisar a literatura sobre a viabilidade de TR de doador falecido com RB. MÉTODO: Revisão de literatura do banco de dados do Medline usando as palavras-chaves: kidney transplantation; rhabdomyolysis; tissue donor e acute kidney injury entre o período de 2000 a 2018. RESULTADO: Sete artigos demonstraram experiências com total de 51 TR de enxertos com RB. Dos 29 doadores com RB, 20,7\% encontravam-se em hemodiálise e a creatinina média era de $1,13 \mathrm{mg} / \mathrm{dL}$. Os TR com enxertos em RB apresentaram função retardada do enxerto em $35,3 \%$ dos casos, mas um mês após a cirurgia os rins mostraram recuperação total e função normal, confirmadas por biópsia. DISCUSSÃO: Existe grande desproporção entre o número de pessoas na fila do transplante renal e doadores disponíveis. Por esta razão, há necessidade de se ampliar e flexibilizar os critérios de aceitação de enxertos renais seja por doadores com parada circulatória ou doadores com LRA. A RB é uma das causas de LRA entre doadores falecidos. Os TR de doadores com RB apresentaram maior incidência de retardo da função do enxerto, mas com total recuperação em cerca de 30 dias após o transplante. CONCLUSÃO: Não há critérios brasileiros bem estabelecidos para uso de enxertos renais com $\mathrm{RB}$, mas os estudos atuais demonstram bons resultados e recuperação da função renal na grande maioria destes casos. Por enquanto, o aproveitamento de enxertos renais com RB deveria ficar a critério e ao julgamento de cada equipe.

Palavras-chave: Transplante renal; Rabdomiólise; Doador de tecidos; Insuficiência renal aguda.

\section{CATEGORIA - VÍDEO}

\section{VID - 01 ABORDAGEM DO DESCOLAMENTO DE RETINA TRAUMÁTICO ATRAVÉS DA VITRECTOMIA VIA PARS PLANA}

Clarissa Maria Gomes de Almeida, Glauco Sergio Avelino de Aquino, Elaine Shizue Novalo-goto, Maria Leticia Lasca Sales Campos, Victor da Costa Kamura, Gustavo Costa Santos, Maria Isabel Cardoso dos Passos Carvalho, Gustavo Junges Filiú, Juliana Taemy Okimoto, Priscila Alves Nascimento

\section{E-mail: clarissa_almeida96@ hotmail.com}

INTRODUÇÃO: O trauma ocular (TO) é a principal causa de cegueira unilateral não-congênita em menores de 20 anos. As lesões oculares traumáticas são comuns e podem causar desde abrasões até ferimentos graves. Este pode cursar com complicações como catarata, descolamento de retina (DR), glaucoma entre outros. Uma vez instalada a complicação, o paciente pode necessitar de cirurgias invasivas, como a vitrectomia via pars plana (VVPP) em caso de DR. Em muitos manejos cirúrgicos, não há recuperação significativa da visão, passando a ser o principal objetivo, a preservação do globo ocular. OBJETIVO: Relatar o caso de um paciente com complicações após TO penetrante e descrever a cirurgia de VVPP. MÉTODO: O paciente ilustrado no vídeo é um menino de 11 anos com histórico de TO penetrante em olho direito (OD). Foi submetido à sutura corneana e encaminhado ao ambulatório da Faculdade de Medicina do ABC. Evoluiu com catarata meses após o trauma, optando-se por facectomia. Na 7a semana de pós-operatório (PO), cursou com DR regmatogênico, sendo necessária abordagem por VVPP. Esta técnica consiste em 3 esclerotomias, para introdução dos instrumentos cirúrgicos. Em seguida, vitrectomia do corpo e saia vítrea, e se presentes, segue-se para retirada de proliferações vitreoretinianas, endocauterização de vasos calibrosos e se necessário, realização de retinectomia. Infunde-se perfluorcarbono para reaplicação da retina e óleo de silicone para tamponamento retiniano prolongado se necessário. RESULTADO: No 2o mês de PO, paciente apresenta acuidade visual de percepção luminosa. Biomicroscopia com cicatriz corneana central, lente intraocular encarcerada e membrana ciclítica. Paciente em programação cirúrgica para explante de lente e exérese de membrana. DISCUSSÃO: O TO penetrante gerou complicações severas, como a catarata e o DR. O caso torna-se ainda mais relevante por abordar um jovem com longa expectativa de vida, mas que terá de aprender a lidar com as limitações visuais. Considerando este caso, pode-se inferir que o principal objetivo do tratamento de TO é evitar complicações que possam piorar o prognóstico visual do paciente. CONCLUSÃO: A VVPP apesar de tecnicamente bem sucedida, não melhorou a visão do paciente, devido as sequelas do DR. O principal objetivo para o paciente a partir de então, será de preservação do globo ocular e seguimento rigoroso do olho contralateral.

Palavras-chave: vitrectomia via pars plana; trauma ocular; descolamento de retina.

\section{VID - 02 CISTECTOMIA RADICAL ROBÓTICA COM BRICKER EXTRACORPÓREO PARA TRATAMENTO DO CARCINOMA PLASMOCITÓIDE DE BEXIGA}

Giulio Bartie Rossi, Rafaela Oliveira de Sousa, Gustavo Luis Ramos Moralejo, Guilherme Ferrari de Araujo, Pedro Ivo Sanches Martins, Victor Tramonte Pereira, Vinicius José Andreotti Panico, Marcos Tobias Machado

\section{E-mail: giulio.rossi@ hotmail.com}

INTRODUÇÃO: O carcinoma plasmocitóide de bexiga corresponde a $1 \%$ das neoplasias malignas vesicais, é um tumor associado a altas taxas de 
disseminação e mortalidade devido a sua agressividade. Os pacientes que apresentam esse carcinoma são operados, em sua maioria, com margem cirúrgica positiva, possuem lenta recuperação pós-operatória e altas chances de recidiva. Tem sobrevida inferior a 1 ano e prognóstico sombrio. OBJETIVO: Relatar a cistectomia robótica associada a quimioterapia adjuvante com resultados que superam as expectativas da literatura. MÉTODO: Paciente de 56 anos, masculino, sem comorbidades, ativo, não fumante, com quadro de hematúria macroscópica indolor e tumor vesical. Realizada RTU que revelou extenso carcinoma plasmocitóide com invasão da camada muscular. Optado por cistectomia radical com linfadenectomia extendida por acesso robótico. O tumor tinha um aspecto de inflamação local intensa e neovascularização, tendo a ablação do tumor transcorrido sem intercorrência. Tempo ablativo de $3 \mathrm{~h}$, sangramento de $200 \mathrm{ml}$. A peça foi removida por uma incisão transumbilical de $6 \mathrm{~cm}$, por onde foi acoplado um afastador Alexis e realizada a reconstrução extracorpórea a Bricker. Tempo reconstrutivo de 2,5h. Paciente teve boa evolução, retirada dos splints no $5^{\circ}$ dia de pós-operatório, drenos abdominais no $6^{\circ}$ dia e alta hospitalar no $7^{\circ}$ dia. O exame anatomopatológico revelou carcinoma plasmocitóide pT4N0 (24 linfonodos retirados). Foi indicada quimioterapia adjuvante com um novo esquema, taxano 15 dias após a cirurgia. RESULTADO: Paciente tolerou bem o tratamento sistêmico voltando às suas atividades habituais após 15 dias do fim do tratamento e está em acompanhamento pelo período de 18 meses sem evidência de recorrência. DISCUSSÃO: A técnica utilizada facilita o acesso à pelve, diminui a exposição das alças intestinais ao meio externo, evitando espoliação do paciente, e intercorrências como evisceração, eventração ou hérnias. Além disso, a quimioterapia adjuvante permitiu recuperação satisfatória, com retomada das atividades diárias rapidamente após tratamento, sem sinais de recidiva até o momento. CONCLUSÃO: A técnica utilizada associada ao esquema de quimioterapia adjuvante resultou em uma recuperação mais rápida e uma sobrevida que supera o encontrado na literatura.

Palavras-chave: Cistectomia; cirurgia robótica; carcinoma plasmocitóide Bricker extracorpóreo.

\section{VID - 03 EXCISÃO DE TUMORES RETRO-ORBITÁRIOS - GRANDES TUMORES E PEQUENAS INCISÕES}

Victor Harasawa Uno, Carolina Scaff Haddad Bartos, Gregorio Daniel Pepeliascov, Carolina Nicolela Susanna, Othon Moritoshi Shiroma, Glauco Sergio Avelino de Aquino, Mustapha Mohamed Mourad, Gustavo Junges Filiú, Guilherme Daher Gonçalves Monteiro dos Reis

E-mail: victorharasawauno@gmail.com

INTRODUÇÃO: Os tumores retro-orbitários (TRO) são de difícil acesso. Técnicas foram descritas para melhor abordagem da região. As primeiras descrições de orbitotomia lateral (OL) datam de 1888. Desde então outras técnicas foram descritas com diferentes incisões, como a incisão de Kron Line; a incisão poptural estendida, na qual a cicatriz ultrapassa o canto lateral; e a cantotomia, que, apesar de pequena, lesa o tendão cantal lateral. OBJETIVO: Retirar um grande TRO com uma pequena incisão na pele, visando melhor resultado estético. MÉTODO: Segue caso atendido na Faculdade de Medicina do $\mathrm{ABC}$, submetido a OL para retirada de TRO através de microincisão palpebral. Técnica cirúrgica: Marcação do local da incisão; incisão da pele com bisturi elétrico; separação dos músculos orbiculares; incisão no periósteo; com o auxílio da serra sagital, confecção da janela óssea; retirada do fragmento ósseo; identificação e separação do músculo reto lateral; dissecção e retirada do tumor; reposicionamento do osso retirado; sutura do periósteo; e sutura da incisão com ponto simples. DISCUSSÃO: A OL com microincisão palpebral é indica para o acesso a TRO profundos, tanto intra quanto extra clonais, laterais ao nervo óptico. Tumores maiores que $2 \mathrm{~cm}$ geralmente necessitam de janela óssea associada para que seja possível sua excisão completa, sem lesar elementos orbitários. RESULTADOS: Essa técnica emprega uma incisão mínima, com bom resultado estético, apesar do tamanho do tumor excisionado e do tamanho da cirurgia, considerando um osso serrado. Optamos por não colocar parafusos nem fixadores na janela óssea, pois os ossos da face não articulam entre si. Assim, na cirurgia, sutura-se a peri órbita com o periósteo, que apesar de proporcionar uma estabilização frouxa, agrega um resultado estético e funcional, semelhantes à consolidação dessa parede lateral. Dessa forma, nós temos uma técnica barata, mais rápida e com a mesma eficiência de técnicas que utilizam placas e parafusos para esse tipo de fixação. CONCLUSÃO: é possível a retirada de grandes TRO através de pequenas incisões, como no caso, e obter ótimo resultado estético pós cirurgico. A OL com microincisão palpebral, além de ter o mesmo objetivo das demais incisões, tem um melhor resultado estético.

Palavras-chave: tumor; retro-orbitário; orbitotomia lateral; microincisão.

\section{VID - 04 IMPLANTE MINIMAMENTE INVASIVO PARA O GLAUCOMA: RELATO DO PRIMEIRO CASO REALIZADO EM SERVIÇO ESCOLA DO PAÍS}

Maria Leticia Lasca Sales Campos, Philipe Franco do Amaral Tafner, Bianca Nicolela Susanna, Carolina Nicolela Susanna, Rodrigo Scabora, Sandra Carina Lopez Calcines, Gregorio Daniel Pepeliascov, Othon Moritoshi Shiroma, Rodrigo Toledo Mota

\section{E-mail: leticialasca@gmail.com}

INTRODUÇÃO: O glaucoma é uma das principais causas de cegueira. O aumento da Pressão Intra Ocular (PIO) é um importante fator de risco para a progressão e seu manejo pode ser de forma clínica ou cirúrgica. As opções cirúrgicas atuais são agressivas, indicadas para casos refratários ou com grande aumento da PIO. Devido a elevada necessidade da abordagem cirúrgica, estudos buscam encontrar uma solução através de métodos menos invasivos. Estes métodos já são uma alternativa viável, são conhecidos como cirurgias de glaucoma minimamente invasivas (MIGS). Destaca-se entre os MIGS, o iStent, o primeiro dispositivo aprovado no Brasil. O iStent realiza desvio da drenagem do humor aquoso da câmara anterior para o espaço supracoroidal. O implante deste dispositivo ocorre através de pequena dissecção escleral cirúrgica, diminuindo a PIO. OBJETIVO: Apresentar técnica minimamente invasiva do implante de iStent, realizado pela primeira vez em serviço universitário do país. MÉTODO: Paciente de 62 anos, com queixa de baixa acuidade visual há 6 meses por glaucoma. Hipertensa e diabética. Biomicroscopia: catarata e relação disco escavação aumentada. Gonioscopia: ângulo aberto em todos os quadrantes. Indicado cirurgia combinada de facectomia e implante de iStent no olho direito, que foi realizada sem intercorrências. O iStent foi colocado sob visualização direta do ângulo com lente de gonioscopia, após a aspiração do visco elástico da câmara anterior e do saco capsular. Utilizou-se o aplicador próprio para liberar o implante no trabeculado e checou-se o posicionamento adequado. RESULTADO: Paciente evoluiu bem sem necessidade de colírio hipotensor no olho direito. Após 60 dias permanece sem uso de colírios no olho direito e apresentouse com redução de $18 \%$ da PIO em relação a condição pré-operatória no olho direito. DISCUSSÃO: Em uma doença com alta prevalência e sem opções ideias para o tratamento, os MIGS são excelentes alternativas, possibilitando não só uma cirurgia menos agressiva, mas também a redução de medicações com impacto na qualidade de vida. Apesar da necessidade de mais estudos e relatos dos MIGS, já são observados na literatura descrições que corroboram com a diminuição da PIO em 18\%. CONCLUSÃO Os resultados preliminares do uso de MIGS com iStent se mostram positivos, no entanto ainda é necessário estudos para verificar a real eficácia do dispositivo.

Palavras-chave: Glaucoma; Cirurgia Minimamente invasivo.

\section{VID - 05 MICRODISCECTOMIA PARA RETIRADA DE HÉRNIA LOMBAR COM AUXÍLIO DO MICROSCÓPIO}

Paola Augusto Gomes, Julia Hoici Brunini, Desiree Elizabeth Pasqualetto Antikievicz, Lucas Abdo Pereira, Reinolds Amiraldo Corrêa Junior, Natália Marques dos Santos, Mustapha Mohamed Mourad, Gustavo Ferrareto Pires, Leonardo Yukio Jorge Asano, Luciano Miller Reis Rodrigues

\section{E-mail: paola-rosa@ hotmail.com}

INTRODUÇÃO: Hérnia discal é o deslocamento de conteúdo discal para além dos limites do espaço do disco intervertebral. As hérnias discais lombares são relativamente frequentes na população e são a principal causa de cirurgia de coluna do adulto. Os indivíduos que no trabalho realizam rotação ou flexão do tronco ou se submetem a fortes vibrações no corpo aumentam as chances de desenvolver uma hérnia de disco lombar. Outros motivos são as alterações posturais, sedentarismo e os componentes genéticos da constituição do disco intervertebral. OBJETIVO: O objetivo é descrever uma técnica com incisão pequena, baixa agressividade, sem perda funcional e alta hospitalar precoce. MÉTODO: Mulher, 47 anos, queixava-se de dor lombar com irradiação para membro inferior esquerdo, há 4 semanas, refratária à analgesia. A ressonância magnética evidenciou uma hérnia lombar extrusa de L5-S1. Optou-se pela sua retirada através de uma microdiscectomia com microscópio. Realizou-se uma incisão transversal de, aproximadamente $2 \mathrm{~cm}$, seguida da dissecção por planos até visualizar a lâmina de L5. Foi colocado um afastador circular e realizada a aproximação do microscópio. Com uma broca tipo cebolinha diamantada 4.0 e auxílio de pinças tipo Kerrison foi retirado um quadrante da lâmina. A dissecção dos tecidos adjacentes permitiu visualizar a hérnia extrusa. Em seguida, afastou-se o cone medular com um protetor de raiz. Com uma lâmina de bisturi $\mathrm{n}^{\circ} 11$, foi feita uma pequena incisão no disco vertebral, sendo o fragmento retirado com uso de curetas e pinças tipo love. Ao fim, certificou-se da descompressão com uso de um probe. RESULTADO: No primeiro dia de pós-operatório, a paciente já apresentou melhora importante da dor, com função motora e sensitiva preservadas. Conseguiu deambular sem auxílio e teve alta domiciliar. No seguimento ambulatorial, apresentou recuperação total do quadro álgico, sem mais queixas até o momento. DISCUSSÃO: Essa técnica reduz a chance de laceração da dura mater, traumatismo de raiz e lesão de grandes vasos. Isso porque o cirurgião tem melhor visão do campo e acesso direto ao espaço intervertebral. Com isso, a hemostasia torna-se fácil, reduzindo riscos de complicações e tempo de internação. CONCLUSÃO: O procedimento cirúrgico descrito se mostrou factível, seguro e com ótimo resultado estético e funcional, com redução da dor durante o período pós-operatório.

Palavras-chave: Microdiscectomia, hérnia lombar, coluna 


\section{VID - 06 RETINOPEXIA PNEUMÁTICA}

Maria Leticia Lasca Sales Campos, Gustavo Junges Filiú, Michelle Fu Min Tong, Victor Harasawa Uno, Othon Moritoshi Shiroma, Rodrigo Goldenstein Schainberg, Carolina Scaff Haddad Bartos, Francisco Zacari Brito, Marina Shiroma

\section{E-mail: leticialasca@gmail.com}

INTRODUÇÃO: O Descolamento de Retina Regmatogênico é caracterizado pela separação anatômica entre a camada neurossensorial e o epitélio pigmentado da retina causado por uma fissura por onde infiltra o líquido originário da cavidade vítrea para o espaço subretiniano. As alternativas para o tratamento do descolamento de retina incluem três técnicas cirurgias: Retinopexia por Introflexão Escleral, Vitrectomia Via Pars Plana e a Retinopexia Pneumática. Essas abordagens são frequentemente associadas. OBJETIVO: Apresentar a técnica cirúrgica de Retinopexia Pneumática realizada em duas pacientes no Centro Cirúrgico do Departamento de Oftalmologia da FMABC em Santo André, SP. MÉTODO: No vídeo abordaremos a técnica de Retinopexia Pneumática, explicando a técnica, suas indicações, contraindicações e complicações. Essa técnica consiste na injeção de um gás expansíve intravítreo que empurra o bolsão de descolamento de retina e tampona a rotura contra a parede do olho. Esse procedimento foi ilustrado no vídeo por meio de dois casos de pacientes com descolamento de retina superior. RESULTADO: Ao exame pós-operatório das pacientes, ambos os casos apresentavam retina aplicada, sendo que em um dos casos ocorreu o aparecimento de uma rotura temporal interior em que foi realizado bloqueio com laser para sua correção. As pacientes seguem em tratamento neste serviço. DISCUSSÃO: Apesar dessa técnica ser conhecida por ser um procedimento minimamente invasivo, relativamente simples de realizar, de baixo custo, e com menores complicações cirúrgicas em relação à introflexão escleral, permanece controversa a sua aplicação devido ao questionamento da sua eficácia. No entanto, a taxa de sucesso é comparável com a introflexão escleral nos grupos fácicos e com rotura superior, o que mostra a necessidade de uma boa indicação desta técnica. CONCLUSÃO: A Retinopexia Pneumática se mostrou como uma boa opção cirúrgica no manejo do descolamento de retina regmatogênico primário em casos bem selecionados, gerando minimos desconfortos para o paciente, baixos riscos cirurgico e boas taxas de sucesso em subgrupos específicos.

Palavras-chave: tratamento cirúrgico; descolamento de retina; técnica cirúrgica.

\section{VID - 07 TRABECULOTOMIA PARA TRATAMENTO DE GLAUCOMA CONGÊNITO ASSOCIADO À SÍNDROME DE STURGE-WEBER (SWS)}

Gustavo Costa Santos, Francisco Zacari Brito, Carolina Scaff Haddad Bartos, Sandra Carina Lopez Calcines, Giulianna Nasi Domingues de Oliveira, Mustapha Mohamed Mourad, Carolina Nicolela Susanna,

Rafael Cunha de Almeida

\section{E-mail: gustavo_c_santos@ hotmail.com}

INTRODUCÃ̃O: A SWS, conhecida como angiomatose encefalotrigeminal, é uma condição que inclui hemangioma leptomemenial, angiomatose facial ou nevo flammeus (conhecida como mancha de vinho do porto) e alterações patológicas oculares. Genes na região 17p1-p13 estão envolvidos com a SWS e a sua incidência é de 1: 50.000 lactentes. A embriologia do SWS tem sido relacionada a um mau desenvolvimento dos precursores celulares na crista neural durante o primeiro trimestre embrionário, levando a malformações no sistema nervoso central, pele e olhos. Cerca de $50 \%$ dos pacientes SWS apresentam alterações oculares patológicas, geralmente ipsilaterais ao hemangioma de face, podendo envolver a pálpebra, câmara anterior, córnea, coróide e retina. A patogênese do glaucoma em SWS relaciona-se ao aumento da pressão venosa episcleral (PVE) devido a shunts arteriovenosos no hemangioma episcleral, baseado na observação de uma estrutura de ângulo normal, sangue no canal de Schlemm e glaucoma. OBJETIVO: Demonstrar a técnica de trabeculotomia para tratamento de glaucoma congênito associado à SWS. Evidenciar a dificuldade de sua realização quando a origem do aumento da pressão intraocular decorre do aumento da PVE. MÉTODO: Foi realizada cirurgia de trabeculotomia em olho direito, sob anestesia geral, focando a filmagem nas veias episclerais, procurando demonstrar o ingurgitamento venoso episcleral. RESULTADO: Cirurgia de trabeculotomia realizada com sucesso em olho direito, bom controle da pressão intraocular no pós-operatório. DISCUSSÃO: Com sinais clínicos clássicos de SWS, tem-se um diagnóstico característico, a presença da mancha do vinho do porto facial unilateral ao longo do primeiro ramo do nervo trigêmeo, hemiatrofia, convulsões progressivas, hemiparesia contralateral, deficiências mentais, hemianopia e glaucoma ipsilateral. As cirurgias goniotomia e trabeculotomia são as mais apropriados para crianças com malformação, principalmente a trabeculotomia para tratamento de glaucoma congênito. CONCLUSÃO: $\mathrm{O}$ vídeo demonstra não apenas a técnica de trabeculotomia para tratamento de glaucoma congênito, mas também evidencia a dificuldade de sua realização quando a origem do aumento da pressão intraocular decorre do aumento da PVE, patogênese em geral relacionada à SWS.

Palavras-chave: Oftalmologia; Sturge-Weber; Glaucoma congênito.

\section{VID - 08 TRATAMENTO CIRÚRGICO DE ESOTROPIA ASSOCIADA AO ALTO MÍOPE}

Maria Leticia Lasca Sales Campos, Carolina Nicolela Susanna Gustavo Junges Filiú, Michelle Fu Min Tong, Elaine Shizue Novalo-Goto, Victor Harasawa Uno, Othon Moritoshi Shiroma, Rodrigo Goldenstein Schainberg, Rodrigo Toledo Mota

\section{E-mail: leticialasca@gmail.com}

INTRODUÇÃO: Há associação entre alta miopia e esotropia (ET) em 3 a 8\% dos casos, onde o paciente geralmente apresenta restrição na elevação e abdução do olho acometido gerando diplopia. O tratamento utilizando as técnicas cirúrgicas convencionais é difícil e geralmente associado a grande taxas de recorrência. Em 2002 Yamada descreveu uma nova técnica cirúrgica mais eficaz do que as anteriores a fim de retornar o olho próximo a posição ortotrópica. OBJETIVO: Apresentar a técnica cirúrgica descrita por Yamada et al realizada no Hospital Estadual Mário Covas em Santo André, SP. MÉTODO: A cirurgia idealizada por Yamada et al consiste na hemitransposição dos músculos reto superior (RS) e reto lateral (RL) com a ressecção do reto medial (RM). Os músculos RS e RL são separados longitudinalmente pela metade por $15 \mathrm{~mm}$ de extensão. As faixas lateral do RS e superior do RL são fixados na esclera juntas, no meio de suas inserções originais, a $7 \mathrm{~mm}$ do limbo. A ressecção do músculo RM é feita em extensão variável com o desvio da paciente, no caso apresentado foi realizada ressecção de $4 \mathrm{~mm}$. RESULTADO: A hemitransposição do RS e do RL e a ressecção do RM são benéficas para centralizar o globo posterior. Comparando exames prévios com a alta cirúrgica, é possível observar uma redução de ET de 50DP para 30DP, bem como HT de 35DP para 15DP direito sobre esquerdo acompanhado de um bom resultado estético sem a presença de diplopia e outras queixas visuais. DISCUSSÃO: A fisiopatologia da esotropia do alto míope ainda não foi esclarecida, mas teorias sugerem que há, em consequência de alterações esclerais, o deslocamento dos músculos extraoculares gerando ET de grande ângulo associado a desvio vertical. Diversas técnicas cirúrgicas foram descritas na tentativa de restabelecer a posição do olhar, porém todas com baixa taxa de sucesso e alto índice de recidivas. A técnica descrita por Yamada permite a normalização do trajeto dos músculos associado a centralização do globo posterior apresentando na literatura bons resultados estéticos e baixa taxa de recidiva. CONCLUSÃO: A técnica de Yamada se apresenta como alternativa no tratamento da esotropia do alto míope com boa taxa de sucesso e menores taxas de recidiva.

Palavras-chave: Esotropia alta; miopia; tratamento cirurgia. 